\title{
Computation of Flow Through Water-Control Structures Using Program Damflo.2
}

Open-File Report 03-473

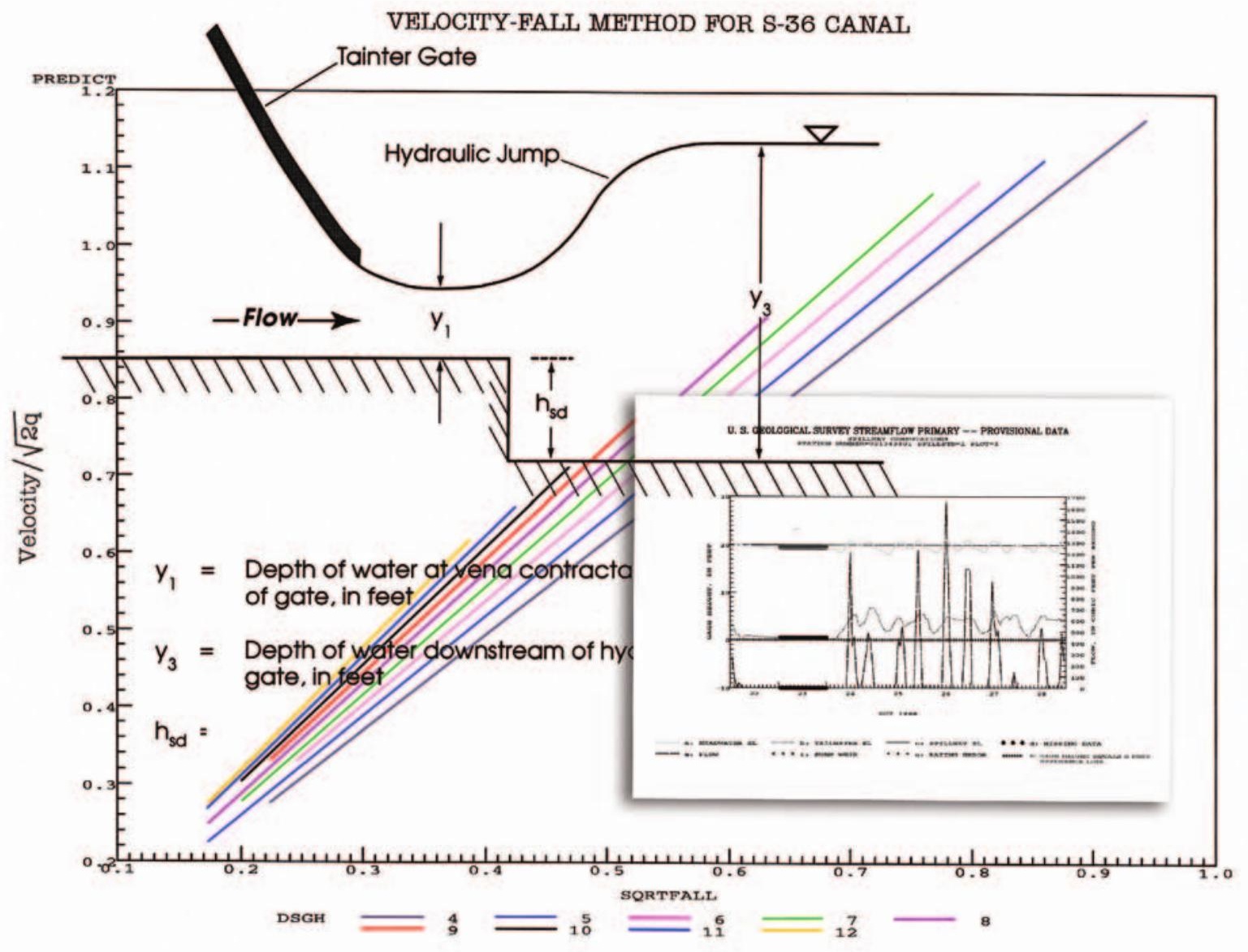




\section{Computation of Flow Through Water-Control Structures Using Program DAMFLO.2}

By Curtis L. Sanders, Jr. and Toby D. Feaster

U.S. Geological Survey

Open-File Report 03-473

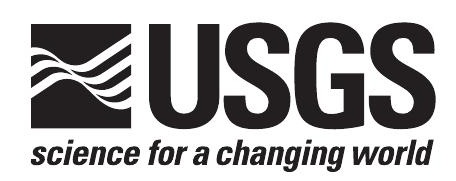




\section{U.S. DEPARTMENT OF THE INTERIOR \\ GALE A. NORTON, Secretary \\ U.S. GEOLOGICAL SURVEY \\ Charles G. Groat, Director}

Use of trade, product, or firm names in this publication is for descriptive purposes only and does not imply endorsement by the U.S. Geological Survey.

For additional information write to:

District Chief

U.S. Geological Survey

Suite 129

720 Gracern Road

Columbia, SC 29210-7651
Copies of this report can be purchased from:

U.S. Geological Survey Branch of Information Services Box 25286

Denver, CO 80225-0286

888-ASK-USGS

Additional information about water resources in South Carolina is available on the internet at http://sc.water.usgs.gov 


\section{CONTENTS}

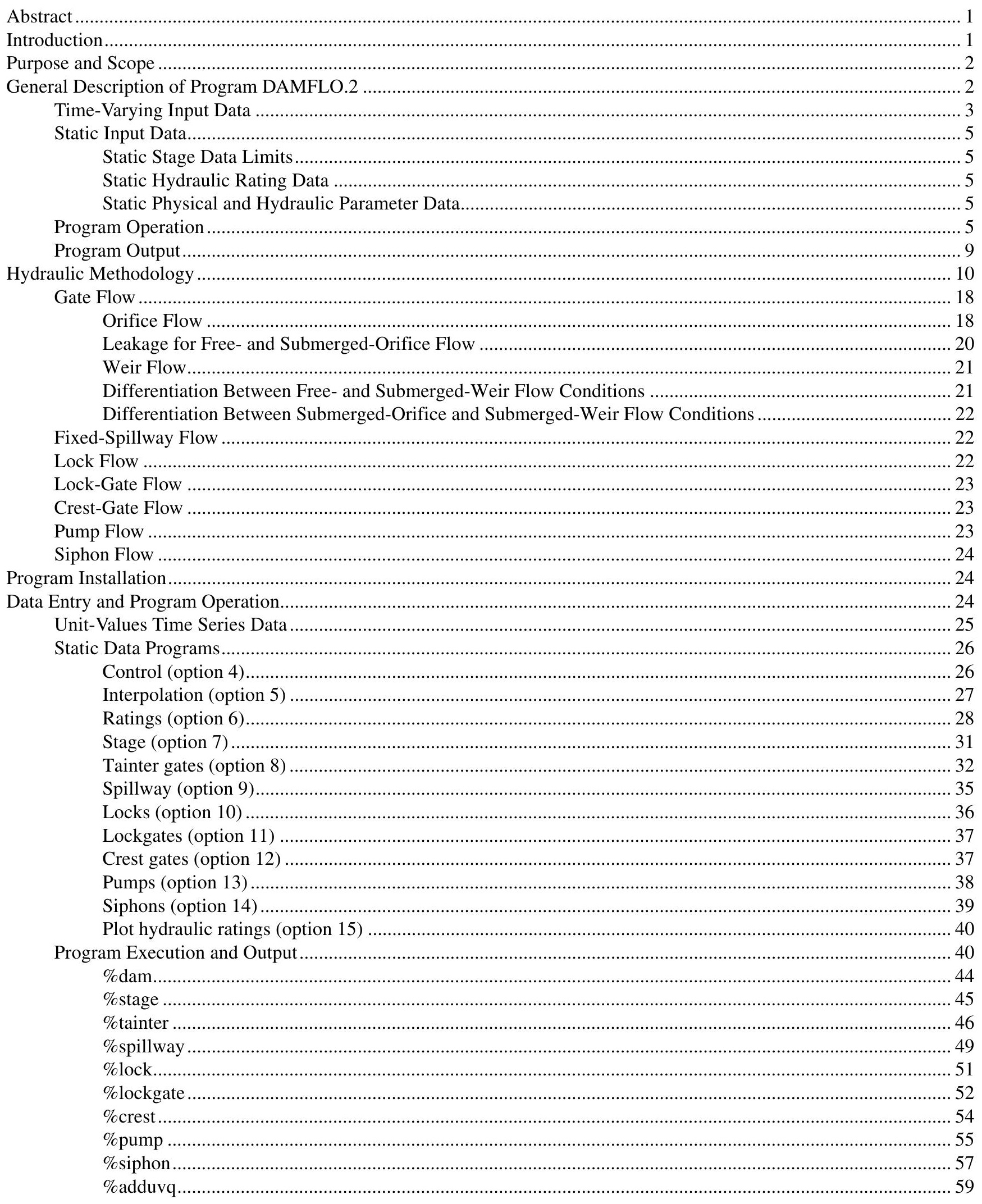




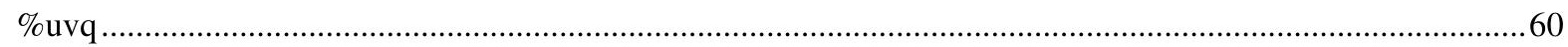

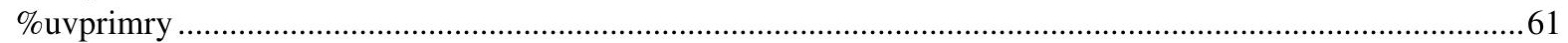

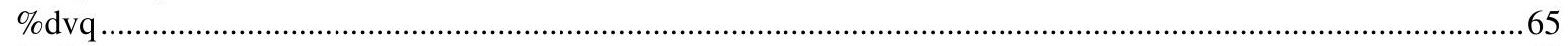

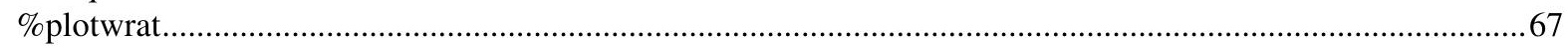

Utility Programs

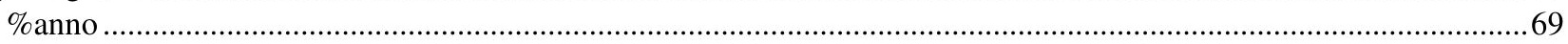

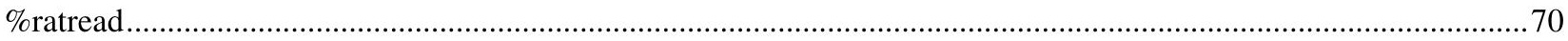

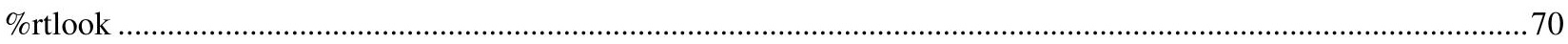

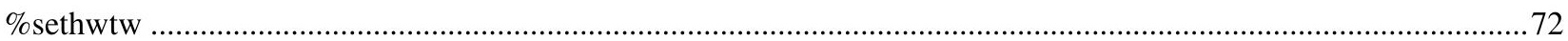

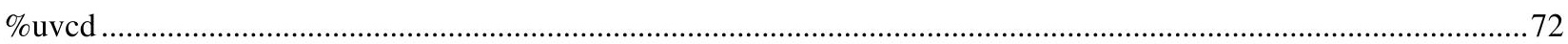

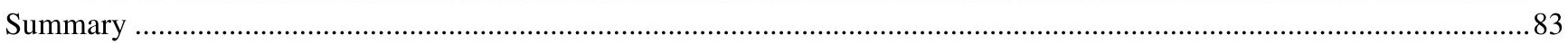

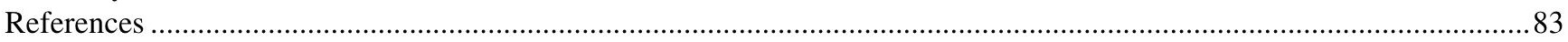

Appendix 1 - Velocity-Fall Method for Computing Submerged-Weir Flow................................................................... 85

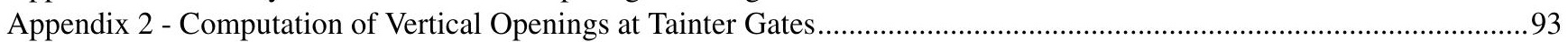

Appendix 3 - Classification of Free- and Submerged-Orifice Flow by Proposed Hydraulic Jump Method............................95

Appendix 4 - Unit-Value and Daily-Value Card Formats ................................................................................................98

\section{FIGURES}

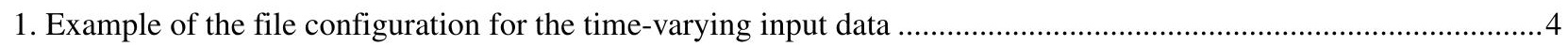

2-3. Printouts showing an example of:

2. damflo menu

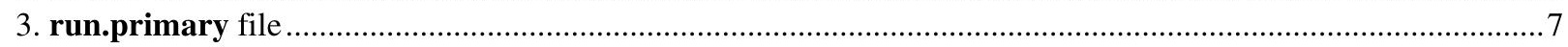

4-5. Illustrations showing:

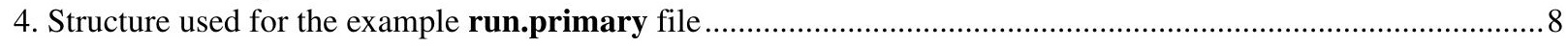

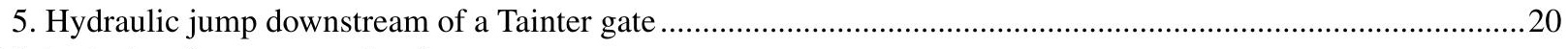

6-49. Printouts showing an example of:

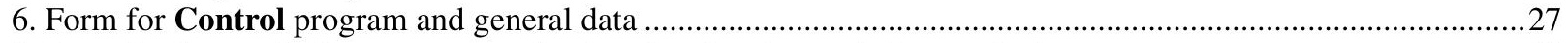

7. Form for Interpolation program and unit-value data interpolation methods...................................................28

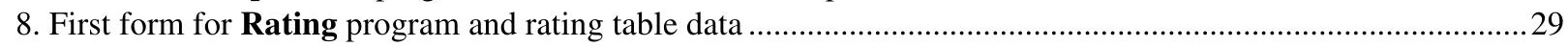

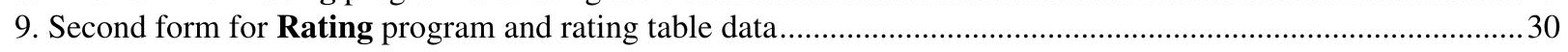

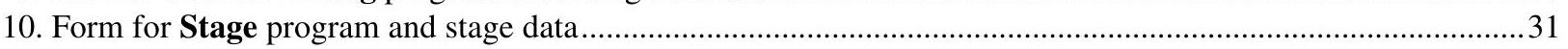

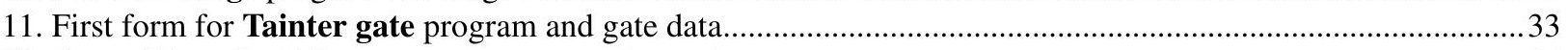

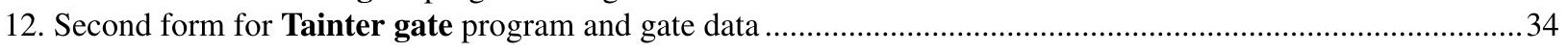

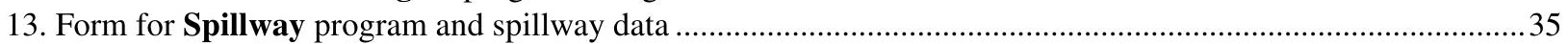

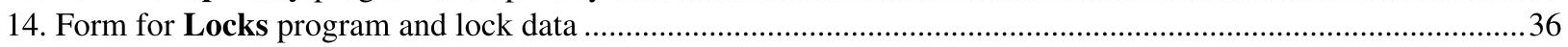

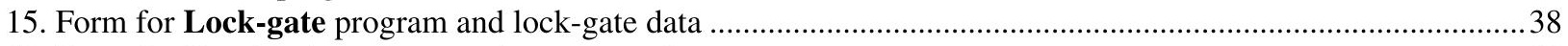

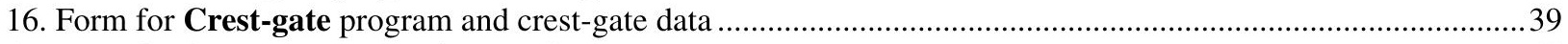

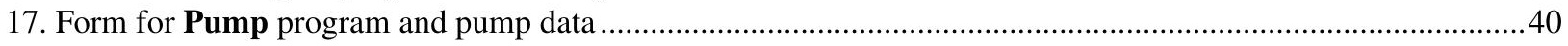

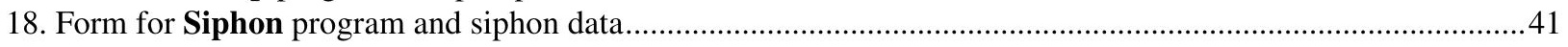

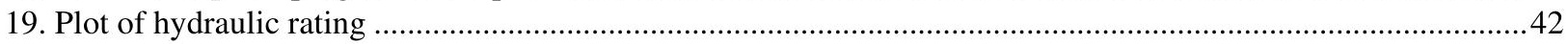

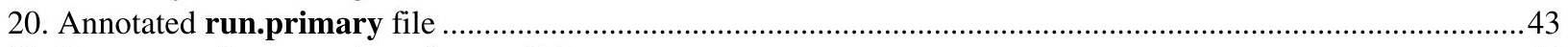

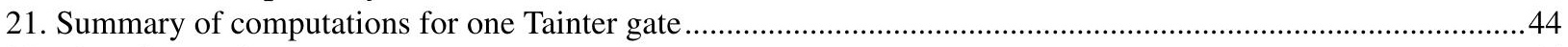

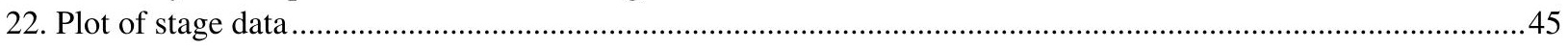

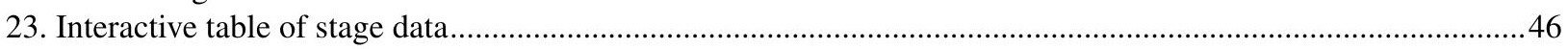

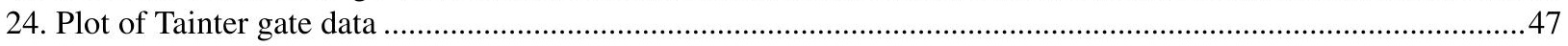

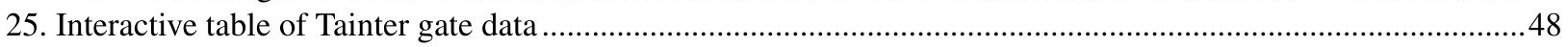

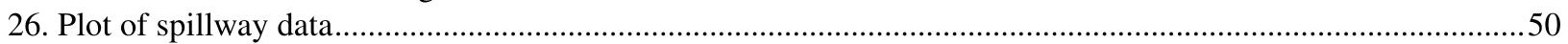

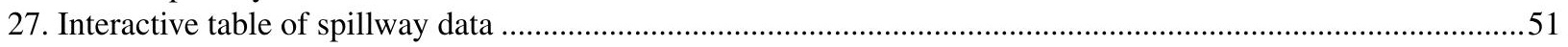

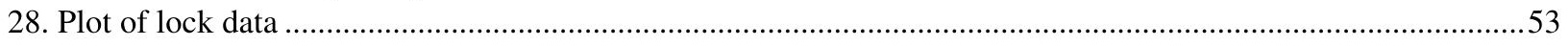

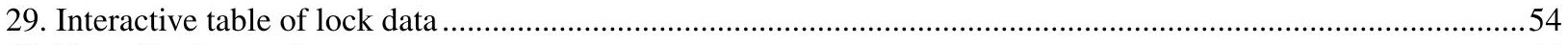

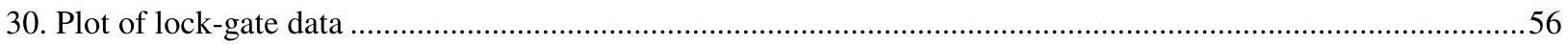

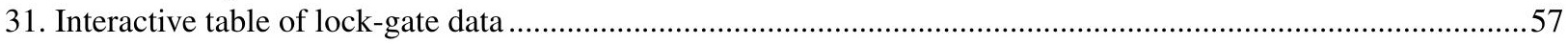

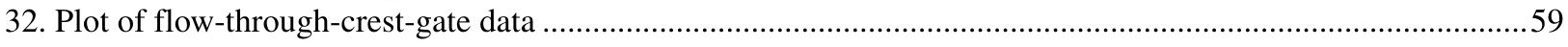

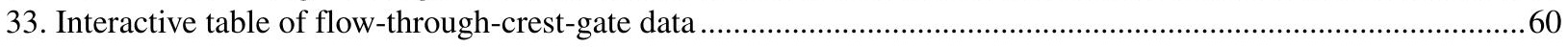


34. Plot of flow-over-crest-gate data

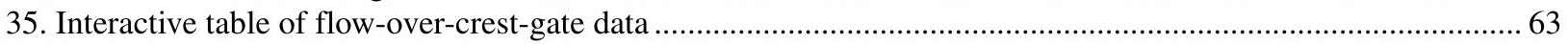

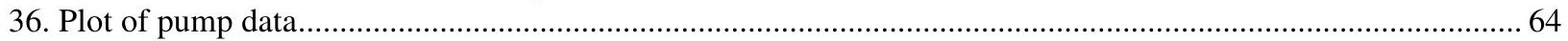

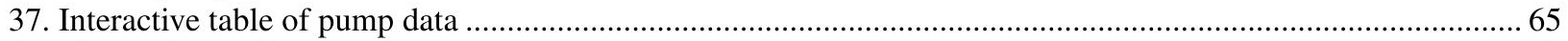

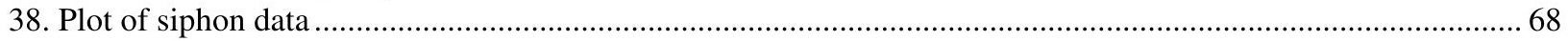

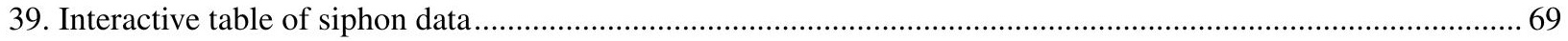

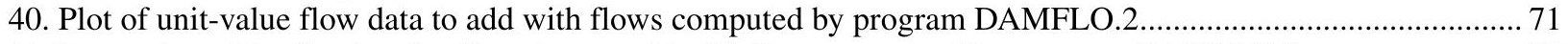

41. Interactive table of unit-value flow data to add with flows computed by program DAMFLO.2 ..................... 72

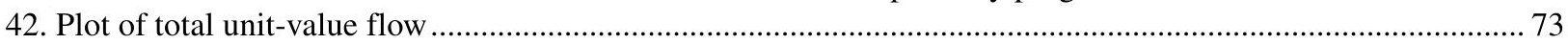

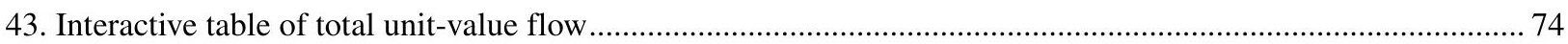

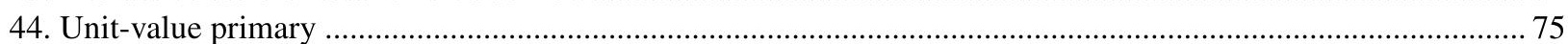

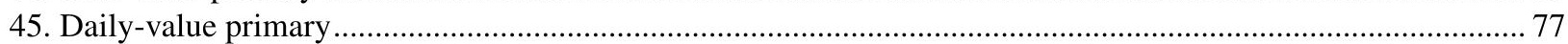

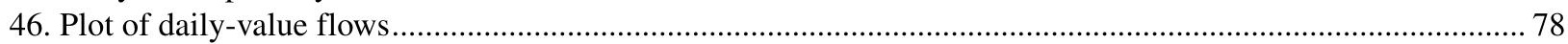

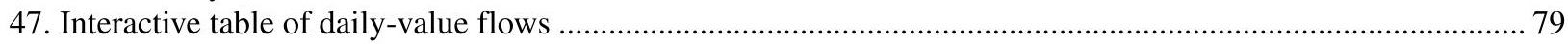

48. Rating plot of total unit-value flow against tailwater elevation for period of computation.............................. 81

49. Rating plot of total unit-value flows against tailwater elevation for one day ............................................... 82

\section{TABLE}

\section{CONVERSION FACTORS, ABBREVIATIONS, AND ACRONYMS}

\begin{tabular}{rll}
\multicolumn{1}{r}{ Multiply } & \multicolumn{1}{c}{ By } & \multicolumn{1}{c}{ To obtain } \\
foot $(\mathrm{ft})$ & 0.3048 & meter \\
square foot $\left(\mathrm{ft}^{2}\right)$ & 0.09294 & square meter \\
cubic foot per second $\left(\mathrm{ft}^{3} / \mathrm{s}\right)$ & 0.02832 & cubic meter per second \\
foot squared per day $\left(\mathrm{ft}^{2} / \mathrm{d}\right)$ & 0.0929 & meter squared per day \\
foot per second $(\mathrm{ft} / \mathrm{s})$ & 0.3048 & meter per second \\
Mgal/d (million gallons per day) & 0.04381 & cubic meter per second
\end{tabular}




\section{ABBREVIATIONS}

ADAPS Automated Data Processing System

ADDUVQ Unit-value flow data stored in ADAPS not computed by DAMFLO.2 to be added to unitvalue flows computed by DAMFLO.2

ADJ Adjusted

ASCII American Standard Code for Information Interchange

CATEGORY Rating type, such as "FWR" for a free weir-flow rating

COUNT Number of unit values used to compute the daily mean discharge

CREST Spillway head to flow rating

CRSTN Crest-gate set number

CRTOP Head over top-of-gate to flow rating

DATAGRP Unit-value data group number

DIFF Difference between the current gate opening and the gate opening at the preceeding time step

DIFF ERRS Number of warnings in one day that a rate of change of input value in one unit-value time increment exceeded a specified value

DTE Date

EL Elevation

ERRFLG1 Flag warning that a headwater elevation may be too high ("H") or too low ("L") or that the rate of change of elevation in one unit-value time step might be to large ("C")

ERRFLG2 Flag warning that a tailwater elevation may be too high ("H") or too low ("L") or that the rate of change of elevation in one unit-value time step might be to large ("C")

FALL The difference between the headwater and tailwater elevations, in feet

FLOWFG Indicates type of flow ("F" = free flow, "S" = submerged flow, "W" = weir flow, or “" (blank) $=$ orifice flow $)$

FO Free-orifice flow

FOR Free-orifice rating for Tainter gates

FSPIL Free-weir rating for spillways

FWR Free-weir rating for Tainter gates

GATEFG Flag warning that a gate opening may be too small ("L") or too large ("H") or that the rate of change of gate openings over a unit-value time step is too large ("C")

GATENUMB The gate number for the current set of gates for which flow is being computed

GATESET Gate set number

$\mathrm{GH}$ Gage height, in feet

GHDIFF Difference between the current gage-height reading and the gage-height reading at the preceeding time step

HCR Height of upstream water surface above the sill of a dam having crest gates

HG Gate opening, in feet

HUC Headwater to adjustment coefficient rating for lock gates

HUQ Gate opening to flow rating for lock gates

HURRSTN Lock-gate set number 
HW Water-surface elevation at the headwater gage, in feet

INPT Input value, such as headwater stage or Tainter gate opening

INVAL Input time-varying data

INVALUE Input value for a rating, such as gate opening, in a gate opening versus free-orifice coefficient rating

ITEM Number of outlet structure within a set of outlet structures, such as Tainter gate number 2 in Tainter gate set 1

LEAKQ Constant lock leakage flow

LKDIFF Number of locks during a computation time increment

LKLEKQ Final lock leakage discharge

LOCKSTN Set number of locks

MAX Maximum

MAXTIME Time of the daily-maximum discharge

MAXUVQ Daily maximum discharge

MEANQ Daily mean discharge

MIN Minimum

MINMAX ERRS

Number of minimum-maximum input value warnings detected for one day

MINTIME Time of the daily minimum discharge

MINUVQ Daily minimum discharge

MNMXFG Flag warning that a value may be too small ("L") or too large ("H")

NDIFFERR Number of warnings in one day that a rate of change of input value exceeded a specified value

NMNMAX Number of minimum-maximum warning flags in one day

NRATECH Number of rate of change of input value warning flags in one day

NRATERR Number of rating error warning flags in one day

NTWQ Number of TWQ flows used within one day

NUMGTS Number of crest gates that are open at a time step

NUV Number of unit-value discharges used to compute daily mean discharge

OBS Observation

OUTVAL Computed output time-varying discharge

OUTVALUE Output value for a rating such as the free-orifice coefficient from a gate opening versus free-orifice coefficient rating

PLOT Plot number

PUDIFF Difference between the current revolutions per minute (rpm) recorded for a pump and the rpm at the previous time step

PUFAL Fall-to-flow rating for pumps

PUMPNUMB The pump number for the current set of pumps for which flow is being computed

PUMPSTN Pump set number

PURPM Pump revolutions per minute (RPM) rating 


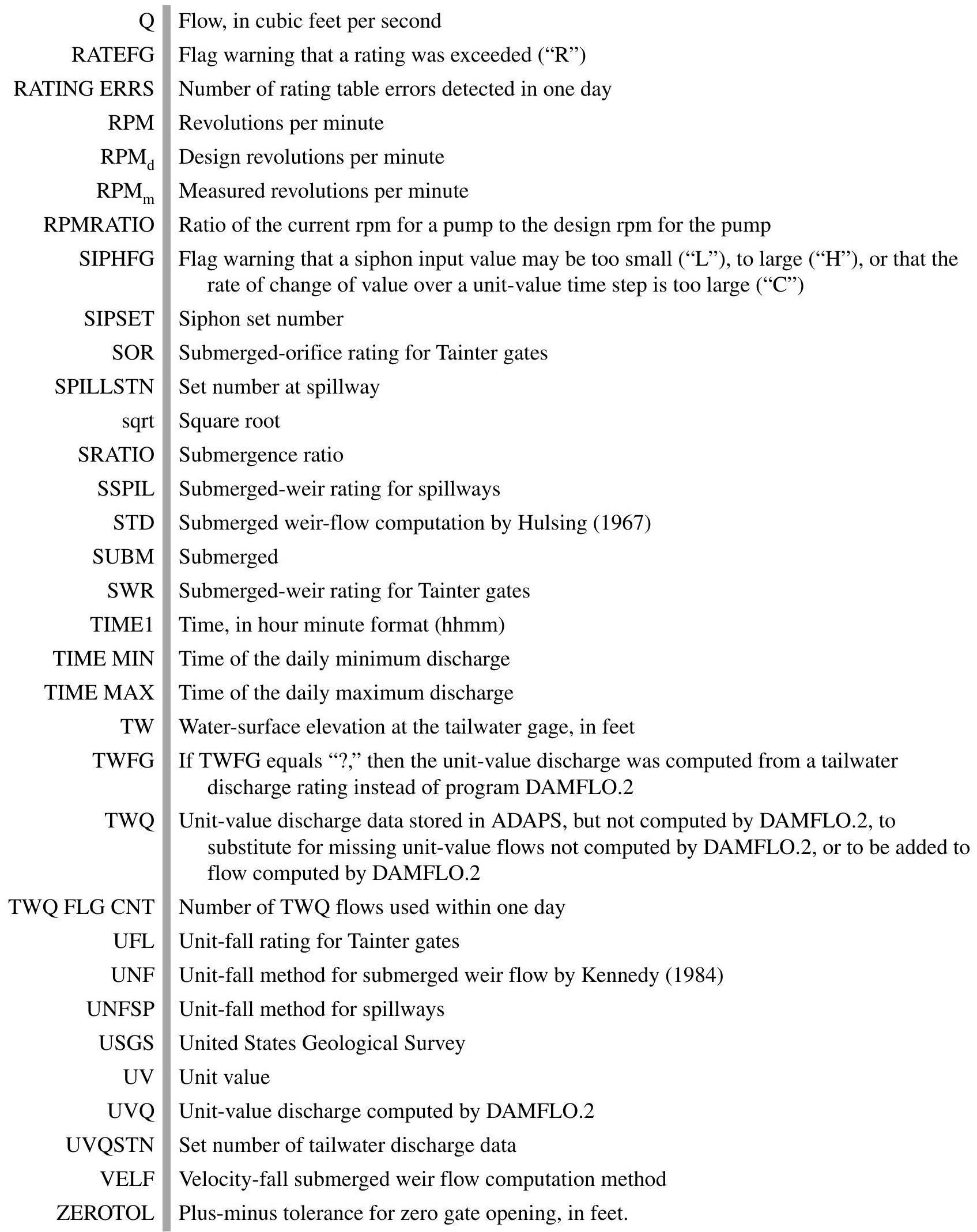




\title{
Computation of Flow Through Water-Control Structures Using Program DAMFLO.2
}

\author{
By Curtis L. Sanders, Jr. and Toby D. Feaster
}

\begin{abstract}
As part of its mission to collect, analyze, and store streamflow data, the U.S. Geological Survey computes flow through several dam structures throughout the country. Flows are computed using hydraulic equations that describe flow through sluice and Tainter gates, crest gates, lock gates, spillways, locks, pumps, and siphons, which are calibrated using flow measurements. The program DAMFLO.2 was written to compute, tabulate, and plot flow through dam structures using data that describe the physical properties of dams and various hydraulic parameters and ratings that use time-varying data, such as lake elevations or gate openings. The program uses electronic computer files of time-varying data, such as lake elevation or gate openings, retrieved from the U.S. Geological Survey Automated Data Processing System. Computed time-varying flow data from DAMFLO.2 are output in flat files, which can be entered into the Automated Data Processing System database. All computations are made in units of feet and seconds. DAMFLO.2 uses the procedures and language developed by the SAS Institute Inc.
\end{abstract}

\section{INTRODUCTION}

As part of its mission to acquire, analyze, and store streamflow data, the U.S. Geological Survey (USGS) computes flow data at several dam structures throughout the country where standard stage-flow or stage-slope-flow methods cannot be accurately used. Program DAMFLO.2 computes, tabulates, and plots flows through sluice and Tainter gates, crest gates, lock gates, spillways, locks, pumps, and siphons using hydraulic equations, time-varying data (such as water-surface elevations and gate openings), physical dimensions of the dam (such as gate widths), and various hydraulic coefficients and ratings specified in the hydraulic equations.

Sluice gates and Tainter gates can be pulled completely out of the water so that weir flow exists in the gate structure. Crest gates are gates on the top of a fixed spillway that are operated either fully raised or fully lowered. In addition, water may flow over the tops of crest gates when they are fully lowered. Flow is a function of headwater elevation and number of crest gates that are open. Lock gates are gates that open horizontally at locks and are sometimes operated in a partially open position to control flow when flow can pass directly through the entire lock. 
Flows can be pumped into upstream lakes, and flows can be siphoned from lakes by conduits for pumps when the pumps are not operating. In addition, siphoning conduits may be used to divert flows of a stream or canal around some obstacle. The hydraulic equations used for computing flow through dam structures usually require watersurface elevations upstream and downstream of the outlet structures.

DAMFLO. 2 is a set of programs created using procedures and language developed by the SAS Institute (1993). The SAS software, licensed for general use by the USGS, was utilized because of its integrated plotting, interactive tabling, data entry by forms, and various statistical, date-time, and data-handling programs. The program required 27 percent of the amount of code that had been required by an earlier DAMFLO program, which was written in FORTRAN 77.

DAMFLO.2 is an example of the use of an integrated software package that produces an "integrated" dataprocessing program. The program is integrated in that all hard-copy tables, flat files of computed unit-value and daily-value flows, and plots appear automatically without the user having to run several programs. Furthermore, practically all the tabulated data, including flow types and error flags, are presented graphically and by interactive table so that the user will not have to scan hundreds of printed data items. The user can produce paper plots or can step forward through interactive plots while searching through an interactive table for specific segments of data.

Coefficients and ratings for the hydraulic equations used in DAMFLO.2 to compute flow through the various controls at a dam are calibrated using flow measurements. Time-varying data, such as water-surface elevations upstream and downstream of the dam, and gate openings are recorded in the field at or near the dam and are stored in the database of the USGS Automated Data Processing System (ADAPS). "Static" data describing the physical properties of the outlets at a dam and various hydraulic parameters and ratings are stored in a SAS database using the SAS forms capability.

The time-varying data from the ADAPS database are retrieved in American Standard Code for Information Interchange (ASCII) files. In this report, ASCII files are called "flat" files. For a selected station, all the timevarying data needed for one computer run are stored in a single file as sequential groups of data types, such as headwater gage height, tailwater gage height, Tainter gate opening, and so forth. In this report, these sequential groups of data are referred to as data groups.

Programs that compute flow through each outlet are executed by separate commands stored in a single file for each dam. This file, which is referred to in this report as the run.primary file, is created by the user, external to SAS, using a text editor. Therefore, DAMFLO.2 is modular in the sense that any configuration of outlet structures can be modeled.

Unit-value and daily-value primary computation tables are produced by the program, in addition to interactive tables and plots of all the data listed on the primaries. Plots also can be directed to printers. Computed unit-value flows and daily minimum, daily maximum, and daily mean flows are produced in flat files in a format suitable for entry into the ADAPS database.

\section{PURPOSE AND SCOPE}

This report describes the methodologies, the inputs, and the outputs from the program DAMFLO.2. The program was written to replace DAMFLO, a program previously implemented on the PRIME computer. The program computes flows through Tainter gates, spillways, locks, lock gates, crest gates, pumps, and siphons.

\section{GENERAL DESCRIPTION OF PROGRAM DAMFLO.2}

The input, operation, and output of DAMFLO.2 are described in this section. Detailed instructions are provided in following sections of the report. 
Weir, Tainter- or sluice-gate, lock, and crest-gate flows are computed using methodology documented by Collins (1977), Stuthman and Sanders (1982), and the lead author of this report. In addition, pump, siphon, and lock-gate flows are computed using undocumented methods developed by the Miami, Florida, office of the USGS. The computational methods (E. Price, U.S. Geological Survey, oral commun., 1991) were carefully analyzed and incorporated into the DAMFLO.2 program and documentation.

Submerged-weir flows also are computed using the unit-fall method documented by Kennedy (1984) and using a modification of the unit-fall method (noted as the velocity-fall method) developed in 1997 (app. 1). Methods of adjusting free-weir flow for submergence, documented by Hulsing (1967), also are used. The program also allows negative weir and orifice flows at low-head dams when the tailwater is higher than the headwater. Separate headwater and tailwater gages can be assigned to any outlet structure at a dam. Flow data computed for nonstandard outlets can be stored in the ADAPS database, then retrieved, and added to flows computed for standard outlets by DAMFLO.2.

\section{Time-Varying Input Data}

DAMFLO.2 was written as a stand-alone program and differs from the ADAPS software because data are not read directly from or written directly to the ADAPS database. Instead, data exchange is accomplished by use of flat files that are either output from or read by ADAPS. One advantage of using the flat files is that the program will not require substantial revisions as national USGS software and databases evolve. In addition, the program is totally independent of the data identification schemes necessary for USGS time-varying data; it requires only that the retrieval of the time-varying data groups be sequential by type in one flat file. For example, all date, time, and gage-height data would be sequentially filed for a headwater gage-height data type (data-group 1), followed by all date, time, and gage-height data for a tailwater gage-height data type (data-group 2), followed by all date, time, and gate-opening data for the gate-opening data type for a Tainter gate (data-group 3), and so forth. The order of the data groups within the time-varying data file can be specified in any order by the user. An example of the file configuration for the time-varying input data file is shown in figure 1. The example input data file contains headwater elevations (HW.DCP), tailwater elevations (TW.DCP), gate openings for four Tainter gates (GATE.1.DCP, GATE.2.DCP, GATE.3.DCP, and GATE.4.DCP), lock data (LOCK.DCP), and tailwater discharge data (TW.Q).

Although the time-varying data file can be generated using software other than ADAPS, the data should be stored in the ADAPS database to ensure that the data are permanently archived. Any needed time, shift, and datum corrections must be applied to the time-varying data by the ADAPS software or other software before the data are retrieved for use in DAMFLO.2. Rating table conversions of time-varying data are done by the ADAPS software where possible to take full advantage of the ADAPS datum and shift corrections and to ensure that as much rating data as possible are stored in the ADAPS database. If software other than ADAPS is used to provide time-varying data, that software will likewise have to perform these rating conversions. All other rating conversions are done by DAMFLO.2 and the rating shown in the DAMFLO.2 rating file.

The user can select time intervals for computations that differ from the time intervals of the time-varying input data, within certain constraints. This is especially convenient when the time-varying data are recorded at different time intervals. Time-varying data can be interpolated by linear or stair-step interpolation. In stair-step interpolation, such as would be used for Tainter gate data, a preceding input value is held constant until changed by a succeeding input value. There are no restraints on the number of outlet structures for which flows can be computed. All time-varying input data are verified by minimum, maximum, and first-difference edit checks. All computations are done in units of feet and seconds. 
TIME SERIES RECORD

\begin{tabular}{|c|c|c|c|c|c|}
\hline NAME & YEAR & MONTH & DAY & MINUTE & VALUE \\
\hline \multicolumn{6}{|c|}{ - - - - - - - - - - - - - - - - - - - - - - - - - - - - - - - - - - - - - - - - - - - - - - - - - - - - - - - - - - - - - - - - - - - - } \\
\hline HW. DCP & 2000 & 12 & 31 & 60 & 102.6 \\
\hline HW . DCP & 2000 & 12 & 31 & 120 & 102.35 \\
\hline $\mathrm{HW}$. DCP & 2000 & 12 & 31 & 180 & 101.98 \\
\hline$\cdots \cdots$ & $\cdots$ & $\cdots$ & $\cdots$ & $\cdots$ & $\ldots \ldots$ \\
\hline$\ldots \ldots$ & $\ldots$ & . & $\cdots$ & $\ldots$ & $\ldots \ldots$ \\
\hline HW . DCP & 2001 & 3 & 31 & 1440 & 102.38 \\
\hline TW.DCP & 2000 & 12 & 31 & 60 & 79.31 \\
\hline TW. DCP & 2000 & 12 & 31 & 120 & 78.72 \\
\hline TW. DCP & 2000 & 12 & 31 & 180 & 78.28 \\
\hline$\cdots \cdots$ & $\cdots$ & $\cdots$ & $\cdots$ & $\cdots$ & $\cdots \cdots$ \\
\hline$\cdots \cdots$ & $\cdots$ & $\cdots$ & $\cdots$ & $\cdots$ & $\cdots \cdots$ \\
\hline $\mathrm{TW} . \mathrm{DCP}$ & 2001 & 3 & 31 & 1440 & 80.97 \\
\hline GATE.1.DCP & 2000 & 12 & 31 & 60 & .6059999 \\
\hline GATE.1.DCP & 2000 & 12 & 31 & 120 & .6059999 \\
\hline GATE.1.DCP & 2000 & 12 & 31 & 180 & .6059999 \\
\hline$\cdots \cdots$ & $\cdots$ & $\cdots$ & . & $\cdots$ & $\ldots \ldots$ \\
\hline$\ldots \ldots$ & $\cdots$ & $\cdots$ & $\cdots$ & $\cdots$ & $\cdots \cdots$ \\
\hline GATE.1.DCP & 2001 & 3 & 31 & 1440 & 1.368 \\
\hline GATE . 2.DCP & 2000 & 12 & 31 & 60 & .524 \\
\hline GATE . 2.DCP & 2000 & 12 & 31 & 120 & .524 \\
\hline GATE . 2.DCP & 2000 & 12 & 31 & 180 & .524 \\
\hline$\cdots \cdots$ & $\cdots$ & $\cdots$ & $\cdots$ & $\cdots$ & $\cdots \cdots$ \\
\hline$\ldots \ldots$ & $\ldots$ & $\cdots$ & $\cdots$ & $\cdots$ & $\ldots \ldots$ \\
\hline GATE . 2.DCP & 2001 & 3 & 31 & 1440 & 1.221 \\
\hline GATE.3.DCP & 2000 & 12 & 31 & 60 & .588 \\
\hline GATE . 3.DCP & 2000 & 12 & 31 & 120 & .588 \\
\hline GATE . 3.DCP & 2000 & 12 & 31 & 180 & .588 \\
\hline$\cdots \cdots$ & $\cdots$ & $\cdots$ & $\cdots$ & $\cdots$ & $\cdots \cdots$ \\
\hline$\ldots \ldots$ & $\cdots$ & $\cdots$ & $\cdots$ & $\cdots$ & $\cdots \cdots$ \\
\hline GATE . 3.DCP & 2001 & 3 & 31 & 1440 & 1.328 \\
\hline GATE . 4.DCP & 2000 & 12 & 31 & 60 & .588 \\
\hline GATE . 4.DCP & 2000 & 12 & 31 & 120 & .588 \\
\hline GATE . 4.DCP & 2000 & 12 & 31 & 180 & .588 \\
\hline$\cdots \cdots$ & $\cdots$ & $\cdots$ & $\cdots$ & $\cdots$ & $\cdots \cdots$ \\
\hline$\ldots \ldots$ & $\ldots$ & . & . & $\ldots$ & $\ldots \ldots$ \\
\hline GATE . 4.DCP & 2001 & 3 & 31 & 1440 & 1.284 \\
\hline LOCK. DCP & 2000 & 12 & 31 & 60 & 1061 \\
\hline LOCK. DCP & 2000 & 12 & 31 & 1200 & 1061 \\
\hline LOCK. DCP & 2000 & 12 & 31 & 1260 & 1062 \\
\hline$\cdots \cdots$ & $\cdots$ & $\cdots$ & $\cdots$ & $\cdots$ & $\cdots \cdots$ \\
\hline$\cdots \cdots$ & $\ldots$ & .. & .. & $\ldots$ & $\ldots \ldots$ \\
\hline LOCK. DCP & 2001 & 3 & 31 & 1440 & 1117 \\
\hline $\mathrm{TW} \cdot \mathrm{Q}$ & 2000 & 12 & 31 & 60 & -9999 \\
\hline $\mathrm{TW} \cdot \mathrm{Q}$ & 2000 & 12 & 31 & 120 & -9999 \\
\hline $\mathrm{TW} \cdot \mathrm{Q}$ & 2000 & 12 & 31 & 180 & -9999 \\
\hline$\cdots \cdots$ & $\cdots$ & $\cdots$ & $\cdots$ & $\cdots$ & $\cdots \cdots$ \\
\hline$\cdots \cdots$ & $\cdots$ & $\cdots$ & $\cdots$ & $\cdots$ & $\cdots \cdots$ \\
\hline $\mathrm{TW} \cdot \mathrm{Q}$ & 2001 & 3 & 31 & 1440 & -9999 \\
\hline
\end{tabular}

Figure 1. Example of the file configuration for the time-varying input data. 


\section{Static Input Data}

Static input data describing the physical characteristics of the dam (such as sill elevations and gate widths), hydraulic ratings for computing coefficients used in the hydraulic equations, and control of flow-computation methodology are entered and updated in a SAS database using the SAS forms capability. A SAS database is used to store these data because there are no provisions in the ADAPS software for archiving such data.

The static input data in DAMFLO.2 are divided into three types: (1) stage limits, (2) hydraulic ratings, and (3) physical and hydraulic parameters. Outlet structures for each type of outlet are aggregated into sets that have similar physical configurations. For example, there could be two sets of Tainter gates at a dam. Set 1 might consist of Tainter gates one through four that have the same sill elevations, widths, hydraulic ratings, and so forth, for all openings in set 1. Likewise, set 2 might consist of Tainter gates five through eight that also have the same sill elevations, widths, hydraulic ratings, and so forth, for all openings in set 2, but differing from the openings in set 1 . The user should keep in mind that the set numbers are relative to the outlet types; therefore, set 1 for Tainter gates would not be the same as set 1 for spillways. In addition, it is recommended that the set numbers for each type of outlet be assigned sequentially beginning with 1 . Furthermore, it should be noted that the term set in the context of the static input data can refer to a group of outlets or to a single outlet (a set of one).

\section{Static Stage Data Limits}

The static input data for stage (or gage height) consist of minimum and maximum expected stage, maximum expected rate of change of stage, and datum corrections. Each set of static input data for stage is referenced using a stage-gage identification number, which should be assigned sequentially beginning with 1 .

\section{Static Hydraulic Rating Data}

The static input data for hydraulic ratings consist of rating type and a set number. As previously discussed, the set number refers to the outlets (or outlet) for which the hydraulic rating applies. In DAMFLO.2, hydraulic ratings are available for five different outlet types: Tainter gates, spillways, pumps, lock gates, and crest gages. For example, if the outlet type is a crest gate, the hydraulic ratings available are spillway head versus discharge or head-over-gate versus discharge.

\section{Static Physical and Hydraulic Parameter Data}

The static input data for the physical and hydraulic parameters at a dam are the data needed to define the physical properties of the outlets, such as sill elevations and gate widths, and various hydraulic coefficients and computational methods associated with the outlets.

\section{Program Operation}

To execute DAMFLO.2, the user must create a directory for each dam to be analyzed and in that directory, store the files containing the time-varying input data, static input data, and a short flat file containing process instructions or "calls" to the SAS programs. From that directory, the user will execute a DAMFLO.2 script program by typing in the following command: damflo. The DAMFLO script file will execute the DAMFLO programs that are stored in the directory /usr/opt/wrdapp/locapp/damflo. After the damflo command is entered, a menu will appear on the screen providing a list of options as shown on figure 2. Options 1 and 2 allow the user to specify whether plots and tables will be sent to the screen or sent to a printer. Option 3 sends unit-value and dailyvalue primary files to a printer and also produces unit-value and daily-value card image files that can be loaded into ADAPS without producing plots. Options 4-14 allow the user to input and edit the static data. Option 15 is used to generate screen plots of all hydraulic ratings. These options are discussed in more detail later in this report.

DAMFLO.2 is instructed to process data by "calls" to the SAS programs. Using a text editor, these calls are entered into a short flat file, which is executed by SAS. The user should name the file something meaningful, such 
RUN PRIMARIES:

1. Plot and table to the terminal screen.

2. Plot and table to the printer.

3. Only print $u v$ and dv primary files and produce $u v$ and $d v$ card image files.

EDIT DAMFLO STATIC DATA SETS:
4. Control
10. Locks
5. Interpolation
11. Lockgates
6. Ratings
12. Crest gates
7. Stage
13. Pumps
8. Tainter gates
14. Siphons
9. Spillways

OTHER PROGRAMS:

15. Plot hydraulic ratings

Select one of options 1-15:

Figure 2. Example of the damflo menu.

as run.primary as a reminder that it is used to perform primary flow computations. An example of such a file for computing flow through four Tainter gates, one lock, and one spillway using one headwater stage gage and one tailwater stage gage is shown in figure 3 . An illustration of the structure for this example is shown in figure 4 . The user invokes the programs to compute flow by choosing option 1,2, or 3 from the damflo menu and then entering the name of the file, such as run.primary. Details for these programs are given in the "Data Entry and Program Operation" section of this report.

The example in figure 3 demonstrates how the SAS code is modular in its application. The first line is a comment statement, delimited by the asterisk and semicolon. For developmental purposes, the asterisk can be used to temporarily deactivate some of the programs in the run.primary file by converting them to comment statements. For example, if tests were being run for one gate, an asterisk could be placed in front of all program calls after the first \%tainter call to temporarily prevent their execution.

The programs beginning with prt list the static data stored in the SAS database. The output is written to a file called sas.pgm.lst. These data should be printed with each primary that will be stored in the station file.

In the \%dam call, the user specifies the name of the file containing the time-varying data, the number of data groups in the time-varying data file (such as headwater gage height or gate opening), and the beginning and ending dates of computation (fig. 1). Other program calls describe pertinent information for flow computations and names of files to hold primary tables and data for input to the ADAPS database. For example, the \% tainter(1,1,2,3,0,1) call represents computation of flow for a Tainter gate (designated by \%tainter). The $(1,1,2,3,0,1)$ of the call specifies six arguments for the call, as described below: 


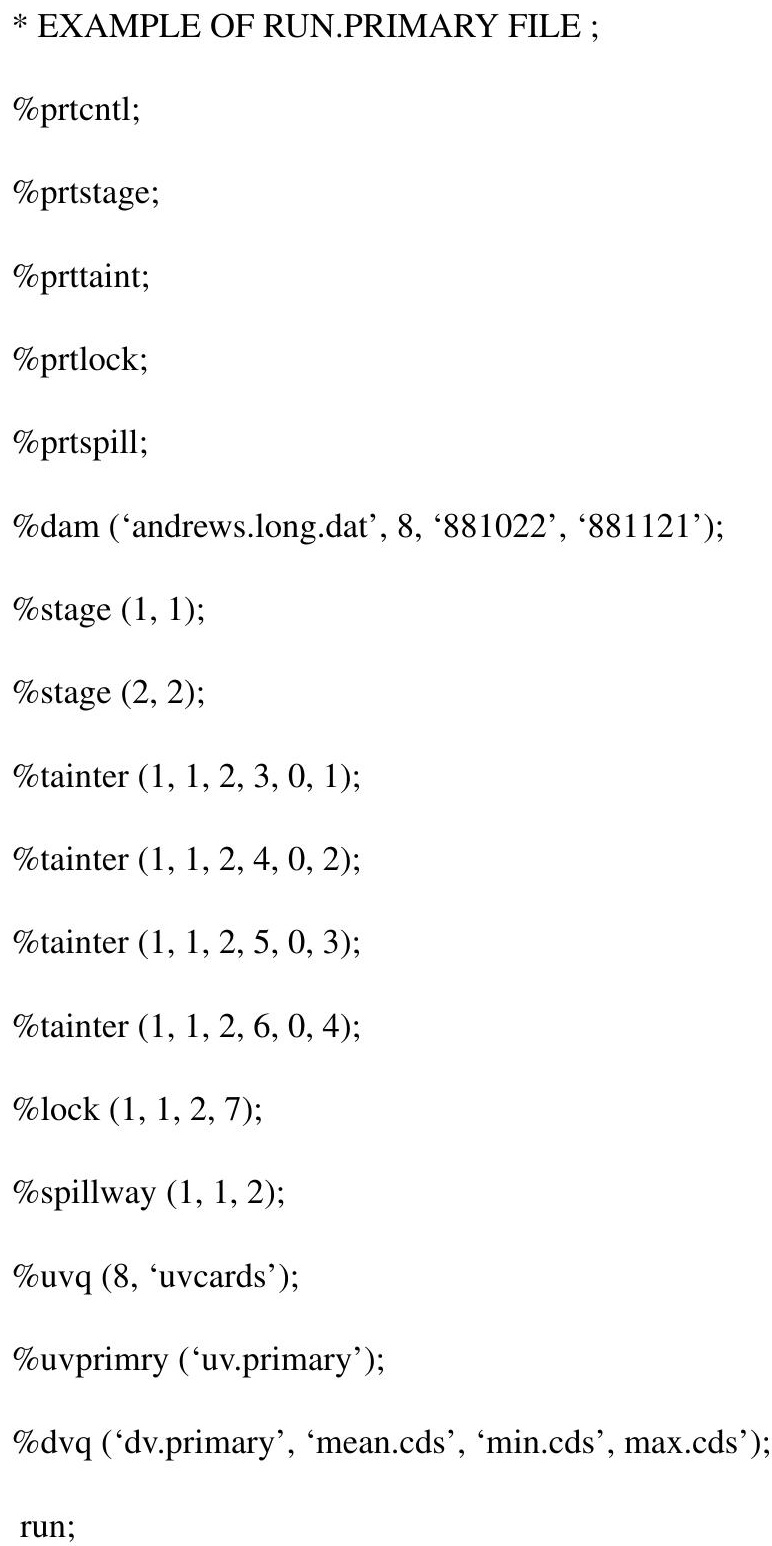

Figure 3. Example of a run.primary file.

Argument 1 (1) specifies that the data set number of the gate is "1", which DAMFLO.2 uses to locate the static physical and hydraulic parameter data for the gate in the static data file.

Argument 2 (1) specifies that the headwater time-varying data for this gate are stored in data group "1" in the time-varying data file.

Argument 3 (2) specifies that the tailwater time-varying data for this gate are stored in data group "2" in the time-varying data file.

Argument 4 (3) specifies that the gate-opening, time-varying data for the gate are stored in data group " 3 " in the time-varying data file. 


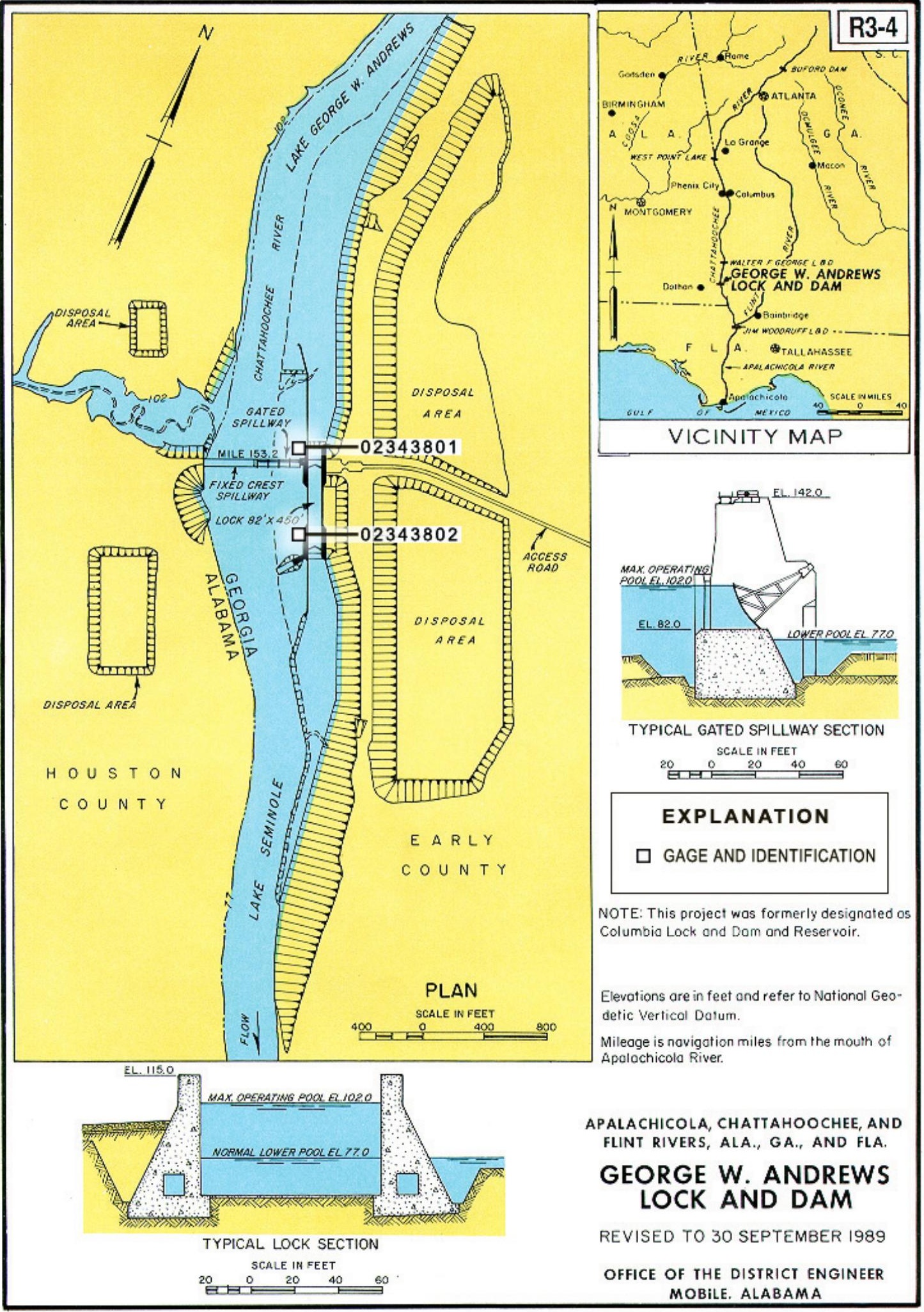

Figure 4. Structure used for the example run.primary file. 
Argument 5 (0) specifies that the difference in the gate-sill elevation and the downstream-bed elevation is zero. This parameter is to be used in an option of the program to determine if submerged orifice flow exists for the Tainter gate. If that option is not selected, then " 0 " is coded.

Argument 6 (1) is the user-specified number for the individual gate, "1" in this case.

In the example shown in figure 3, flows are to be computed for four gates. Once again referring to $\%$ tainter commands, argument 4 specifies gate-opening, time-varying data groups 3-6 and argument 6 specifies four individual gate openings (1-4). It is not necessary for all four gates to have the same values for arguments 2 and 3. For example, some of the gates may have time-varying headwater data behind stop logs whereas the others do not. In the example shown on figure 3, all four gates have the same physical and hydraulic parameter data in the static file indentified by argument 1 (set 1). Flows for any number of gates, locks, spillways, pumps, siphons, lock gates, and crest gates may be similarly computed by calls to the respective programs.

The arguments in single quotes in the last three calls (\%uvq, \%uvprimry, and \%dvq) identify the names of flat files that will contain primary computation listings and unit-value and daily-value data output in ADAPS cardinput format. The "run;" command at the end of the run.primary file is the SAS command used to execute the programs.

\section{Program Output}

From the damflo menu (options 1-3), the user can choose to have data plots and tables sent to the screen or to a printer. Options 1-3 will produce unit-value and daily-value primary computation tables and card-image files of unit-value and daily-value data for entry into ADAPS. Option 1 will send the primary computation tables and plots to the computer screen, whereas option 2 sends them to a printer. Option 3 will print out the primary computation tables without printing out the plots. Option 3 is useful for recomputing after errors detected by reviewing the initial plots have been corrected, and the user does not want to reproduce the plots.

The unit-value primary displays input data, submergence ratios, computed flows, flow types, and warning messages. The user can specify the time interval for tabulations. The time interval must be such that the number of tabulated values per day is evenly divisible by 12 , and the tabulation interval cannot be shorter than the computation interval. The daily-value primary displays daily minimum, daily maximum, and daily mean statistics of flow, and summarizes warning messages. The daily-value primary is printed separate from the unit-value primary to provide a compact summary of flows and warning messages. The primaries also are contained in flat files that can be printed.

Daily means of all instantaneous flows are computed using trapezoidal subareas of the hydrograph. Trapezoidal subareas of total unit-value flows are obtained by using the average of successive pairs of flows. The trapezoidal method is not used for lockage flows because those flows are mean flows over a computational time interval and not instantaneous.

Under flow conditions where the dam is no longer the control, such as when downstream stages are greater than a specified elevation or when the fall in the water-surface elevation across the dam is less than a specified amount, DAMFLO.2 can be forced to use flows determined from a tailwater gage. In addition, DAMFLO.2 also can be forced to use flows from a tailwater gage when an input parameter is missing in the computations.

In the transition between flows computed by DAMFLO.2 and flows from a tailwater flow station, an average of consecutive tailwater flows is used in the trapezoidal-averaging method for computing daily flows, rather than the average of the computed flow and the tailwater flow on either side of the transition, which would be more

accurate. For example, suppose that flows at the downstream stage-discharge station are 10,000 and 11,000 $\mathrm{ft}^{3} / \mathrm{s}$ at 2:00 and 3:00, respectively. Suppose that a flow of $9,000 \mathrm{ft}^{3} / \mathrm{s}$ is computed through the dam by DAMFLO.2 at 2:00, and that flow from the tailwater station is requested at 3:00 for one of the reasons listed above. For daily-value trapezoidal averaging, the $9,000 \mathrm{ft}^{3} / \mathrm{s}$ computed at 2:00 by DAMFLO.2 should be averaged with $11,000 \mathrm{ft}^{3} / \mathrm{s}$ 
computed by the tailwater rating. However, the program averages the 10,000 and $11,000 \mathrm{ft}^{3} / \mathrm{s}$ computed by the tailwater rating. This is done for computational expedience, because part of the computed total flow could be lock flow, which should not be trapezoidally averaged.

Graphic and interactive tabling capabilities of SAS are utilized by DAMFLO.2 to represent all the data contained in the unit-value and daily-value primary listings, including the input data, computed flows, warning flags, flow-type flags, and a representation of submergence ratio as appropriate for the outlet. An important feature of the program is that almost all information shown on the unit-value and daily-value primaries is shown on the plots; therefore, the user will not have to scan literally thousands of numbers.

For plots of unit-value data, the program will subdivide the selected time period of computation into subplots with a user-specified number of days per plot for each set of gates, locks, and so forth. For example, the user can specify that for a 47-day computation period, Tainter-gate data will be plotted in 4-day subplots to provide more detail, whereas headwater stage data could be plotted in 14-day subplots, if desired. Horizontal and vertical axes are uniformly scaled by category of plot within each execution of the program.

If the user chooses to display the plots and tables to the screen, the user progresses through the plots by clicking on the graph or by using the enter key on the keyboard. The user cannot back up through the plots. Questionable data detected by viewing the plots can be located in the interactive table by using the WHERE command listed at the top of the screen displaying the data. For example, the WHERE command can be used to list data where the submergence ratio is greater than a specified amount, or it can be used to list all data having a specified warning flag. Once the user is finished viewing the table, the screen can be closed by selecting FILE and CLOSE.

Total computed unit-value flows also are plotted with appropriate warning flags. It is possible to plot tailwater elevations against total computed outflow to evaluate the amount of backwater downstream of the dam, or more specifically, the lack of backwater at high stages when the dam outlets are totally submerged and submergence ratings are no longer valid. A hydrograph of daily minimum, maximum, and mean flows also is produced by the program. All warning messages included in the daily-values primary are presented on the hydrograph.

Running DAMFLO.2 requires more time to interactively examine the generated plots and tables than simply running the original FORTRAN 77 DAMFLO program, which runs quickly, but produces only primary listings. It should be kept in mind, however, that the subsequent visual evaluation of these lengthy numerical primaries without the aid of graphics would be longer than, and certainly not as effective as, a graphic evaluation. Alternately, by choosing option 2 from the damflo menu, the user can execute the DAMFLO.2 program in a batch mode without stepping through the interactive graphics and tabling. In this mode, the primary printouts, flow data for entry into ADAPS, and the plots are produced in files that are automatically sent to a printer for subsequent evaluation and storage in the station folder.

\section{HYDRAULIC METHODOLOGY}

Uniform, steady flow is assumed to exist during a computational interval. Seven different types of flow controls may be present at a structure: Tainter or sluice gates, fixed spillways, navigation locks, lock gates, crest gates, pumps, and siphons. As described below, flow computations are based on hydraulic theory and, in some cases, arbitrary flow-type classification methods. Collins (1977) described computational methods for calibrating most of the relations described below. Equations 1-21 for all flow computations are shown in table 1. 
Table 1. Flow controls and hydraulic equations, symbols, definitions, and units

[--, does not apply; <, less than; $\geq$, greater than or equal to; $\leq$, less than or equal to; >, greater than;. Symbols, definitions, and units are listed at the end of this table]

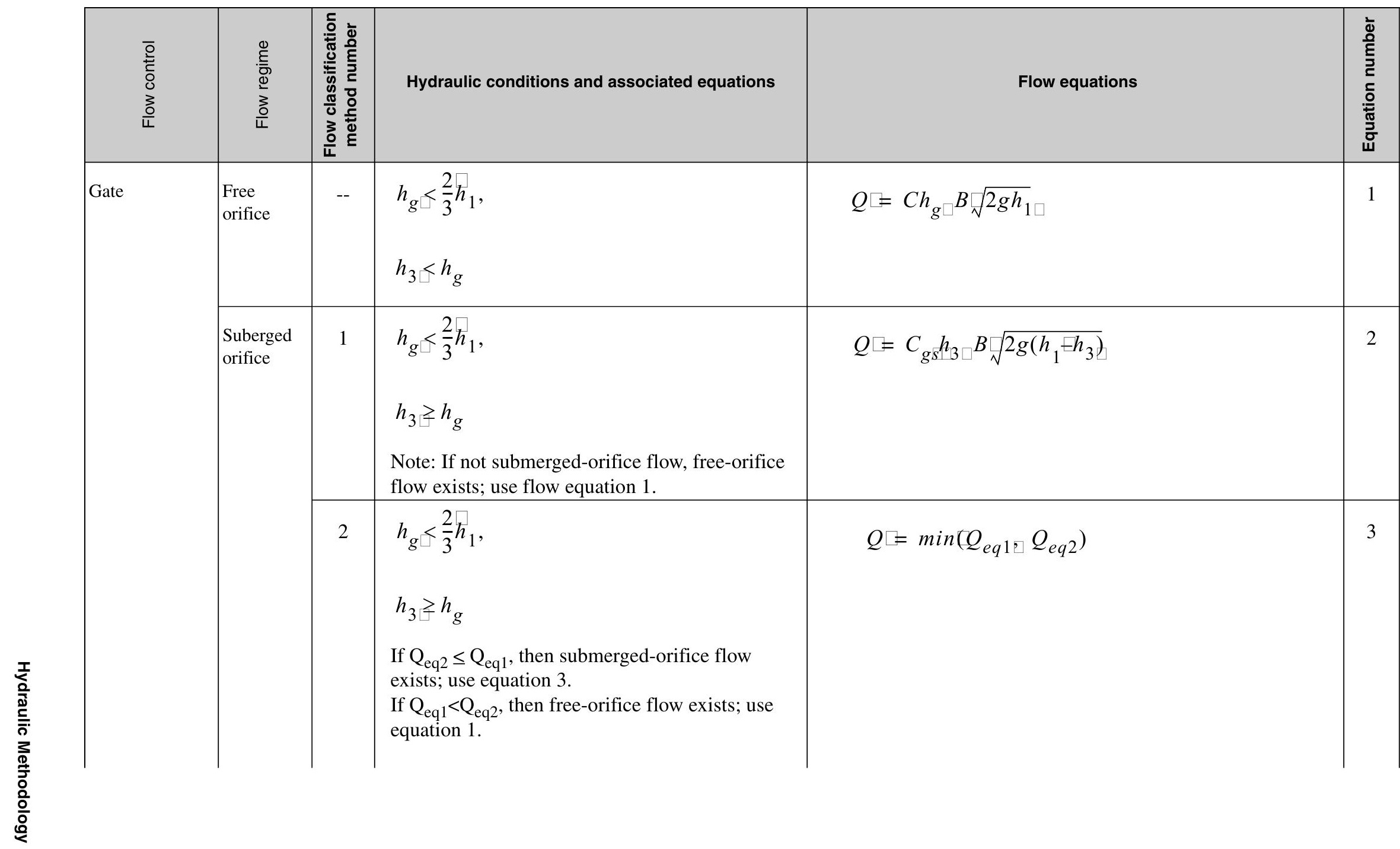


Table 1. Flow controls and hydraulic equations, symbols, definitions, and units (Continued)

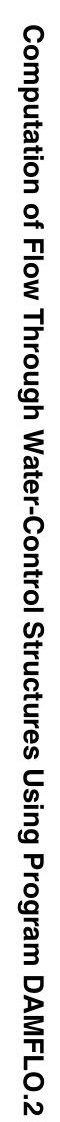

[--, does not apply; <, less than; $\geq$, greater than or equal to; $\leq$, less than or equal to; >, greater than;. Symbols, definitions, and units are listed at the end of this table]

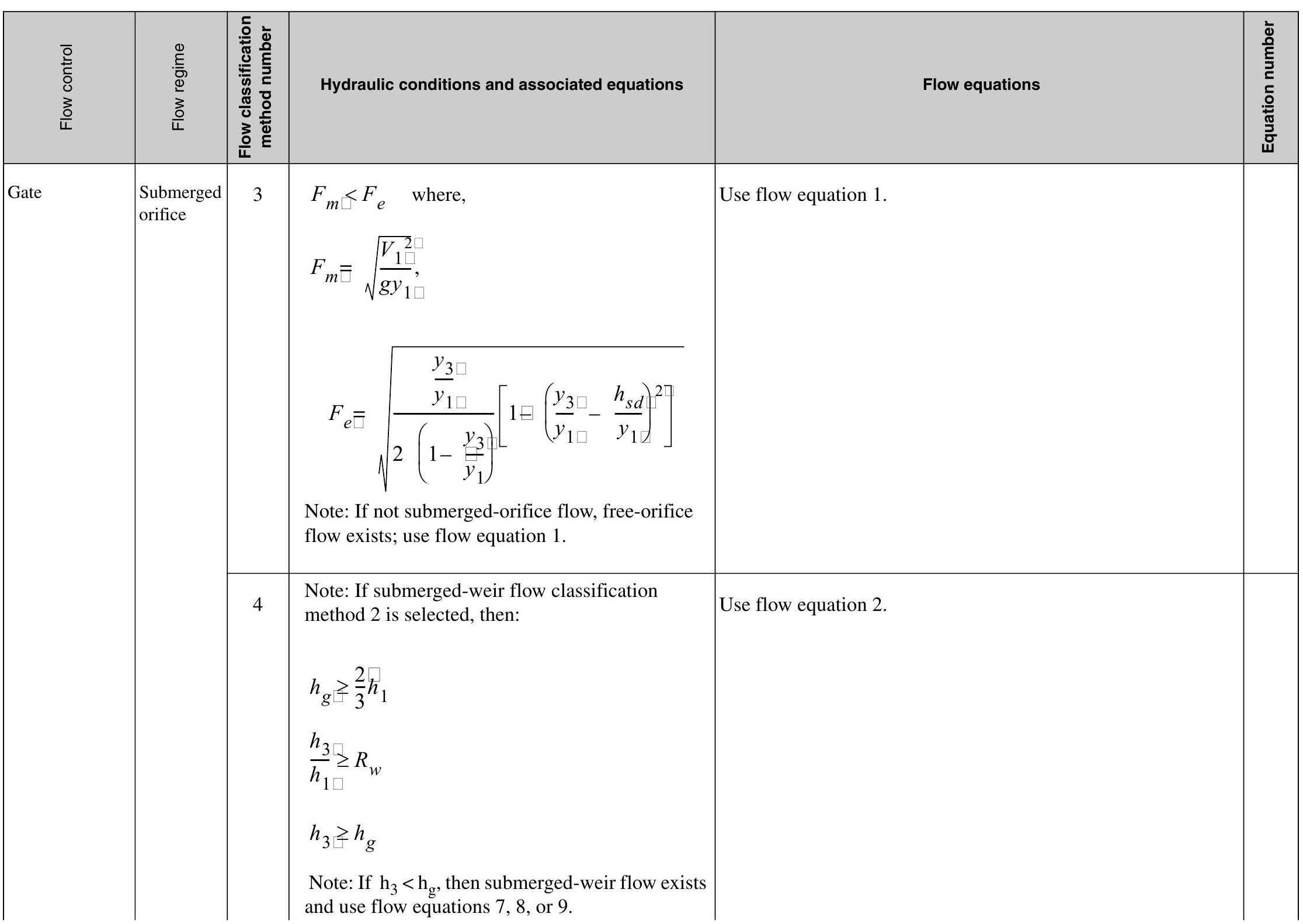


Table 1. Flow controls and hydraulic equations, symbols, definitions, and units (Continued)

[--, does not apply; <, less than; $\geq$, greater than or equal to; $\leq$, less than or equal to; >, greater than;. Symbols, definitions, and units are listed at the end of this table]

\begin{tabular}{|c|c|c|c|c|c|}
\hline $\begin{array}{l}\overline{0} \\
\text { 오 } \\
\overline{0} \\
\text { ż } \\
\text { 은 }\end{array}$ & 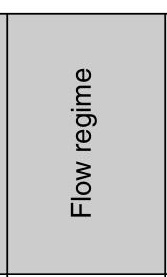 & 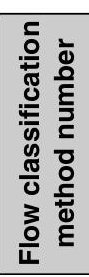 & Hydraulic conditions and associated equations & Flow equations & 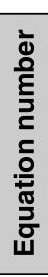 \\
\hline \multirow[t]{4}{*}{ Gate } & $\begin{array}{l}\text { Free orifice } \\
\text { leakage }\end{array}$ & -- & $h_{3} \leq h_{g l}$ & $Q \varpi=h_{g l \square} B \sqrt{2 g h_{1}}$ & 4 \\
\hline & \begin{tabular}{|l} 
Submerged \\
orifice \\
leakage
\end{tabular} & -- & $h_{3}>h_{g l}$ & $Q \sqsubset=h_{g l \square} B \sqrt{2 g\left(h_{1 \square} h_{3}\right)}$ & 5 \\
\hline & Free weir & -- & $\begin{array}{l}h_{g} \geq \frac{2}{3} h_{1}, \\
\frac{h_{3}}{h_{1}}<R_{w}\end{array}$ & $Q \square=C_{w} B h_{1 \square}^{3 / 2}$ & 6 \\
\hline & $\begin{array}{l}\text { Submerged } \\
\text { weir }\end{array}$ & 1 & $\begin{array}{c}h_{g} \geq \frac{2}{3} h_{1}, \\
\frac{h_{3}}{h_{1 \square}} \geq R_{w}\end{array}$ & $Q \sqsubseteq=C_{w} C_{w s} B h_{1 \square}^{3 / 2}$ & 7 \\
\hline
\end{tabular}


Table 1. Flow controls and hydraulic equations, symbols, definitions, and units (Continued)

[--, does not apply; <, less than; $\geq$, greater than or equal to; $\leq$, less than or equal to; >, greater than;. Symbols, definitions, and units are listed at the end of this table]

\begin{tabular}{|c|c|c|c|c|c|}
\hline 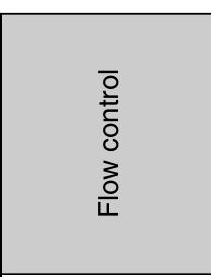 & 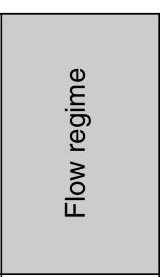 & 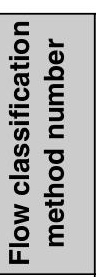 & Hydraulic conditions and associated equations & Flow equations & 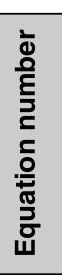 \\
\hline \multirow[t]{4}{*}{ Gate } & \multirow[t]{4}{*}{$\begin{array}{l}\text { Submerged } \\
\text { weir }\end{array}$} & \multirow[t]{4}{*}{2} & \multirow{4}{*}{$\begin{array}{l}h_{g} \geq \frac{2}{3} h_{1}, \\
\frac{h_{3}}{h_{1}} \geq R_{w} \\
h_{3}<h_{g} \\
\text { Note: If } h_{3} \geq \mathrm{h}_{\mathrm{g}} \text {, then submerged-orifice flow } \\
\text { exists and use equation } 2 \text {. }\end{array}$} & $Q \sqsubseteq=\sqrt{h_{1 \square} h_{3 \square}} f\left(h_{3}\right)$ & 8 \\
\hline & & & & & \\
\hline & & & & & \\
\hline & & & & $Q \sqsubseteq=\sqrt{2 g} \quad h_{3 \square} B \quad\left(J \sqrt{h_{1}-h_{3}}+K \sqrt{h_{3}} \sqrt{h_{1 \sqsubset} h_{3}}\right)$ & 9 \\
\hline Fixed spillway & Free weir & -- & $\frac{h_{3 s} \square}{h_{1 s}}<R_{w s}$ & $Q \sqsubset=C_{s w} B_{s} h_{1 s \square}^{3 / 2}$ & 10 \\
\hline \multirow[t]{3}{*}{ Fixed Spillway } & \multirow[t]{3}{*}{$\begin{array}{l}\text { Suberged } \\
\text { weir }\end{array}$} & \multirow[t]{3}{*}{--} & \multirow[t]{3}{*}{$\frac{h_{3 s}}{h_{1 s}} \geq R_{w s}$} & $Q \sqsubset=C_{s w} C_{s w s} B_{s} h_{1 s \square}^{3 / 2}$ & 11 \\
\hline & & & & $Q \sqsubseteq=\sqrt{h_{1 \square}-h_{3 \square}} f\left(h_{3}\right)$ & 12 \\
\hline & & & & $Q \sqsubseteq \sqrt{2 g} h_{3 s} B_{s \square}\left(D \sqrt{h_{1 \sqsubset}^{-h_{3}}}+M \sqrt{h_{3 s} \square} \sqrt{h_{1 \sqsubset} h_{3}}\right)$ & 13 \\
\hline Locks & Lock flow & -- & $\left(h_{1 \square} h_{3}\right)>0 \square$ & $Q \sqsubseteq=N A \frac{\left(h_{1}-h_{3}\right)}{\left(T_{2 \square}-T_{1}\right)}$ & 14 \\
\hline
\end{tabular}


Table 1. Flow controls and hydraulic equations, symbols, definitions, and units (Continued)

[--, does not apply; <, less than; $\geq$, greater than or equal to; $\leq$, less than or equal to; >, greater than;. Symbols, definitions, and units are listed at the end of this table]

\begin{tabular}{|c|c|c|c|c|c|}
\hline $\begin{array}{l}\overline{0} \\
\text { 오 } \\
\overline{0} \\
\text { ż } \\
\text { 은 }\end{array}$ & 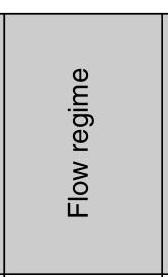 & 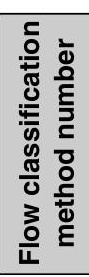 & Hydraulic conditions and associated equations & Flow equations & 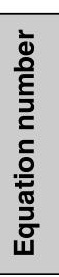 \\
\hline & Leakage & -- & $\left(h_{1 \varpi} h_{3}\right)>0$ & $Q \sqsubset=$ constant & 15 \\
\hline Lock gates & \begin{tabular}{|l|} 
Submerged \\
weir
\end{tabular} & -- & Assumed to be submerged for estuarine streams. & $Q \sqsubseteq \sqrt{h_{1 \sqsubset} h_{3}} f\left(h_{l k g}\right) f\left(h_{1}\right)$ & 17 \\
\hline & $\begin{array}{l}\text { Free weir, } \\
\text { over top } \\
\text { of gate }\end{array}$ & & $h_{1 c}>h_{1 t}$ & $Q \sqsubset=N_{c s} f\left(h_{l t}\right)$ & 19 \\
\hline Pumps & -- & -- & $h_{1 \sqsubset} h_{3}>0$ & $Q=f\left(h_{1}-h_{3}\right) f\left(\frac{R P M_{m}}{R P M_{d}}\right)$ & 20 \\
\hline Siphons & -- & -- & -- & 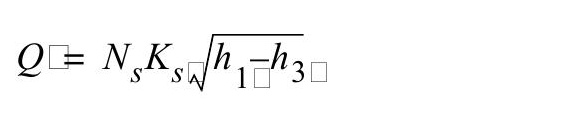 & 21 \\
\hline
\end{tabular}




\section{Symbols, definitions, and units (for table 1)}

\begin{tabular}{|c|c|c|}
\hline Symbol & Definition & Unit \\
\hline A & Plan area of lock chamber & square foot \\
\hline B & Lateral width of tainter gate & foot \\
\hline $\mathrm{B}_{\mathrm{s}}$ & Length of fixed spillway & foot \\
\hline $\mathrm{C}$ & Free-orifice flow coefficient & \\
\hline $\mathrm{C}_{\mathrm{gs}}$ & Submerged-orifice flow coefficient & \\
\hline $\mathrm{C}_{\mathrm{sw}}$ & Free-weir flow coefficient for fixed spillway & \\
\hline $\mathrm{C}_{\mathrm{sws}}$ & Submerged-weir coefficient for fixed spillway & \\
\hline $\mathrm{C}_{\mathrm{w}}$ & Free-weir flow coefficient for gate & \\
\hline $\mathrm{C}_{\mathrm{ws}}$ & Submerged-weir flow coefficient for gate & \\
\hline $\mathrm{D}$ & Regression coefficient & \\
\hline $\mathrm{F}_{\mathrm{e}}$ & A critical value at which a hydraulic jump will move upstream & \\
\hline $\mathrm{F}_{\mathrm{m}}$ & Froude number of free-orifice flow at vena contracta & \\
\hline $\mathrm{g}$ & Acceleration of gravity & square foot per second \\
\hline $\mathrm{h}_{1}$ & Static headwater elevation referenced to gate sill & foot \\
\hline $\mathrm{h}_{1 \mathrm{c}}$ & Static headwater elevation referenced to crest gate sill & foot \\
\hline $\mathrm{h}_{1 \mathrm{~s}}$ & Static headwater elevation referenced to fixed spillway crest & foot \\
\hline $\mathrm{h}_{1 \mathrm{t}}$ & Static headwater elevation referenced to top of crest gates & foot \\
\hline $\mathrm{h}_{3}$ & Static tailwater elevation referenced to gate sill & foot \\
\hline $\mathrm{h}_{3 \mathrm{~s}}$ & Static tailwater elevation referenced to fixed-spillway crest & foot \\
\hline $\mathrm{h}_{\mathrm{d}}$ & Design $\mathrm{h} 1$ - $\mathrm{h} 3$ for lock leakage computations & foot \\
\hline $\mathrm{h}_{\mathrm{g}}$ & Vertical gate opening & foot \\
\hline $\mathrm{h}_{\mathrm{gl}}$ & Vertical gate opening for gate leakage & foot \\
\hline $\mathrm{h}_{\mathrm{lkg}}$ & Horizontal opening of lock gate & foot \\
\hline $\mathrm{h}_{\mathrm{sd}}$ & Difference between gate sill elevation and streambed elevation downstream of the sill & foot \\
\hline $\mathrm{J}$ & Regression coefficient & \\
\hline $\mathrm{K}$ & Regression coefficient & \\
\hline
\end{tabular}




\section{Symbols, definitions, and units (for table 1)}

\begin{tabular}{|c|c|c|}
\hline Symbol & Definition & Unit \\
\hline $\mathrm{K}_{\mathrm{s}}$ & Constant in siphon-flow equation & \\
\hline M & Regression coefficient & \\
\hline $\mathrm{N}$ & Number of lockages during computation interval & \\
\hline $\mathrm{N}_{\mathrm{c}}$ & Number of open crest gates during computation interval & \\
\hline $\mathrm{N}_{\mathrm{cs}}$ & Number of closed crest gates & \\
\hline $\mathrm{N}_{\mathrm{s}}$ & Number of siphons in operation during a computation interval & \\
\hline $\mathrm{q}_{11}$ & Lock leakage factor & cubic foot per second \\
\hline Q & Flow & cubic foot per second \\
\hline $\mathrm{R}_{\mathrm{w}}$ & Value of $h_{3} / h_{1}$ (usually 0.6 ) above which submerged weir flow exists at Tainter gate & \\
\hline $\mathrm{R}_{\mathrm{ws}}$ & Value of $h_{3} / h_{1}$ (usually 0.6 ) above which submerged weir flow exists at fixed spillway & \\
\hline $\mathrm{RPM}_{\mathrm{d}}$ & Design pump revolutions per minute & \\
\hline $\mathrm{RPM}_{\mathrm{m}}$ & Measured pump revolutions per minute & \\
\hline $\mathrm{T}_{1}$ & Time at beginning of computation interval & second \\
\hline $\mathrm{T}_{2}$ & Time at end of computation interval & second \\
\hline $\mathrm{V}_{1}$ & Velocity of free-orifice flow at vena contracta downstream of gate & foot per second \\
\hline $\mathrm{y}_{1}$ & Depth of water at vena contracta of free-orifice flow downstream of the gate & foot \\
\hline $\mathrm{y}_{3}$ & Depth of water downstream of hydraulic jump downstream of gate & foot \\
\hline
\end{tabular}




\section{Gate Flow}

Gates may be either Tainter gates or flat sluice gates. Normally, water flows in only one direction through gates, but DAMFLO.2 allows upstream flows, which sometimes occur in south Florida. Flow through gates may be orifice flow or weir flow, depending on the gate opening and its relation to the headwater and tailwater elevations. In orifice flow, water flows beneath the partially opened gate. In weir flow, the gate is removed from the water and does not affect flow through the structure. Both flow types may be free or submerged, depending on the magnitude of the tailwater elevation relative to the headwater and gate opening.

Unlike sluice gate openings, Tainter gate openings usually cannot be measured directly. For Tainter gates, a cable driving a recording instrument usually is attached to a reference point on the top of the gate or to a shaft that opens the gate. The instrument readings are correlated to gate openings, which can be computed using equations developed by Collins (1977) and shown in appendix 2.

\section{Orifice Flow}

The "C" coefficient in equation 1 (table 1 ) for free-orifice flow is related to the vertical gate opening $\left(\mathrm{h}_{\mathrm{g}}\right)$ by calibration, and the relation is loaded into a free-orifice rating (FOR) as described in the "Ratings (option 6)", section of this report. The free-orifice equation agrees with equations presented in most textbooks, and will not be discussed further.

The submerged-orifice-flow equation, however, does differ. Most textbooks (Merritt, 1983) give the following equation for submerged-orifice flow:

$$
Q \sqsubset=C_{g t} h_{g} B \sqrt{2 g\left(h_{1 \square} h_{3}\right)},
$$

where

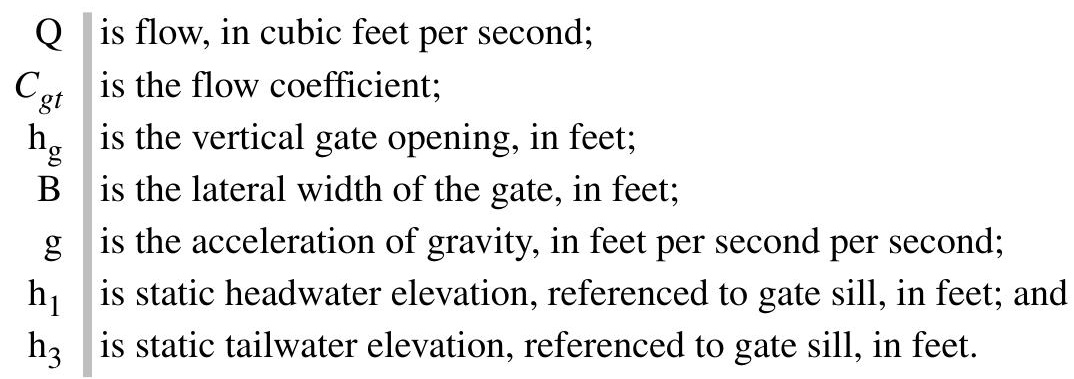

This equation differs from the USGS equation in that $h_{3}$ is used by the USGS (Collins, 1977) rather than $h_{g}$ (eq. 2, table 1). Collins used equation 2, because it simplified the development of a calibration relation. Flows should be directly related to $h_{g}$, as shown in equation 2 , and inversely related to $h_{3}$, as shown by equation 22 , because the "control" section for the flow is the opening of the gate $\left(\mathrm{h}_{\mathrm{g}}\right)$, not the tailwater section $\left(\mathrm{h}_{3}\right)$. In the USGS method as presented by Collins (1977), $\mathrm{C}_{\mathrm{gs}}$ is related to the submergence ratio $\left(\mathrm{h}_{3} / \mathrm{h}_{\mathrm{g}}\right)$ by calibration using equation 23. In DAMFLO.2, this relation is loaded into a submerged-orifice rating (SOR) as described in the "Ratings" section of this report.

$$
C_{g s}=C_{g t}\left(\frac{h_{3}}{h_{g}}\right)^{y},
$$

where

$\mathrm{h}_{3}$ is static tailwater elevation, referenced to gate sill, in feet;

$\mathrm{h}_{\mathrm{g}}$ is the vertical gate opening, in feet; and

$\mathrm{y}$ is the slope of the regression line for the relation between $\mathrm{h}_{3} / \mathrm{h}_{\mathrm{g}}$ and $\mathrm{C}_{\mathrm{gs}}$. 
When $y=-1.00$, the USGS $C_{g s}$ is related to the textbook $C_{g t}$, as shown in equation 23. In addition, if $y=-1.00$, then equation 23 can be substituted into the equation 2 (table 1) for submerged orfice flow to get the textbook submergedorifice flow equation 22 .

The USGS $\mathrm{C}_{\mathrm{gs}}$ coefficient appears to be strongly related to the submergence ratio $\left(\mathrm{h}_{3} / \mathrm{h}_{1}\right)$, but this is only an artifact of the use of $h_{3}$ in the flow equation 2, rather than $h_{g}$. However, the exponent of the USGS equation for computing $\mathrm{C}_{\mathrm{gs}}$ is not always exactly -1.00 , and at low submergence ratios, the relation sometimes becomes curvilinear. In the zone where the relation is curvilinear, flows are probably in transition from submerged-orifice flow to free-orifice flow, or flows may be free-orifice flow but erroneously classified as submerged flow. Therefore, the relation is useful in defining zones of transitional flow. Limited tests have shown that the USGS and textbook methods for computing free-orifice flow give the same flow results.

In DAMFLO.2, three methods are provided to differentiate between free- and submerged-orifice flow (table 1). A fourth method shown in table 1 is used to differentiate between submerged-orifice and submerged-weir flow, as discussed in the "Differentiation Between Submerged-Orifice and Submerged-Weir Flow Conditions" section. In method 1, Collins (1977) assumed that submerged-orifice flow (eq. 2) exists when $h_{g}<2 / 3 h_{1}$ (the gate opening is less than critical-flow depth at the gate) and $h_{3} \geq h_{g}$ (the tailwater is higher than the lower lip of the Tainter gate) (flow-classification method 1, eq. 2, table 1). Obviously, with small gate openings and very high velocities (20 to $30 \mathrm{ft} / \mathrm{s}$ ), a hydraulic jump could occur downstream and free-orifice flow could exist, with $\mathrm{h}_{3}$ being much higher than $\mathrm{h}_{\mathrm{g}}$.

In method 2, both free and submerged-orifice flows are computed, and the lesser of the two is arbitrarily chosen as the computed flow (flow-classification method 2, eq. 3, table 1). This method accounts for free-orifice flow when $h_{3}$ is greater than $h_{g}$.

Flow-classification method 3 is an alternative method for distinguishing between free- and submerged-orifice flow, and has not been extensively tested within the USGS. As such, flow-classification method 3 (also referred to as the hydraulic jump method) should not be used without verification by flow measurements. Method 3 is presented as an alternative to methods 1 and 2, which are not based on hydraulic theory. In the verification process, DAMFLO.2 can be used to generate flows and flow types that can be inspected with comparisons of the relation of tailwater elevation to the amount of vertical gate opening to help determine whether method 3 is valid (flowclassification method 3, eq. 2, table 1).

Flow-classification method 3 is based on the idea that a free jet of water flowing through a Tainter gate will be in supercritical flow, which will result in a hydraulic jump downstream (fig. 5). If the sequent depth of the hydraulic jump is large enough and the jump is too close to the Tainter gate, then it may drown out the jet, resulting in submerged-orifice flow. The location of the hydraulic jump is a function of the downstream geometry and the jet velocity. Typically, structures are designed so that the hydraulic jump will form near the sill, but may actually form closer to the orifice if the jet velocity is too low. The criterion for the flow downstream of the Tainter gate can be expressed in terms of the Froude number, $F_{m}$ (table 1), at the vena contracta. A critical value, $F_{e}$ (table 1), as presented by Chow (1959, p. 412-414) can be computed at the vena contracta for the condition where a downstream hydraulic jump will start moving upstream. It is assumed that if the hydraulic jump moves upstream of the vena contracta, then some form of submerged-orifice flow may exist. $F_{\mathrm{e}}$ is computed using the depth of the water at the vena contracta, the depth of water downstream of the hydraulic jump, and the amount of drop-off in the bottom of the stream in the vicinity of the hydraulic jump. If $F_{m}$ is less than $F_{e}$, then the hydraulic jump will move upstream and some form of submerged-orifice flow should exist; otherwise, free-orifice flow should exist.

Three types of orifice flow may occur at a gate: (1) truly free flow where flow at the vena contracta is supercritical, (2) truly submerged orifice flow where the water surface downstream of the gate is ponded all the way to the gate, and (3) an indeterminate zone of submerged-orifice flow where the vena contracta downstream of the gate is partially submerged by a hydraulic jump. Flow-classification method 3 would consider flow types 2 and 3 to be submerged-orifice flow. A detailed discussion of the theory for method 3 is provided in appendix 3 of this report. 

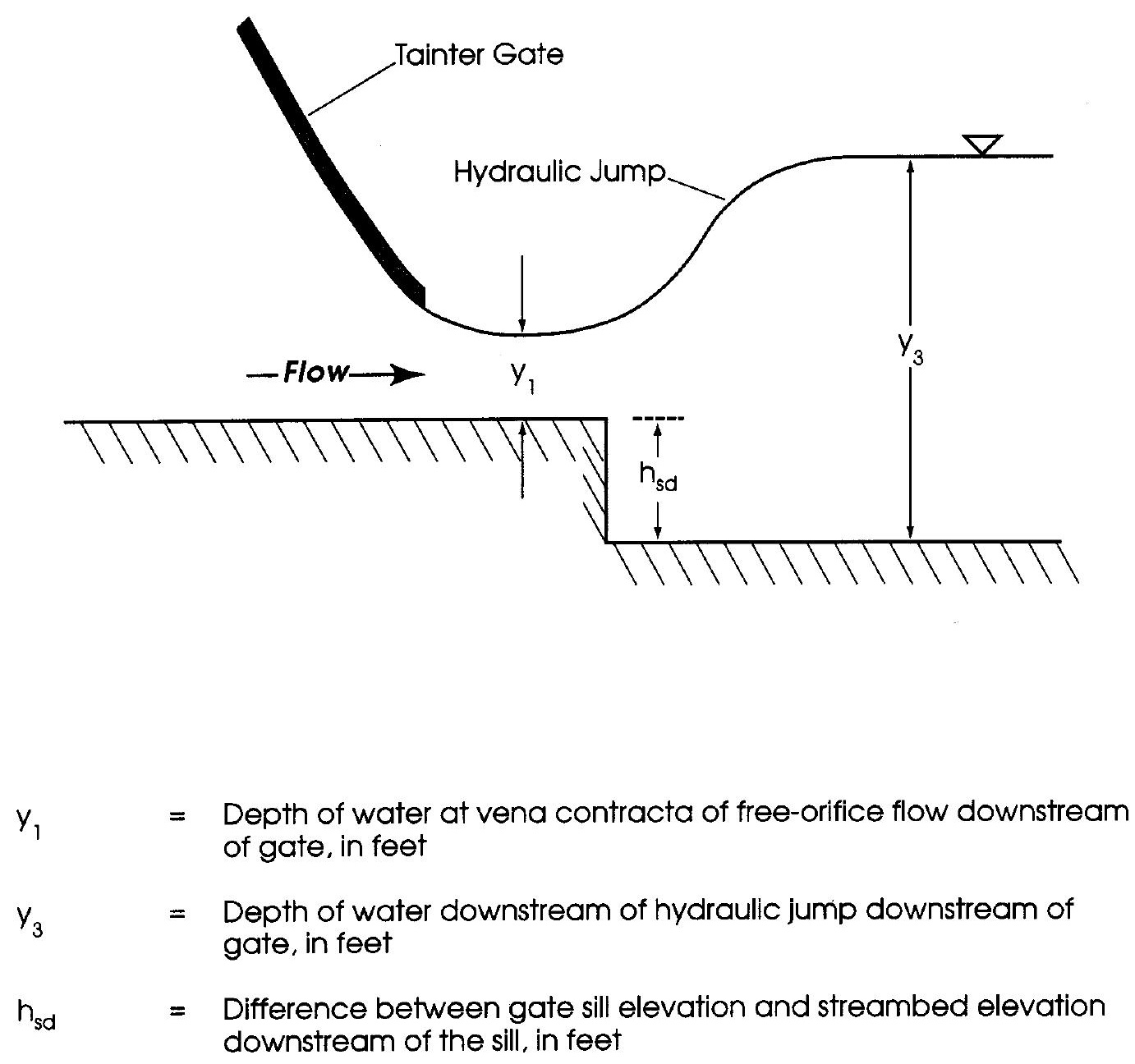

Figure 5. Hydraulic jump downstream of a Tainter gate.

\section{Leakage for Free- and Submerged-Orifice Flow}

Leakage for free- and submerged-orifice flow is computed using equations 4 and 5, respectively, as listed in table 1. Leakage is assumed to occur along the lower edge of a gate when it is closed, and no leakage is assumed to occur when the gate is opened. An effective gate opening $\left(\mathrm{h}_{\mathrm{g}}\right)$ for the leakage is computed by inserting values of $\mathrm{Q}$, $\mathrm{B}, \mathrm{h}_{1}$, and $\mathrm{h}_{3}$ in equations 4 or 5 and solving for $\mathrm{h}_{\mathrm{g} 1}$. Equations 4 and 5 are based on equation 1 for free-orifice flow, except that $h_{1}-h_{3}$ is used for submerged-orifice leakage, rather than $h_{1}$. The "C" coefficient (eq. 1) is incorporated in the calibrated $\mathrm{h}_{\mathrm{gl}}$ (eqs. 4 and 5) on the assumption that $\mathrm{h}_{\mathrm{gl}}$ does not change and, therefore, " $\mathrm{C}$ " should not change. It also is assumed that $\mathrm{h}_{\mathrm{gl}}$ for free-orifice leakage would be the same as for submerged-orifice leakage, but this should be verified by flow measurements. Submerged-orifice leakage flow is assumed to occur when $h_{3}$ is greater than $\mathrm{h}_{\mathrm{gl}}$, because the leakage flows are probably so small that a large hydraulic jump could not be formed downstream of the gate. 


\section{Weir Flow}

According to Collins (1977), the broad-crested weir equations 6 and 7 (table 1) with static head as the explanatory variable can be used to compute free- and submerged-weir flow through the gates, respectively. The " $\mathrm{C}_{\mathrm{w}}$ " coefficient for free-weir flow in equation 6 is related to $\mathrm{h}_{1}$ by calibration and is loaded into a free-weir rating (FWR) as described in the "Ratings (option 6)" section of this report. The submerged-weir flow equation uses methods documented by Hulsing (1967), in which the submergence coefficient, $\mathrm{C}_{\mathrm{ws}}$, that adjusts $\mathrm{C}_{\mathrm{w}}$ is related to the submergence ratio $\left(\mathrm{h}_{3} / \mathrm{h}_{1}\right)$ by calibration, and the relation is loaded into a submerged-weir rating (SWR) as described in the "Ratings (option 6)" section of this report (flow classification method 1, eq. 7, table 1). As shown by Hulsing (1967) for round-crested weirs and highway embankments, the relation for the submergence coefficient is curvilinear, an undesirable feature if extrapolation is necessary. Therefore, two additional methods that use the square root of fall are provided for computing submerged-weir flow. Flow-computation method 2 utilizes the unit fall method documented by Kennedy (1984). In this method, the ratio of the measured flow to the square root of measured fall is related to $\mathrm{h}_{3}$ (eq. 8 , table 1 ) by calibration, and the relation is loaded into a unit-fall rating (UFL) as described in the "Ratings (option 6)" section of this report. The advantage of this relation is that it is usually linear, and flow goes to zero as the square root of fall goes to zero. A disadvantage of flow-computation method 2 is that the ratio of measured flow to the square root of measured fall cannot be evaluated at a zero fall, and the rating cannot be defined as fall approaches zero. The method, however, can be used when the upstream velocity head minus the friction losses between $h_{1}$ and $h_{3}$ can be assumed to equal zero for all $h_{3}$ 's and when the fall does not approach zero.

If the difference between upstream and downstream velocity head, entrance losses, and friction losses between $h_{1}$ and $h_{3}$ cannot be neglected, and fall goes to zero, or very close to zero, then submerged-weir flows can be computed using the velocity-fall method (VELF) (eq. 9, table 1), which is described in appendix 1. In the VELF method, velocity / $(2 \mathrm{~g})^{0.5}$ is related to the square root of the fall and the cross-product of the square root of $h_{3}$ and the square root of fall. The $(2 \mathrm{~g})^{0.5}$ term is included to produce a regression coefficient that approximates a contraction coefficient. Equation 9 is determined by regression, and a rating table is not needed. As described in appendix 1, the velocity-fall method was tested using flow data from dams in south Florida and synthetic data from a step-backwater model.

\section{Differentiation Between Free- and Submerged-Weir Flow Conditions}

Collins (1977) stated:

The criteria for distinguishing free- and submerged-weir flow is not well defined in the literature. In fact, very little information is available on submerged broad-crested weir flow. Hulsing (1967) stated that submergence has no effect on the discharge of a broad-crested weir if the submergence ratio is less than 0.85 . The geometric and hydraulic properties of gate sills are similar to the geometric and hydraulic properties of a large Parshall flume. Chow (1959) stated that the discharge for a large Parshall flume is not affected by submergence if the ratio is less than 0.80. Hulsing (1967) also presented curves for ogee-shaped spillways and highway embankments, showing that the discharge is reduced slightly at submergence ratios greater than 0.5. After considering the above information, a submergence ratio of 0.6 was chosen... However, the equations used for free- and submerged-weir flow allow this point to be flexible. If the known breakpoint is greater than 0.6 , the value of the submergence correction, $\mathrm{C}_{\mathrm{ws}}$, will be 1.0 for all submergence ratios between 0.6 and the known breakpoint. Many structures where these methods would be used normally are not operated with weir control if the submergence ratio is less than about 0.8 .

The "breakpoint" ( $\mathrm{R}_{\mathrm{w}}$ in table 1) described by Collins (1977) is better defined as the lower limit of submerged-weir flow. In DAMFLO.2, the user may vary the submergence ratio $\left(\mathrm{h}_{3} / \mathrm{h}_{1}\right.$ in table 1$)$ used for the lower limit $\left(\mathrm{R}_{\mathrm{w}}\right.$ in table 1$)$ from 0.6 to 1.00 . These comments also apply for the fixed-spillway computations described below. 


\section{Differentiation Between Submerged-Orifice and Submerged-Weir Flow Conditions}

Two methods are provided for distinguishing submerged-weir flow from submerged-orifice flow in table 1. Flow-classification method 1 for submerged-weir flow, developed by Collins (1977), requires that the submergence ratio $\left(h_{3} / h_{1}\right)$ must be greater than 0.6 (approximately the depth of critical flow) at the gate, and that $h_{\mathrm{g}}$ must be greater than or equal to $2 / 3 \mathrm{~h}_{1}$ (approximately the depth of critical flow) at the gate for submerged-weir flow to exist. In other words, subcritical flow must exist at the gate, and the lower lip of the gate must be at an elevation higher than critical depth.

If $h_{3}$ were larger than $h_{g}$, however, then submerged-orifice flow could possibly exist rather than submergedweir flow. Therefore, in flow-classification method 2 for submerged-weir flow, a third criterion is added to distinguish between submerged-weir flow and submerged-orifice flow. When $h_{3}$ is less than $h_{g}$, then submergedweir flow is assumed. When $h_{3}$ is greater than or equal to $h_{g}$, then submerged-orifice flow is assumed (flowclassification method 4 for submerged-orifice flow). If a large amount of fall exists across the dam, and $h_{3}$ is not much larger than $h_{g}$, it might be possible that flow is drawn down below the gate, but recovers elevation downstream of the gate. In that case, method 1 might be satisfactory. In addition, if the gate is only partially in the water for a large gate opening, the gate may be causing only minor energy losses and has not formed a submergedorifice control section. In this case, method 1 should be used. If the fall and velocities across the dam are somewhat low, and $\mathrm{h}_{3}$ is much larger than $\mathrm{h}_{\mathrm{g}}$, then method 2 might be more applicable.

\section{Fixed-Spillway Flow}

The fixed spillway at most structures has an ogee or rounded crest. Equation 10 (table 1) is used for computing free-weir flow. The " $\mathrm{C}_{\mathrm{sw}}$ " coefficient is related to $\mathrm{h}_{1}$ by calibration, and the relation is loaded into freeweir rating for spillways (FSPIL) as described in the "Ratings (option 6)" section of this report. Submerged-weir flow for fixed spillways can be computed using equation 11 (Hulsing, 1967), using equation 12 (the unit-fall method by Kennedy, 1984), or using equation 13 (the velocity-fall method). See the "Weir-Flow" section of this report and appendix 1 for detailed explanations of these alternatives for computing submerged-weir flow. In equation 11 , the " $\mathrm{C}_{\mathrm{sws}}$ " coefficient is related to the submergence ratio $\left(\mathrm{h}_{3} / \mathrm{h}_{1}\right)$ by calibration, and the relation is loaded into a submerged-weir rating (SSPIL) as described in the "Ratings (option 6)" section of this report. In equation 12, the ratio of flow divided by the square root of fall is related to $h_{3}$ by calibration, and the relation is loaded into a unit-fall rating (UNFSP) as described in the "Ratings (option 6)" of this report. In equation 13, velocity/ $(2 \mathrm{~g})^{0.5}$ is related to the square root of fall and the cross-product of the square root of $h_{3}$ and the square root of fall. The relation is used directly, so a rating table is not necessary.

A submergence ratio $\left(\mathrm{h}_{3 \mathrm{~s}} / \mathrm{h}_{1 \mathrm{~s}}\right)$ of 0.6 is recommended by Collins (1977) as the limiting point for free- or submerged-weir flow by the same criteria described for gates. If enough data are available to define a unique limiting point for a site, then a value between 0.6 and 1.0 can be specified in the program. DAMFLO.2 allows for positive and negative flows across the spillway. For more detail, see the discussion of weir flow in the "Gate Flow" section and appendix 1 of this report.

\section{Lock Flow}

Lock flow is the total volume of water (in cubic feet) passing through the lock during a computational time period, divided by the length of the time period (in seconds), as shown by equation 14 in table 1 . The program accepts a direct lock count over a recording time interval, or a cumulated lock count, measured by a potentiometer, that is differenced once every recording interval to compute the number of lock operations (lockages) in the interval. The equation for converting potentiometer reading to lock count is shown in the "Locks (option 10)" section of this report, where input data are discussed. 
Lock leakage can be specified in DAMFLO.2 by a constant leakage (equation 15 in table 1), or by equation 16 listed in table 1 , where $\mathrm{q}_{11}$ is a constant lock leakage term. The value of $\mathrm{q}_{11}$ is determined from equation 16 by solving the equation for $\mathrm{q}_{11}$ and then substituting measured leakage flow, $\mathrm{h}_{1}, \mathrm{~h}_{3}$, and $\mathrm{h}_{\mathrm{d}}$ (the design head loss for the structure).

\section{Lock-Gate Flow}

During extremely high floods at most upland streams, standard lock gates may be opened fully to allow more water to flow through a dam. In south Florida, however, lock gates may be operated partially open to control flow. These gates are like two large doors hinged at the lock wall. Flows are related to $h_{1}$, gate opening $\left(h_{g}\right)$, and the square root of the fall across the gates $\left(h_{1}-h_{3}\right)$. Relations of a rating flow to gate opening and of $h_{1}$ to an adjustment factor are established, and the relations are loaded into ratings HUQ and HUC, respectively, as described in the "Ratings (option 6)" section of this report. Rating flows are measured flows divided by the square roots of measured falls across the gate $\left(h_{1}-h_{3}\right)$. Flows are computed by obtaining a rating flow from the first relation, an adjustment coefficient from the second relation, and multiplying the two values by the square root of the fall, as shown by equation 17 listed in table 1 .

\section{Crest-Gate Flow}

Crest gates are used to release high flows and generally are operated either fully opened or fully closed (Collins, 1977) with the amount of release controlled by the number of gates that are open. The crests of the weir on which these gates rest when closed are rounded and at elevations where submergence cannot occur. Therefore, only the free-weir flow regime must be calibrated. The relation is expressed as a table relating effective headwater and flow data for a single gate, as shown in equation 18 (table 1). The relation of flow to headwater elevation minus the spillway elevation is established by flow measurements or theoretical methods, and the relation is loaded into a crest-gate rating (CREST) as described in the "Ratings (option 6)" section of this report. The total flow is computed by multiplying the number of open gates by the flow through one gate obtained from the CREST rating table.

At crest gates, water also may flow over the tops of the closed crest gates. The relation of flow over the gates to headwater elevation minus the elevation of the tops of the gates is established by flow measurements or theoretical methods, and the relation is loaded into a top-of-crest-gate rating (CRTOP) as described in the "Ratings (option 6)" section of this report. The total flow is computed by multiplying the number of closed gates by the flow over the top of one gate obtained from the CRTOP rating as shown by equation 19 (table 1).

\section{Pump Flow}

Pumps are used at dams to transfer water across a dam or embankment. Computed flows can be considered positive or negative, depending on the arrangement of lakes and canals. Flow through a pump is a function of the speed of rotation of the pump shaft and the head generated by the pump.

Because pumps normally are driven by electric motors, which usually operate at constant rotational speeds, pump performance is usually presented as a relation of pump head (in this case, fall across a dam) and flow rate for a constant rotational speed. Therefore, rating flows for a pump operation at a fixed design magnitude of revolutions per minute $\left(R P M_{d}\right)$ are related to the fall across the dam $\left(h_{1}-h_{3}\right)$, and the relation is loaded into a pump-fall rating (PUFAL) as described in the "Ratings (option 6)" section of this report. Manufacturers sometimes provide this rating, which can be verified by flow measurements, or the rating can be determined entirely by flow measurements. 
Flow through a pump also varies with the speed of rotation. Therefore, an adjustment factor to be multiplied against the rating flows (eq. 20 in table 1) is related to the ratio of the measured revolutions per minute $\left(\mathrm{RPM}_{\mathrm{m}}\right)$ to the design revolutions per minute $\left(\mathrm{RPM}_{\mathrm{d}}\right)$, and the relation is loaded into a pump-rpm rating (PURPM) as described in the "Rating (option 6)" section of this report. This rating can be calibrated using flow measurements. To compute flows, a rating flow is computed using the fall across the dam. An adjustment factor is computed by entering the second relation with the ratio of $R P M_{m} / R P M_{d}$. The final flow is computed by multiplying the rating flow by the adjustment factor and a conversion factor of -1 to make the flow negative, if necessary.

\section{Siphon Flow}

At dams where existing pumps are not running, flow can be siphoned through the pump conduits. It is physically possible for siphons to exist at dams or around obstructions in streams or canals without pumps being present. Flow through siphons is directly related to the number of siphons and the square root of the fall across the siphons, as shown by equation 21 (table 1). An elementary principle of fluid mechanics of closed-conduit flow is that the flow varies with the square root of the fall across the conduit. Flows are computed by multiplying the square root of the fall by the number of siphons $\left(\mathrm{N}_{\mathrm{s}}\right)$ in operation and a constant $\left(\mathrm{K}_{\mathrm{s}}\right)$. The program allows positive and negative flows through the siphons, depending on the head differences and the arrangement of lakes and canals.

\section{PROGRAM INSTALLATION}

The installation shell script damflo_install.sh is available for downloading over the Internet from the public anonymous File Transfer Protocol (FTP) server sun1dsccmb.er.usgs.gov (internet address 144.47.8.248) in the directory /pub/damflo. When the system administrator executes the installation script file damflo_install.sh with root access from any directory on the SUN computer, it will transfer, install, and create the necessary programs, directories, and links. The DAMFLO.2 programs are stored in the directory /usr/opt/wrdapp/locapp/damflo by the damflo_install.sh script program. DAMFLO.2 utilizes the SAS software package marketed by the SAS institute, Inc. (1993). Therefore, at least one copy of the SAS software also needs to be installed on the same SUN computer.

\section{DATA ENTRY AND PROGRAM OPERATION}

Several steps are required prior to executing the DAMFLO.2 program. A working directory should be created for the station where the dam computations are being made. In the station directory, all time-varying data required for computations at the dam of interest must be retrieved and stored sequentially in a single file. The static input data defining the hydraulic parameters for the outlets must be entered into the SAS database by typing damflo and using the appropriate options (4-14) from the damflo menu. Using a text editor, a run.primary file with the specific calls needed for the flow computations at the dam of interest must be created and stored in the working directory. After completing these tasks, the program is executed by typing damflo and choosing option 1, 2, or 3 from the screen menu (fig. 2).

Data entry and program operation are discussed together, because they are highly associated with each other. The first section discusses the creation of a flat file of unit-values data in ADAPS flat-file format for input to DAMFLO.2. These data include stage, gate-openings, and lock counts, recorded at regular time intervals such as 15 or 60 minutes. The second section discusses the input of static data, such as sill elevations and gate widths, by means of interactive forms. The third section describes how separate SAS programs are used to compute, tabulate, and plot data for stage, Tainter gates, spillways, locks, and so forth. Program output is discussed in detail. 


\section{Unit-Value Time Series Data}

The DAMFLO.2 program is designed to read a flat file of unit-value time-varying data output from the ADAPS database using the SAS free-format reading capability. The program currently reads unit-value data in "flat-file" format produced by the FL option within the OUTWAT option of ADAPS. If the "flat-file" format of ADAPS is changed or abandoned, another ADAPS output format must be selected for DAMFLO.2, and the timevarying data reading code of DAMFLO.2 must be modified to read the new format. No other modification to DAMFLO. 2 needs to be made. It is necessary to specify zero for the time step, which is the variable time-step option, in the OUTWAT menu and to retrieve all the data into one file, rather than separate files for each type or data group of unit-value data. Selection of a time step of zero allows the time-varying data to be retrieved sequentially by data group. For example, for a dam having data-group types headwater elevations, tailwater elevations, and a single Tainter gate, the headwater data would come first in the file, followed by the tailwater data, and then the Tainter gate data, or in a different order specified by the user. If time-step zero were not selected, data for the data groups headwater, tailwater, and Tainter gate would appear in three columns, one for each data group. For convenience, the user should create and use an ADAPS group file describing the station numbers and datadescriptor numbers for the data to be retrieved. The name of the group file can be submitted rather than the individual station and data-descriptor numbers, and the predetermined order of retrieval can be more easily maintained from computation to computation. The file should be stored in the station directory established for the station being computed.

The DAMFLO.2 program is designed to use data retrieved from the ADAPS database, thereby utilizing the data storage and processing capabilities of ADAPS as much as possible. Therefore, most of the collected data are permanently archived in the ADAPS databases, and redundant software is not necessary. For example, the DAMFLO.2 program assumes that all time corrections, unit-value time-series datum corrections, shifts, and selected rating-table conversions have been accomplished by ADAPS before retrieval. Unit-value datum corrections are used to replace erroneous data or to prorate datum corrections with time. The DAMFLO.2 program assumes that the following types of data will undergo conversion by ratings in ADAPS before retrieval:

A. Recorded data indicating Tainter-, sluice-, and lock-gate openings must be converted to actual gate opening data by rating table conversion within ADAPS before retrieval.

B. Flows from stage-streamflow stations, slope stations, and so forth, in the tailwater of a dam can be used when flow cannot be computed through the dam.

C. Flows computed by methods other than those provided by DAMFLO.2 can be added to flows that are computed by the program. These flows should be fully processed by the ADAPS software, including shifting of the ratings, before retrieval.

For entry into DAMFLO.2, the unit-values data are retrieved in one flat file in an order determined by the user (fig. 1). For example, the order may be headwater elevation, tailwater elevation, gate opening data for four gates, and lock counter data, thus comprising seven sequential data groups of unit-values data in one file. The user refers to each data group in order of 1 to 7, and uses these numbers in DAMFLO.2 to direct the program to the appropriate data group and type, such as headwater, tailwater, gate opening groups, and so forth. Therefore, the data may be stored in the ADAPS database under any data identification scheme that will allow the proper conversion of input data to output data. It is a good practice, however, to store the data with proper identifiers so that archived data will be correctly identified for subsequent retrievals.

A characteristic of the ADAPS retrieval program is that if no data are available for retrieval, then a missingvalue indicator needed by the DAMFLO.2 program is not included in the retrieved data. Currently, DAMFLO.2 assumes that no time-varying data are missing. Therefore, the user must either estimate the missing data and store it in the ADAPS database prior to running DAMFLO.2 or break the computer runs to skip the missing data. If the data set from ADAPS includes missing data, then DAMFLO.2 will interpolate the missing data. Therefore, if only very short periods are missing, then the user can accept the DAMFLO.2 interpolation. In this case, the user should review the interpolated data to verify that the DAMFLO.2 interpolation is acceptable. 
For the specific case where DAMFLO.2 cannot compute an outflow because a rating is exceeded, a tailwater elevation exceeds a specified height, or a fall across the dam is less than a specified amount, DAMFLO.2 will use flows from a tailwater-discharge station, which are stored in ADAPS. Typically, backwater conditions will exist at some stages of the tailwater-discharge station. In this case, those stages in the rating should be coded with discharges of $-9999 \mathrm{ft}^{3} / \mathrm{s}$. This will cause flows of $-9999 \mathrm{ft}^{3} / \mathrm{s}$ to be computed for flows missing because the rating was exceeded. When DAMFLO. 2 encounters time-varying data for tailwater discharges equal to $-9999 \mathrm{ft}^{3} / \mathrm{s}$, the program will consider those to be missing data.

At some dams, time-series data are entered in the ADAPS database by hand from operator log books, rather than from recording devices. Typically, the data may be unchanging for long time periods, or are not recorded at uniform time increments, as required by the ADAPS database. A FORTRAN program, bcards, creates time-series data sets in B-card format suitable for entry into the ADAPS database. The program allows entry of data at nonuniform time increments, and will interpolate the data at uniform time increments, using linear or stair-step interpolation. In the stair-step interpolation, such as for gate openings, a preceding input value is held constant until a different input value is encountered.

\section{Static Data Programs}

Static data are defined as those data that do not change, or change very little from run to run, such as sill elevation, gate width, ratings, or number of days per plot. These data are somewhat extensive for flow computations at dams, and are conveniently managed by interactive forms. The forms are invoked and modified from the damflo menu options 4-14. If a value is modified on the form, the modified value is stored in the SAS database when exiting from the form. Input for all forms are discussed below. In most of the forms, data are requested for "minimum expected," "maximum expected," and "maximum expected rate of change" of input value. These are expected limits that only raise warning flags in the output. The hydraulic ratings can be printed using option 15 .

\section{Control (option 4)}

Option 4 calls program edit.cntl. The control form (fig. 6) contains general data to be used throughout the program.

A. Station number.

B. Station name.

C. Readings per day for computations. The program will interpolate or truncate time-series data and compute flows using the required readings per day input on this line (see the "Interpolation (option 5)" section of this report). This option is required where time-series unit-value data are not all recorded at the same time interval.

D. Readings per day for uv primary. The readings per day for the unit-value primary output listing, evenly divisible by 12, can be specified here. The readings per day cannot be more than the readings per day for the computation interval, but can be less. It is possible to print all data computed, or, for example, only to print bi-hourly readings.

E. Allowable number of missing punches for daily mean Q. If the number of missing total unit-value flow data are equal to or less than this value, then the daily mean flow will still be computed. Otherwise, the daily mean flow will not be computed. Total unit-value flow is the sum of all the flows from the outlets of the dam during a computation interval.

F. Number of days per plot for total unit-values flow. 


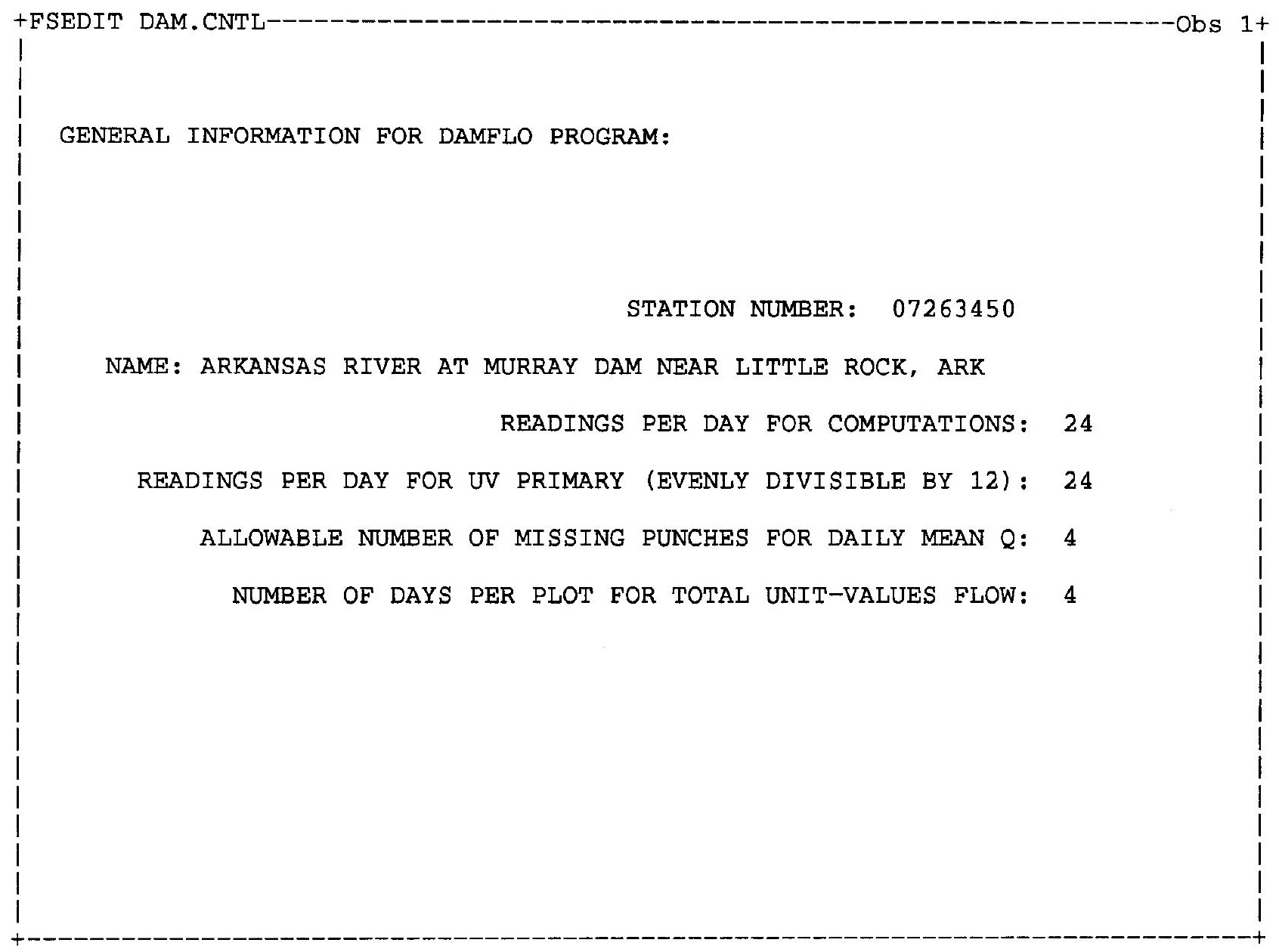

Figure 6. Form for Control program and general data.

\section{Interpolation (option 5)}

Option 5 calls the edit.interpolation program. The interpolation form (fig. 7) contains data describing how to interpolate between consecutive values of time-varying data, if interpolation is required by the computation interval specified on the "Control" form.

A. Data-group number. This is the sequential number of the data group to be interpolated in the unit-values time-varying data set retrieved from ADAPS. For example, if the third group of unit-values data were for Tainter gate 1, then the data-group number would be 3 .

B. Interpolation method $(1,2$, or 3$)$.

1. Data are interpolated linearly between adjacent input data if method 1 is selected.

2. Data are interpolated in a stairstep fashion if method 2 is selected. In this method, the last input value is held constant without interpolation until superseded by a different input value. This method should be used for gate opening data and accumulated counts of locks or number of open crest gates per computation interval. 


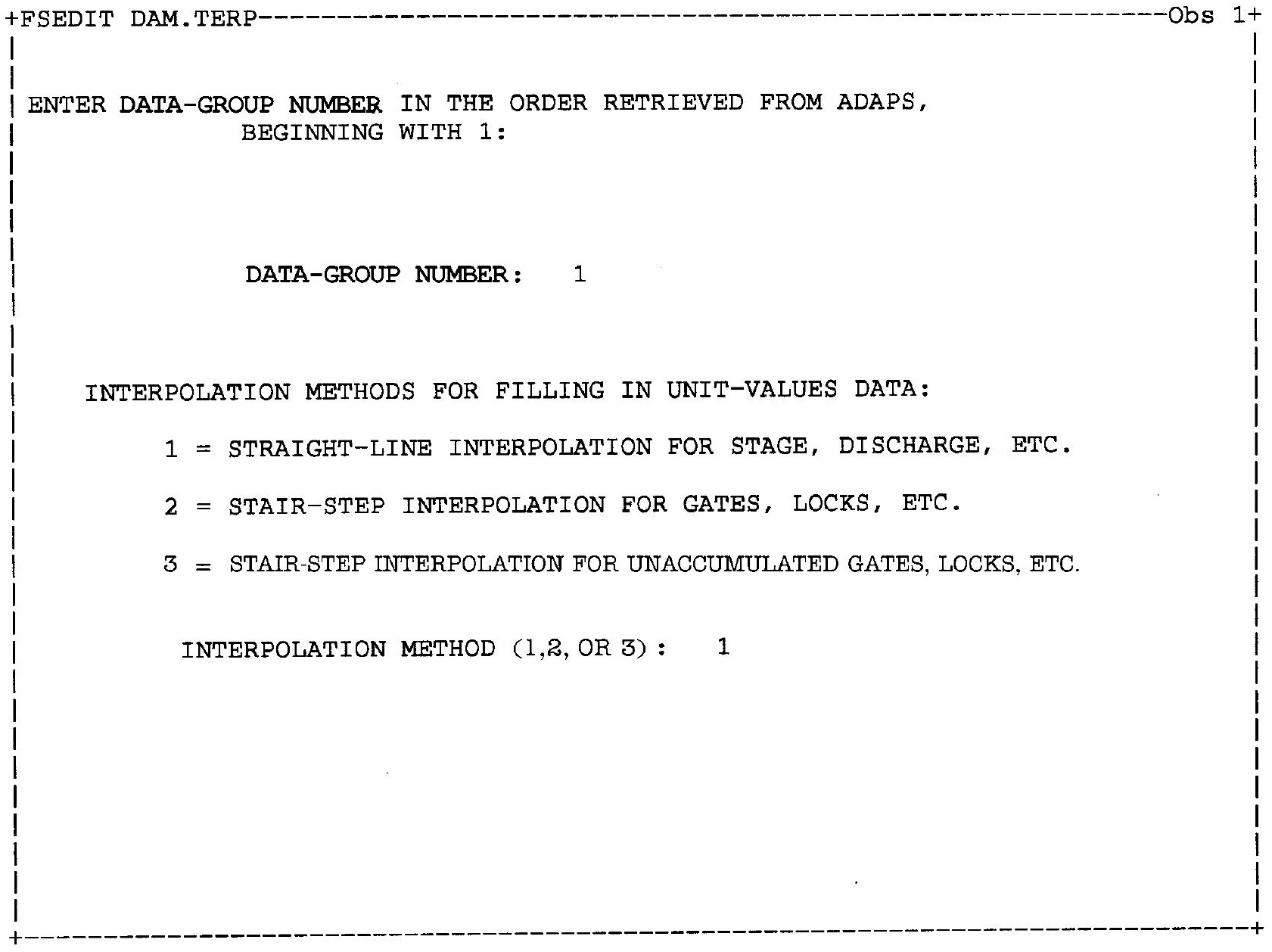

Figure 7. Form for Interpolation program and unit-value data interpolation methods.

3. Method 3 must be selected for stairstep interpolation of unaccumulated lock counts. In method 3, for interpolated values, lock counts are set to zero after the last nonmissing lock count. As with method 2 for accumulated lock counts, the interpolation method will consider all locks to be within the last interpolated time interval.

\section{Ratings (option 6)}

Option 6 calls the edit.rating program. The forms for hydraulic rating data (figs. 8 and 9) require three windows. Information on the input data is presented below.

A. Set number (fig. 8). This identifies the set of outlets (gates, locks, pumps, and so forth) associated with the rating. That is, all outlets using the same hydraulic rating are referenced by the same set number. For example, sets 1 and 2 of Tainter gate data could have several gates per set, but each set would have different sill elevations, gate widths, and so forth. For the purposes of this report, a set also may contain a single outlet. 


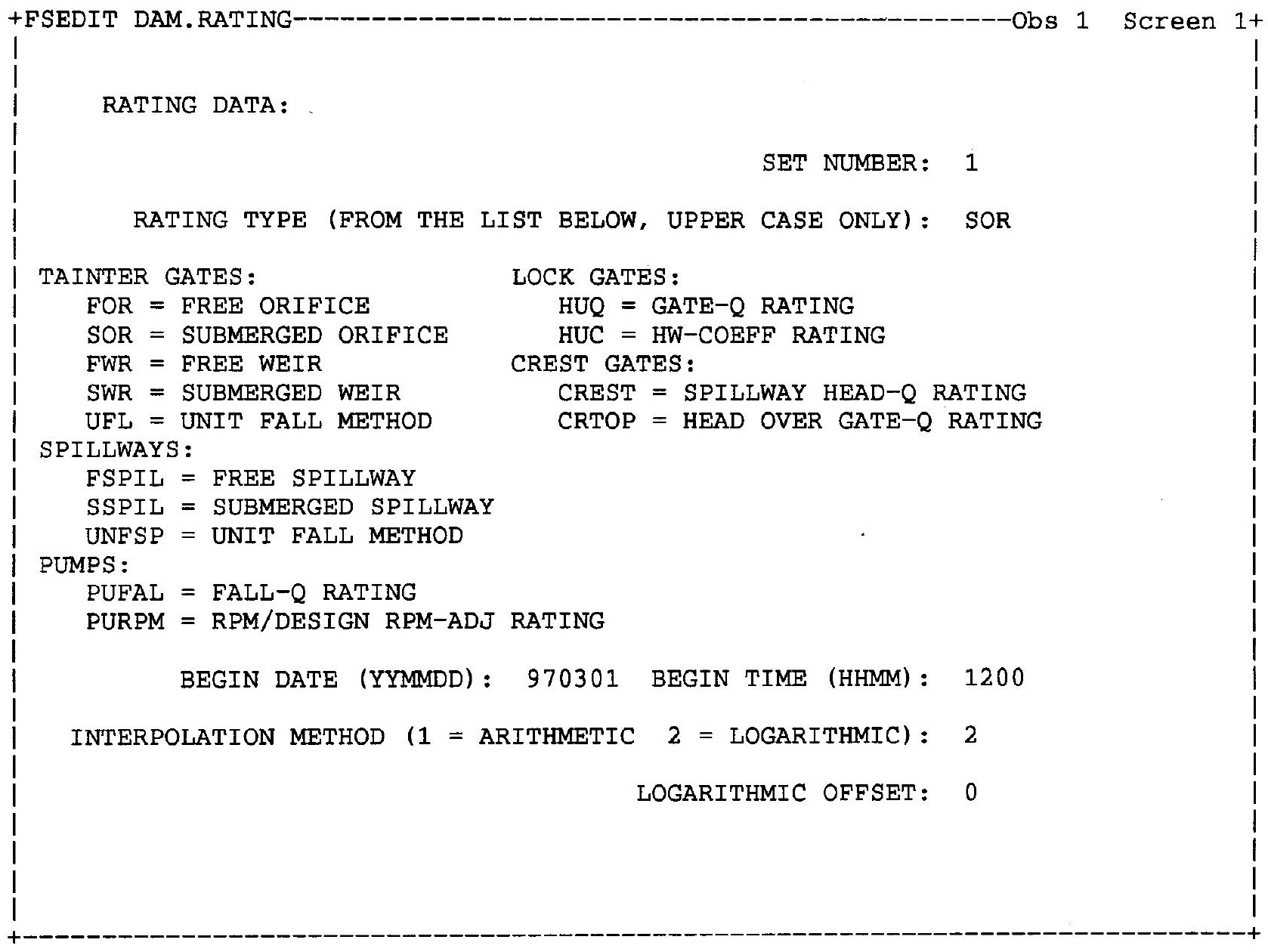

Figure 8. First form for Rating program and rating table data.

B. Rating type. Rating types identify what type of hydraulic rating is being coded, as described by the list shown in the window. The rating type must be entered in upper-case letters. More detail is provided below.

1. Tainter gates

FOR -- gate opening-to-free-orifice flow coefficient

SOR -- submergence coefficient $\left(\mathrm{h}_{3} / \mathrm{h}_{\mathrm{g}}\right)$-to-submerged-orifice coefficient

FWR -- $\mathrm{h}_{1}$-to-free-weir flow coefficient

SWR -- submergence ratio $\left(h_{3} / h_{1}\right)$-to-submerged-weir coefficient for method 1 (Hulsing, 1967), weir-flow computation method

UFL -- flow-to-square root of fall $\left(\mathrm{h}_{1}-\mathrm{h}_{3}\right)$ for method 2 (Kennedy, 1984), unit fall weir-flow computation method

Note: A rating table is not needed for the velocity-fall submerged-weir flow computation method for gates and fixed spillways. Flows are computed by equations 9 and 13 (table 1).

2. Spillways

FSPIL -- $h_{1 s}$-to-free-weir flow coefficient, where $h_{1 s}$ is $h_{1}$ minus the elevation of the spillway crest 


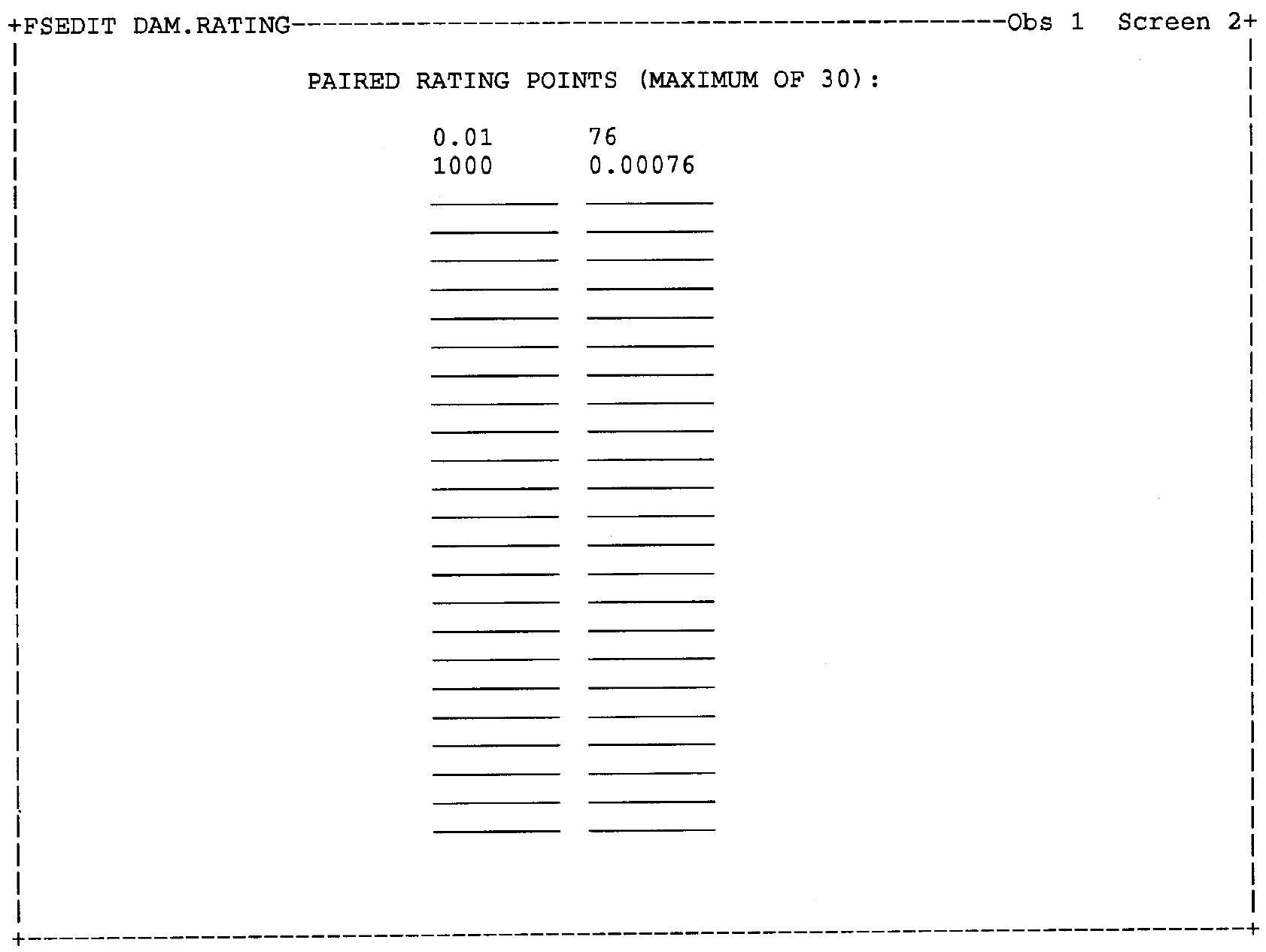

Figure 9. Second form for Rating program and rating table data.

SSPIL -- submergence ratio $\left(h_{1 s} / h_{3 s}\right)$-to-submergence coefficient, where $h_{3 s}$ is $h_{3}$ minus the elevation of the crest of the spillway, for method 1 (Hulsing, 1967), weir-flow computation

UNFSP -- flow-to-square root of fall $\left(h_{1}-h_{3}\right)$, for method 2 (Kennedy, 1984), unit fall weir-flow computation

3. Pumps

PUFAL -- fall $\left(\mathrm{h}_{1}-\mathrm{h}_{3}\right)$-to-flow

PURPM -- ratio $\left(\mathrm{RPM}_{\mathrm{M}} / \mathrm{RPM}_{\mathrm{D}}\right)$-to-adjustment coefficient

4. Lock gates

HUQ -- gate opening-to-flow

HUC -- $\mathrm{h}_{1}$-to-adjustment coefficient

\section{Crest gates}

CREST -- $h_{1 s}$-to-flow, where $h_{1 s}$ is $h_{1}$ minus the elevation of the crest of the spillway

CRTOP -- $h_{1 t}$-to-flow, where $h_{1 t}$ is $h_{1}$ minus the elevation of the tops of the crest gates 
C. Beginning date and time for the rating. Ratings will be held in effect until a new rating with a different begin date and time are encountered by the program.

D. Interpolation method. Enter "1" for arithmetic or "2" for logarithmic.

E. Logarithmic offset. Enter zero if the interpolation method is arithmetic.

F. Paired rating points (fig. 9). A maximum of 30 paired rating table data points may be entered on the second and third forms.

\section{Stage (option 7)}

Option 7 calls program edit.stage. The stage form (fig. 10) contains information necessary for quality control, datum corrections, and number of days per plot for stage data. The stage data are for headwater and tailwater gages. Any number of groups of stage data (identified by the stage-gage indentification number) may be entered as necessary. For instance, it may be necessary to have one headwater stage gage for locks and spillways, and another inside the trash racks for Tainter gates. To add a new record, click on edit, add record.

A. Stage-gage identification number (fig. 10). Assign stage-gage identification numbers sequentially from one group of stage data to another.

B. Minimum expected stage, in feet.

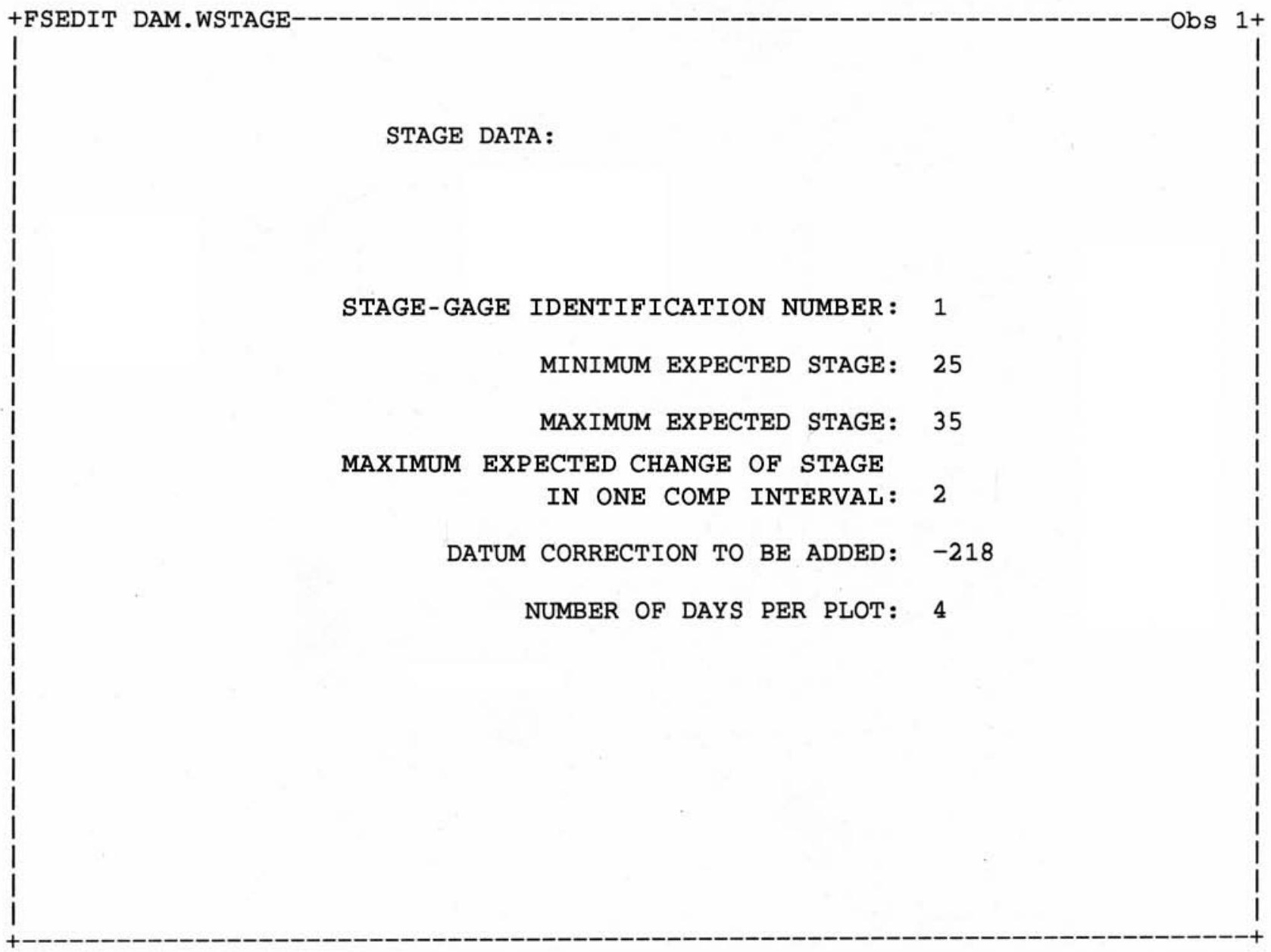

Figure 10. Form for Stage program and stage data. 
C. Maximum expected stage, in feet.

D. Maximum expected rate of change of stage, in feet per computation interval.

E. Datum correction to be added, in feet. Stages, gate-sill elevations, and spillway-crest elevations must all be referenced to the same datum. For various reasons, however, stage data may not be recorded at the same datum as used for sill and spillway elevations. Therefore, in DAMFLO.2, datum corrections can be added to recorded stages. Tainter-gate sill elevations (“Tainter gates" form (option 8)) and spillway crest elevations ("Spillway" form (option 9)) should be referenced to the same datum as the headwater and tailwater stages.

F. Number of days per plot.

\section{Tainter gates (option 8)}

Option 8 calls program edit.tainter. The Tainter gates form requires two windows (figs. 11 and 12), and contains the information needed to compute flow through Tainter gates.

A. Set number. Assign a set number for each set of gates having the same sill elevation, gate width, and so forth. The set numbers should begin with 1 and be sequential.

B. Sill elevation, in feet. The datums of the sill elevation, stage gages, and fixed spillway must agree.

C. Tainter gate length, in feet.

D. Minimum expected gate opening, in feet.

E. Maximum expected gate opening, in feet.

F. Maximum expected change in gate opening, in feet per computation interval.

G. Top limit of gate opening, in feet, when pulled out of water.

H. Change from free to submerged orifice criteria $(1,2,3)$. The following methods for determining change from free- to submerged-orifice flow are described in the "Hydraulic Methodology" section of the report.

1. Collins (1977) method for submerged-orifice flow.

2. Use minimum of computed free-orifice or submerged-orifice flow.

3. Hydraulic-jump method (app. 3).

I. Change from submerged (subm) weir to subm orifice criteria (1 or 2). The following methods for distinguishing between submerged weir and submerged orifice flow are described in the "Hydraulic Methodology" section of the report.

1. Collins (1977) method for submerged-weir flow.

2. Same as Collins (1977) method for submerged-weir flow, except that a third hydraulic condition is added: $h_{3}<h_{g}$. If $h_{3} \geq h_{g}$, submerged-orifice flow is assumed.

J. Weir-flow computation method ( $1=\mathrm{STD} ; 2=\mathrm{UNF} ; 3=\mathrm{VELF})$. The following methods are described in the "Hydraulic Methods" section of this report.

1. Hulsing (1967) method (STD). Adjustment of free-weir flow by submergence coefficient, $\mathrm{C}_{\mathrm{ws}}$.

2. Unit-fall method (UNF) documented by Kennedy (1984).

3. Velocity-fall method (VELF) (app. 1).

K. Fall, in feet, below which to use flow from a tailwater gage. If the fall across the dam is less than this value, then flow from a downstream flow gage will be used, if available, and requested in the \% uvq program documented below. This option is used when there is insufficient fall through weirs or over spillways for an accurate submerged-weir flow rating. Enter zero, if no tailwater flow is available.

L. Gage height above which to use tailwater flow. Downstream stage above which the tailwater flow described in $(\mathrm{K})$ above will be used, rather than computed flows. If data from a downstream flow station are not available, then code a large number, such as 999. 


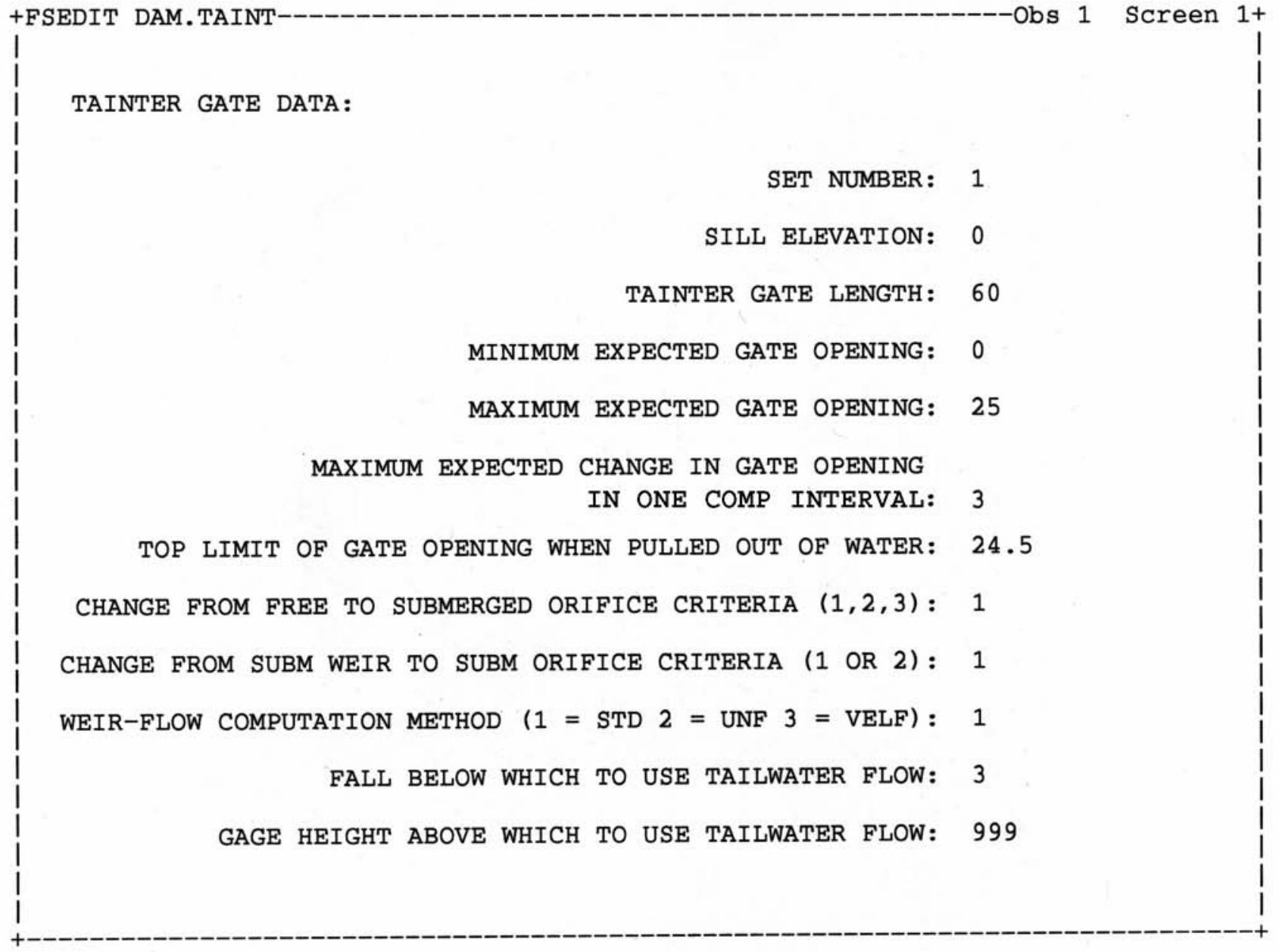

Figure 11. First form for Tainter gate program and gate data.

M. Exponent for the free-weir flow equation. The exponent is usually 1.5, as shown by equation 6 (table 1), but can be modified if necessary.

$\mathrm{N}$. Constant for the submerged-orifice coefficient $\left(\mathrm{C}_{\mathrm{gs}}\right)$ equation. If a submergence ratio-to-submergence coefficient rating is not provided, then the coefficient can be described by the equation:

$$
C_{g s}=K\left(\frac{h_{3}}{h_{g}}\right)^{E},
$$

where

$C_{g s}$ is the submerged-orifice coefficient, dimensionless;

$K$ is the constant of the equation, dimensionless;

$h_{3}$ is the static tailwater elevation, referenced to the sill, in feet;

$h_{g}$ is the vertical gate opening, in feet; and

$E$ is the exponent of the equation.

$\mathrm{K}$ and $\mathrm{E}$ are determined graphically or by regression, using measured values of $\mathrm{C}_{\mathrm{gs}}, \mathrm{h}_{3}$, and $\mathrm{h}_{\mathrm{g}}$. 


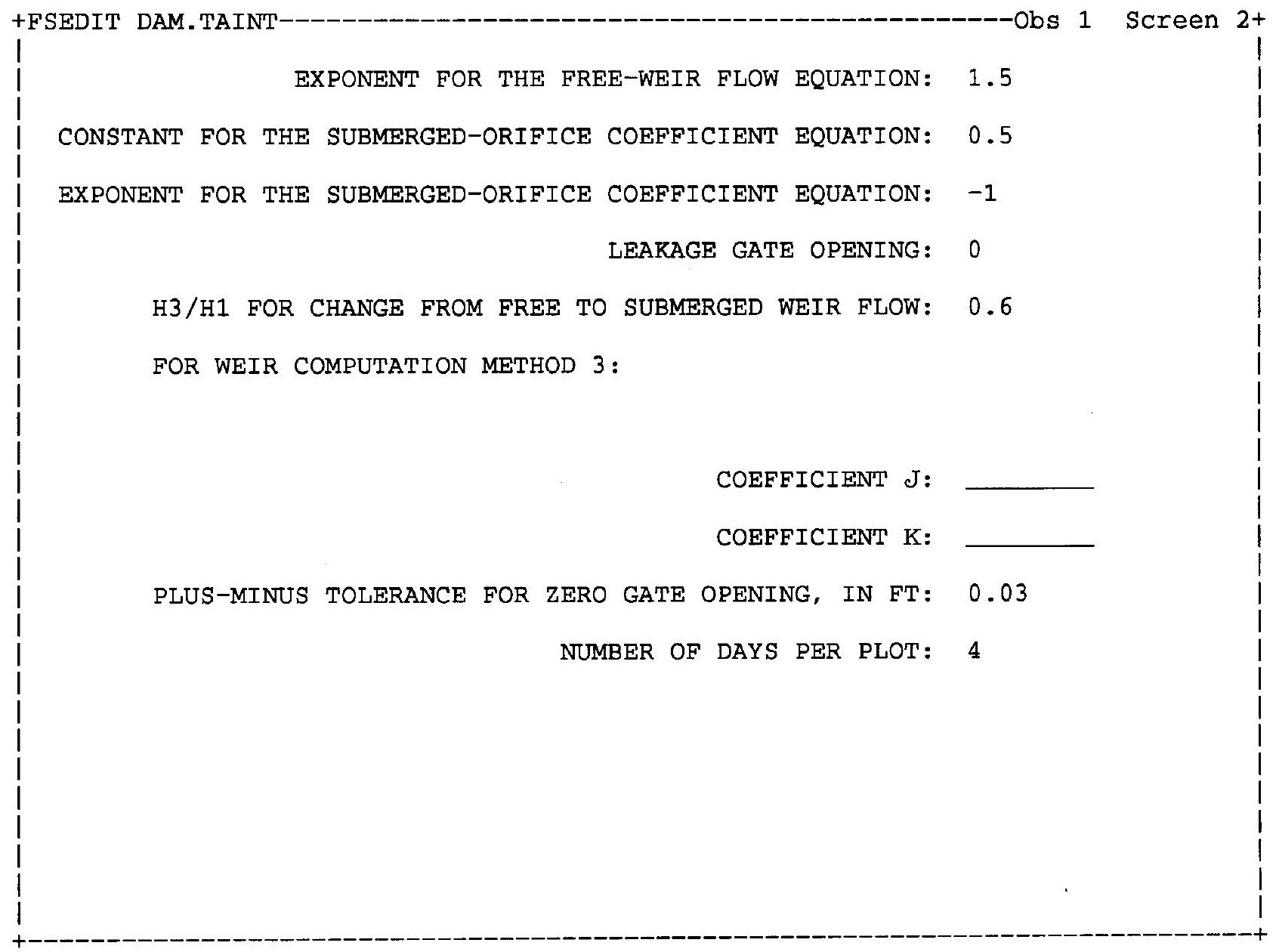

Figure 12. Second form for Tainter gate program and gate data.

O. Exponent for the submerged-orifice coefficient $\left(C_{g s}\right)$ equation. This is the exponent, "E" in equation 24, usually very close to -1.0 .

P. Leakage gate opening, $\mathrm{h}_{\mathrm{gl}}$, in feet.

Q. $\mathrm{H}_{3} / \mathrm{H}_{1}$ for change from free- to submerged-weir flow. Submerged-weir ratio, $\mathrm{h}_{3} / \mathrm{h}_{1}$, above which flow will change from free-weir flow to submerged-weir flow. The ratio can range from 0.6 to 1.0 , and the default is 0.6.

R. Coefficient $J$ of equation 9 (table 1) for the VELF method for computing submerged-weir flow.

S. Coefficient K of equation 9 (table 1) for the VELF method for computing submerged-weir flow.

T. Plus-minus tolerance for zero gate opening, in feet. Because of slack in the gate and instrumentation mechanisms and, because of datum corrections applied in ADAPS, very small negative or positive gate openings may be recorded when the actual gate opening should be zero. The gate opening is set equal to zero when the absolute value of the gate opening is less than the plus-minus tolerance for zero gate opening. To prevent the creation of small negative gate openings by ADAPS, code zero gate openings in the ADAPS gate rating for input values lower than input values at which the gate opening is zero.

U. Number of days per plot. 


\section{Spillway (option 9)}

Option 9 calls program edit.spillway. Data for computing flow over fixed spillways are presented on this form (fig. 13).

A. Set number.

B. Spillway elevation, in feet. The datum of the spillway crest must agree with the datums of the stage gages and Tainter-gate sill elevations.

C. Weir-flow computation method $(1=\mathrm{STD} ; 2=\mathrm{UNF} ; 3=\mathrm{VELF})$.

1. Hulsing (1967) (STD), adjustment of free-weir flow by submergence coefficient, $\mathrm{C}_{\mathrm{sws}}$

2. Unit-fall method (UNF) documented by Kennedy (1984)

3. Velocity-fall method (VELF)

D. Spillway length, in feet.

E. Exponent for free-weir flow equation. This exponent is usually 1.5, as shown in equation 10 in table 1.

F. $\mathrm{H}_{3} / \mathrm{H}_{1}$ for change from free- to submerged-weir flow. Submerged-weir ratio $\left(\mathrm{h}_{3 \mathrm{~s}} / \mathrm{h}_{1 \mathrm{~s}}\right)$ above which flow will change from free-weir flow to submerged-weir flow. The ratio can range from 0.6 to 1.0 and the default is 0.6 .

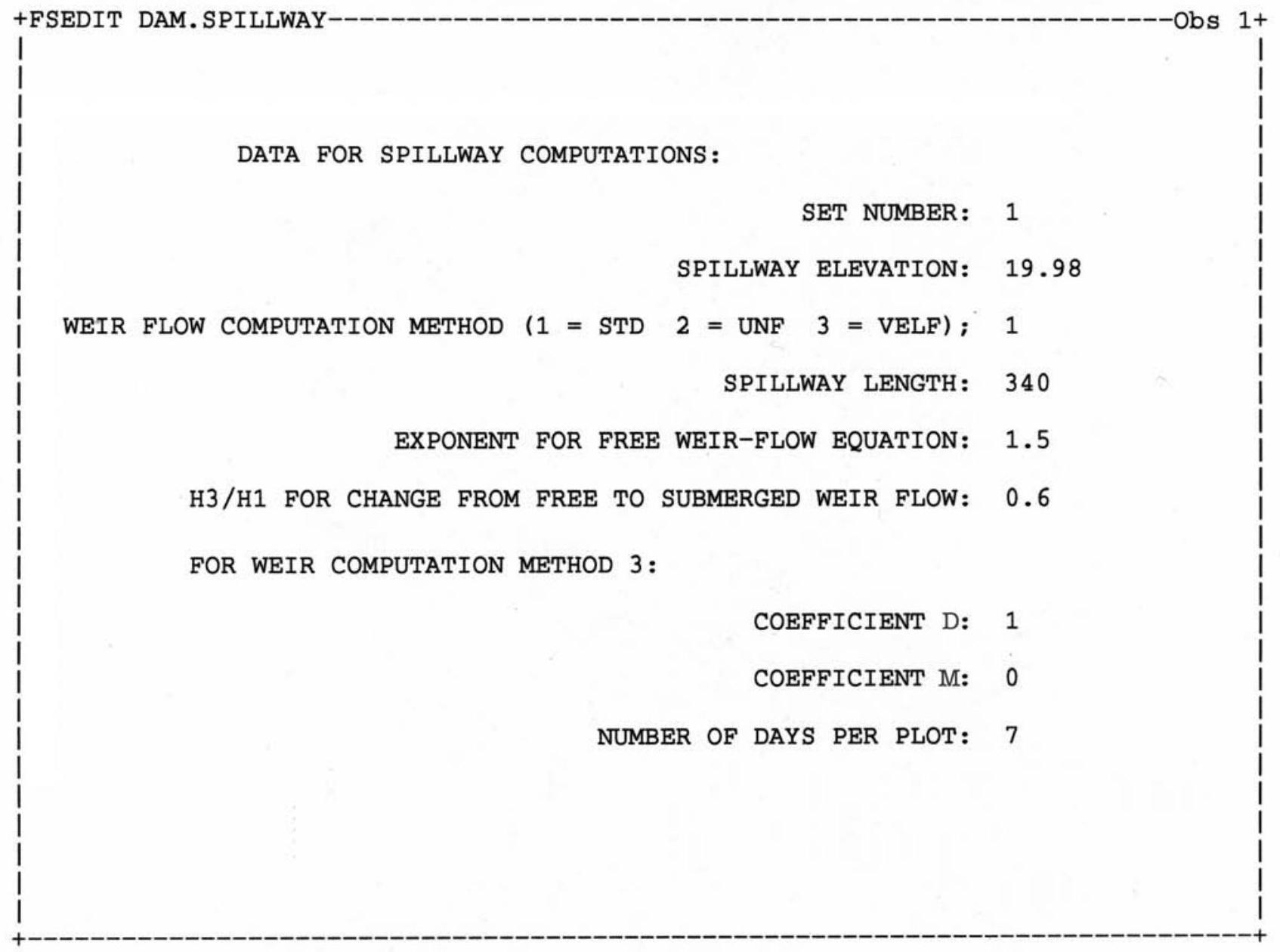

Figure 13. Form for Spillway program and spillway data. 
G. Coefficient D of equation 13 (table 1) for the VELF method for computing submerged-weir flow.

H. Coefficient M of equation 13 (table 1) for the VELF method for computing submerged-weir flow.

I. Number of days per plot.

\section{Locks (option 10)}

Option 10 calls program edit.locks. Data for computing lock flows are presented on this form (fig. 14).
A. Set number.
B. Plan area of lock, in square feet.
C. Method of recording lockages (1 or 2).

1. Potentiometer readings represent accumulated lockage counts. The number of lockages per computation interval are computed using the equation:

$$
N_{1}=\frac{D_{a}-D_{o}}{M \square},
$$

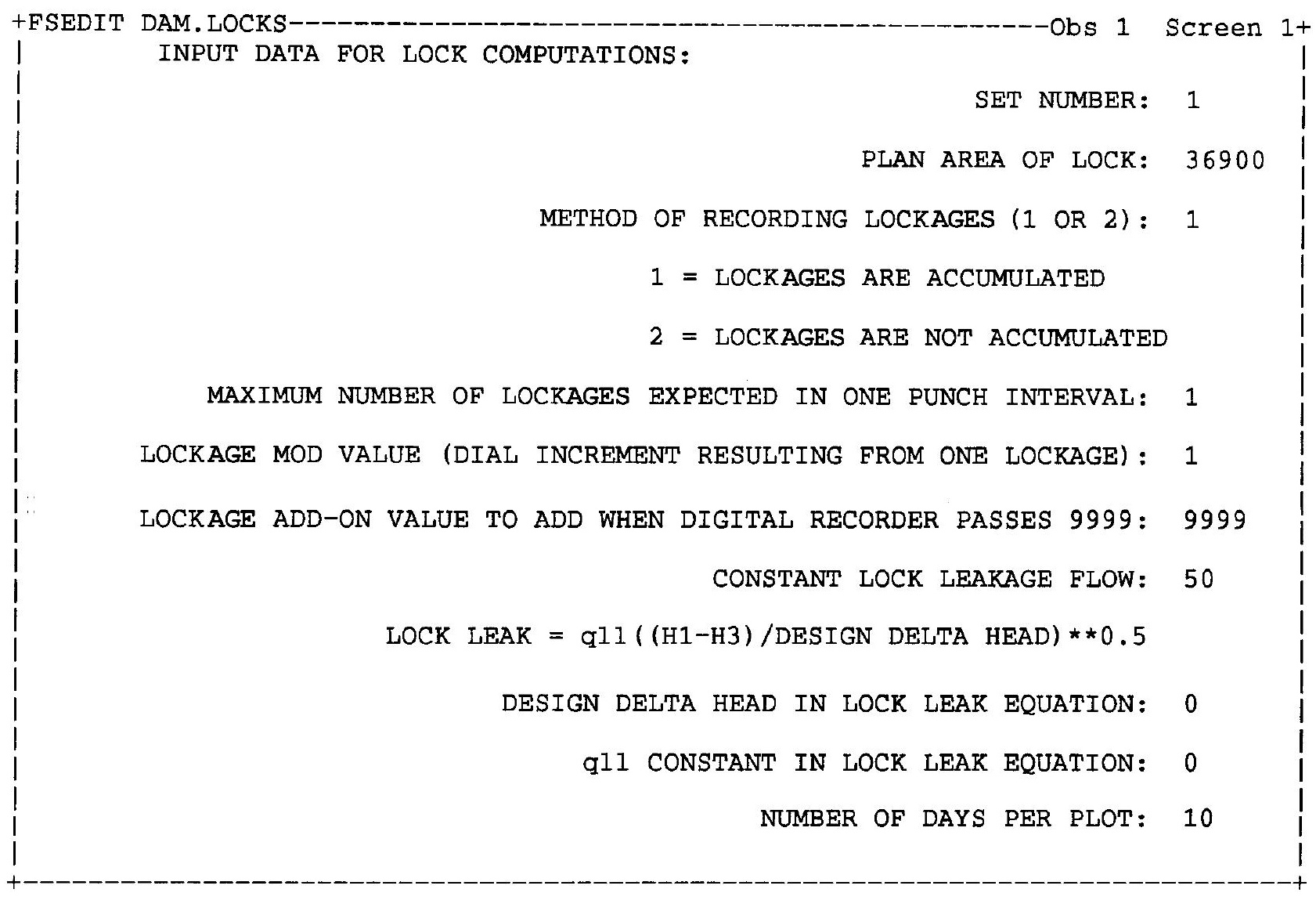

Figure 14. Form for Locks program and lock data. 
where

$\mathrm{N}_{1}$ is the number of lockages in a recorded time interval;

$\mathrm{D}_{\mathrm{a}}$ is the adjusted dial reading computed by equation 26 (below); and

$\mathrm{D}_{\mathrm{o}} \quad$ is $\mathrm{D}_{\mathrm{a}}$ computed for the previous time step; and

M is the lockage-mod value, or approximate change of dial reading per lockage;

$$
D_{a}=D_{n}-M O D\left(D_{n}, M\right),
$$

where

$D_{n}$ is the current direct dial reading, and

$\operatorname{MOD}\left(D_{n}, M\right)$ gives the remainder after dividing $D_{n}$ by $M$.

2. Lockage counts per recording interval are recorded directly, without accumulation

D. Maximum number of lockages expected in one computation interval.

E. Lockage mod value, M (dial increment resulting from one lockage), equations 25 and 26.

F. Lockage add-on value to add when digital recorder passes 9999. The dial of a digital recorder is set to zero at the number 10000. Therefore, if a recorded value is less than a preceding recorded value, then a value of 10000 should be added.

G. Constant lock leakage flow.

H. Design delta head, $\mathrm{h}_{\mathrm{d}}$, in lock leak equation 16 in table 1.

I. $\mathrm{q}_{11}$ constant in lock leak equation 16 shown in table 1 .

J. Number of days per plot.

\section{Lockgates (option 11)}

Option 11 calls program edit.lockgate. Other than required ratings, the only data needed for lock-gate computations (fig. 15) are limits for quality control.

A. Set number.

B. Minimum expected gate opening, in feet.

C. Maximum expected gate opening, in feet.

D. Maximum expected change in gate opening, in feet per computation interval.

E. Number of days per plot.

\section{Crest gates (option 12)}

Option 12 calls program edit.crest. Data necessary to compute flow through crest gates (fig. 16) are as follows:
A. Set number.
B. Spillway crest elevation, in feet.
C. Elevation of top of crest gates, in feet.
D. Number of crest gates.
E. Number of days per plot. 


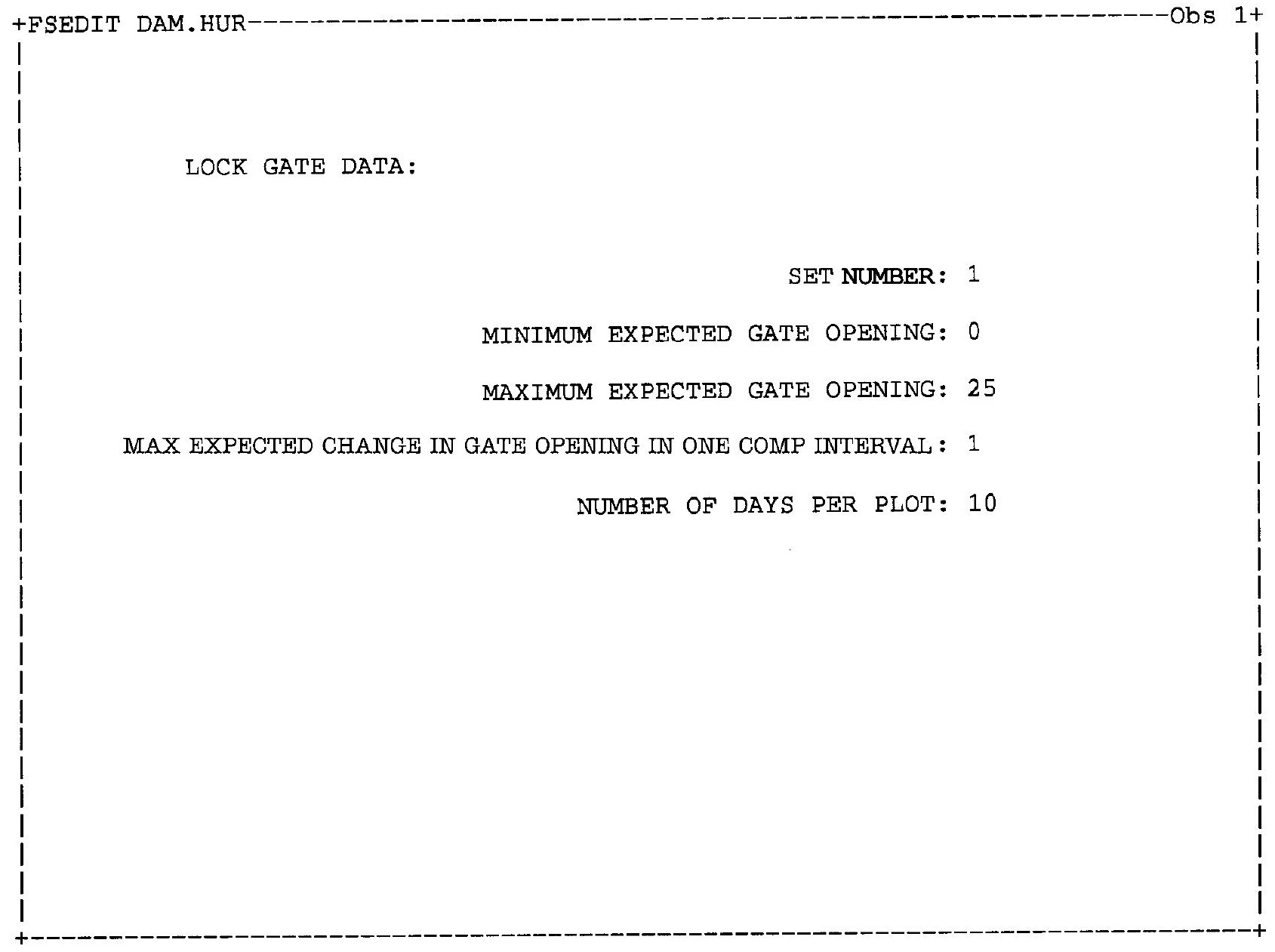

Figure 15. Form for Lock-gate program and lock-gate data.

\section{Pumps (option 13)}

Option 13 calls program edit.pumps. Data necessary for computation of pump flows (fig. 17) are as follows:
A. Set number.
B. Design rpm (revolutions per minute $\left.\left(\mathrm{RPM}_{\mathrm{d}}\right)\right)$.
C. Minimum expected pump rpm.
D. Maximum expected pump rpm.
E. Maximum expected change of pump rpm per computation interval.
F. Enter -1 for negative flow (from tailwater to headwater) or 1 for positive flow (from headwater to tailwater). Direction of flow is determined by multiplying computed flows by -1 or 1 .
G. Number of days per plot. 


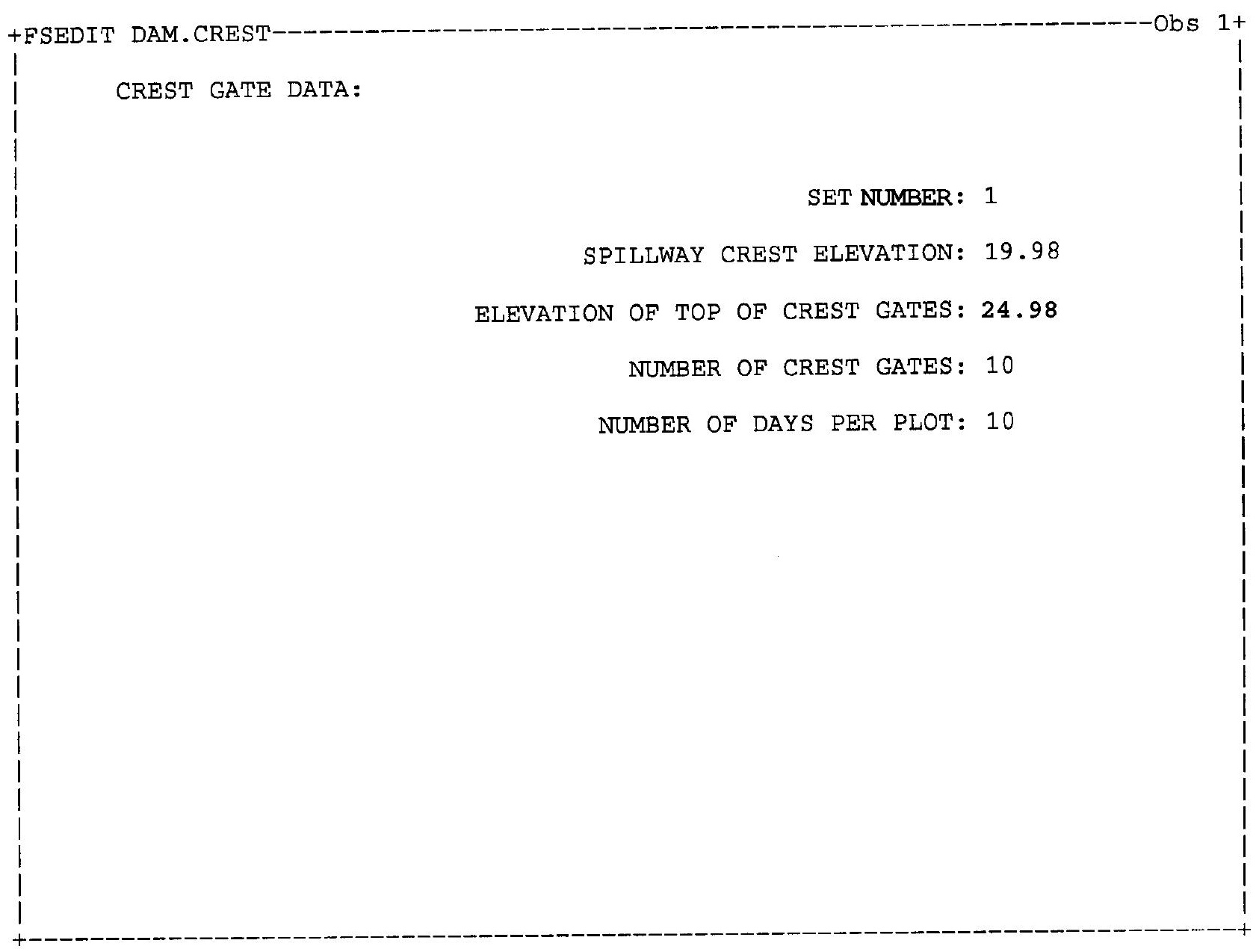

Figure 16. Form for Crest-gate program and crest-gate data.

\section{Siphons (option 14)}

Option 14 calls program edit.siphon. Data necessary for computing flow through siphons (fig. 18) are as follows:
A. Set number.
B. Siphon constant. This is the constant, $\mathrm{K}_{\mathrm{s}}$ in equation 21 shown in table 1 .
C. Minimum expected number of siphons.
D. Maximum expected number of siphons.
E. Maximum expected change in the number of siphons per computation interval.
F. Number of days per plot. 


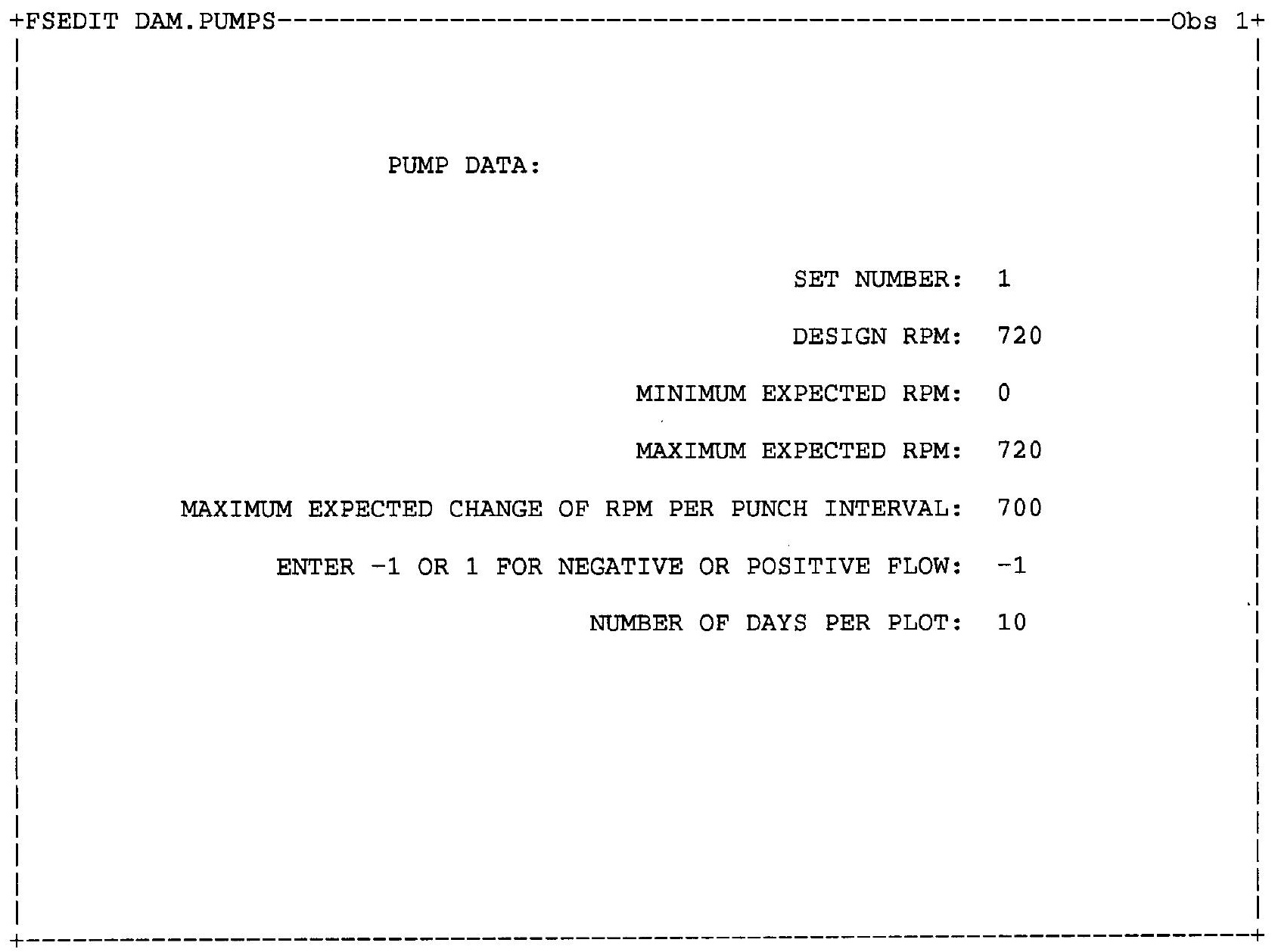

Figure 17. Form for Pump program and pump data.

\section{Plot hydraulic ratings (option 15)}

Option 15 calls program plot.rating. All ratings stored in the permanent SAS data set can be plotted (fig. 19) by choosing the plot hydraulic ratings option. All plots are plotted to both arithmetic and logarithmic scales. Plots should be made and examined to verify that the data are entered correctly and that data pairs adequately define the curvature of the relation.

\section{PROGRAM EXECUTION AND OUTPUT}

Program execution and output are discussed together, because program execution is determined by the desired output. The SAS programs that process stage data and compute flow data through the various outlets are executed by "calls" coded in a short file usually named run.primary, as shown by the annotated example in figure 20 . The user creates and maintains this file using a text editor. The example demonstrates how a run.primary file would be set up to call all the programs. Optional comment cards, delimited by the asterisk and semicolon give short descriptions of the arguments and purpose of the programs to provide a general understanding of the run.primary file without having to read through the detailed discussions that follow. It is not necessary to include these comments in an operational run.primary file, though comments describing the arguments might be useful. 


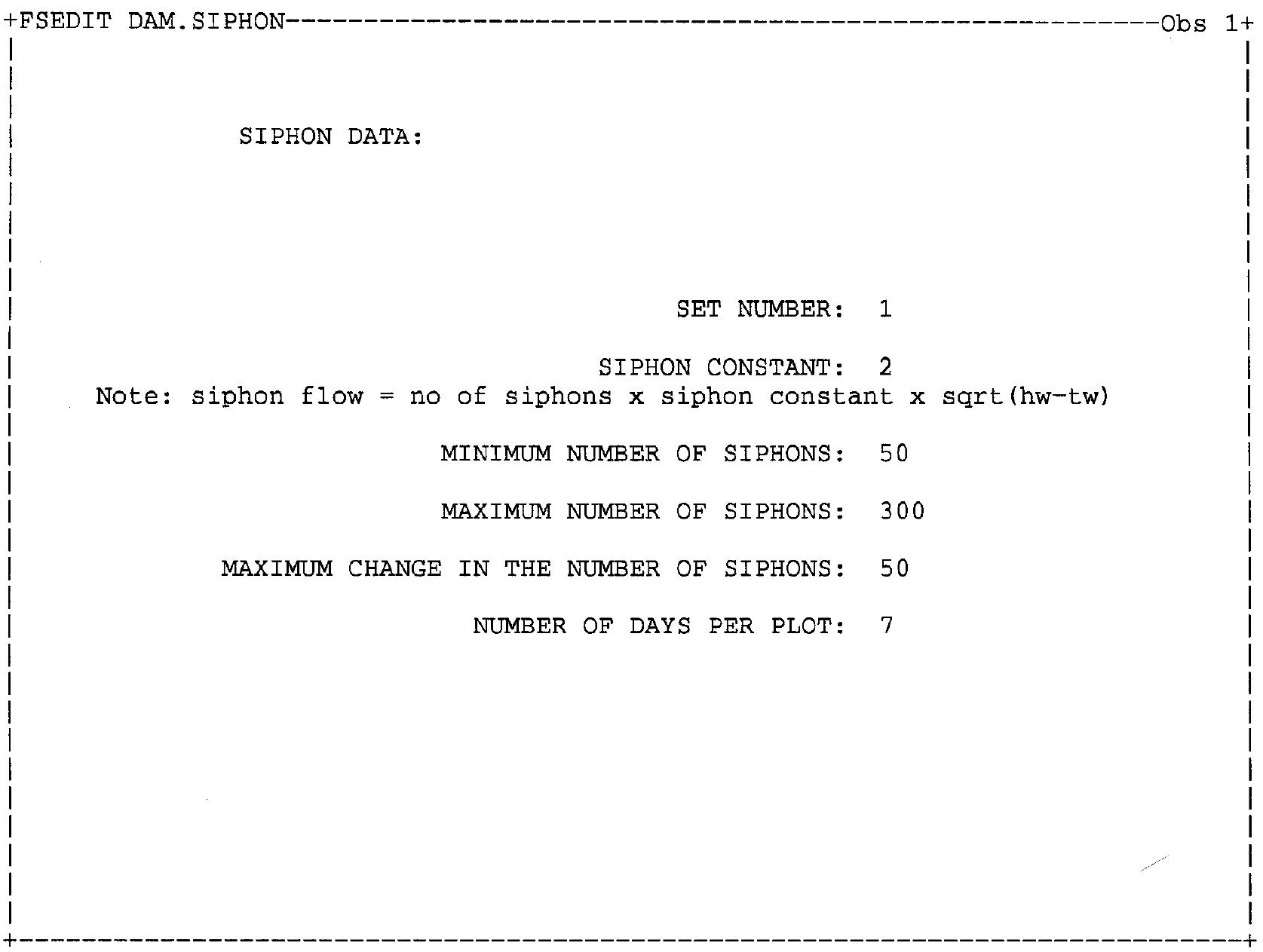

Figure 18. Form for Siphon program and siphon data.

Arguments of the programs and the outputs are discussed in detail below. In the discussion, data-group number refers to the number assigned to the group of unit-value time-series data stored in the flat file produced by ADAPS. The shortened column headings shown in the interactive table figures are explained in the ABBREVIATIONS listing on page IX of the table of contents. In addition, error flag codes also are explained in the ABBREVIATIONS listing and at the bottom of the primary computations output.

Data used to show examples of plots and tables generated from the DAMFLO.2 programs include both measured and synthesized data. The measured data were obtained from the following stations: USGS stream-gaging station 02343801, Chattahoochee River at Andrews Lock and Dam near Columbia, Alabama; USGS stream-gaging station 02343802, Chattahoochee River below Andrews Lock and Dam; USGS stream-gaging station 07263450, Arkansas River at Murray Dam near Little Rock, Arkansas; and USGS stream-gaging station 02292000, Caloosahatchee CA at Moore Haven, Florida. Most of the observed data came from stations 02343801 and 02343802 . A plan and cross-section view of George W. Andrews Lock and Dam, which includes a fixed crest spillway, four Tainter gates, and a lock, are shown in figure 4. Because the data came from both real and fictitious structures, the examples that follow should be viewed as showing output for each particular capability of DAMFLO.2 and may not correspond to the other examples. That is, dates, flows, headwater elevations, etc. may not necessarily correspond between the examples. 

SET $=1$ CATEGORY $=$ FWR

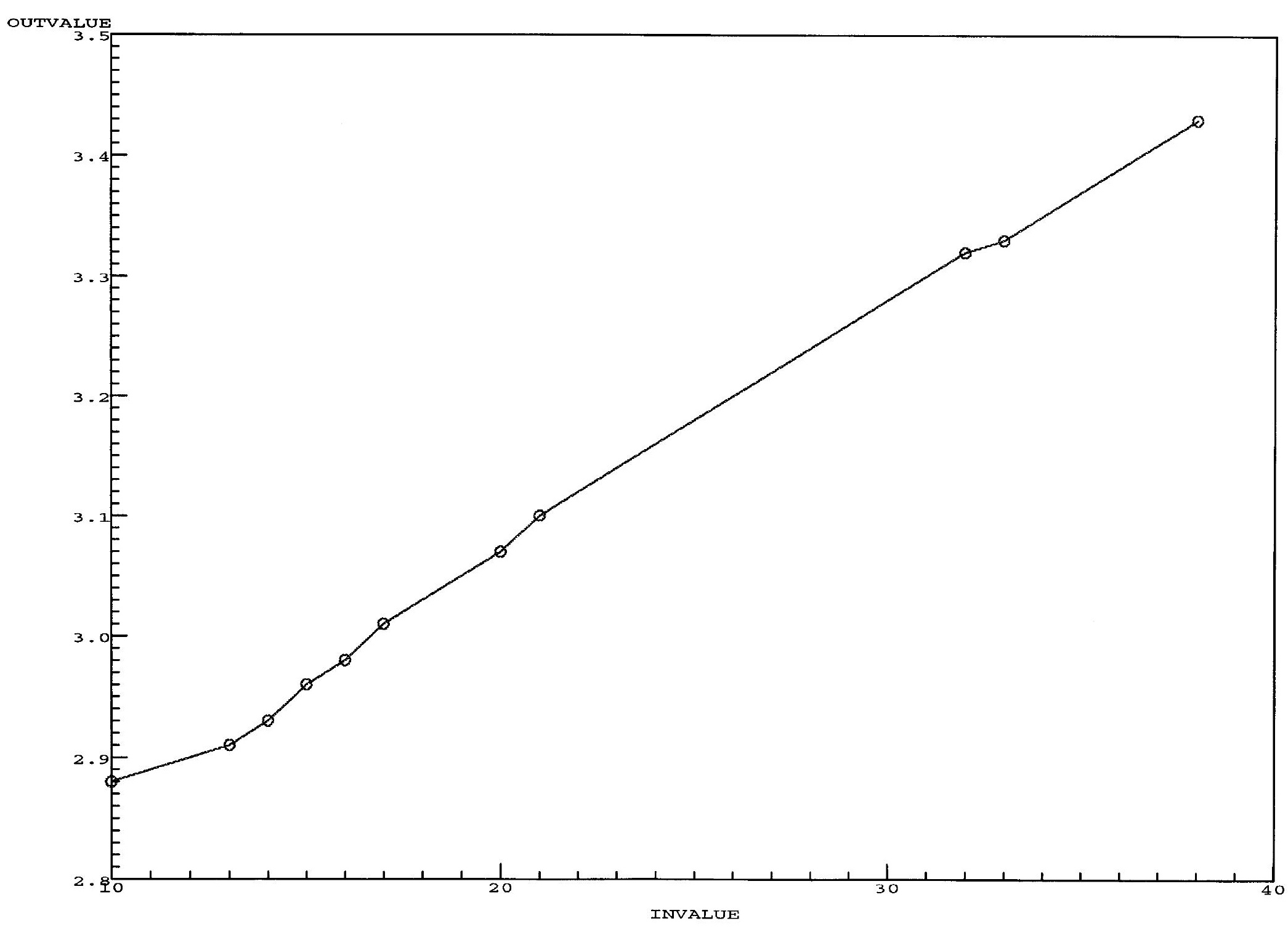

Figure 19. Plot of hydraulic rating. 


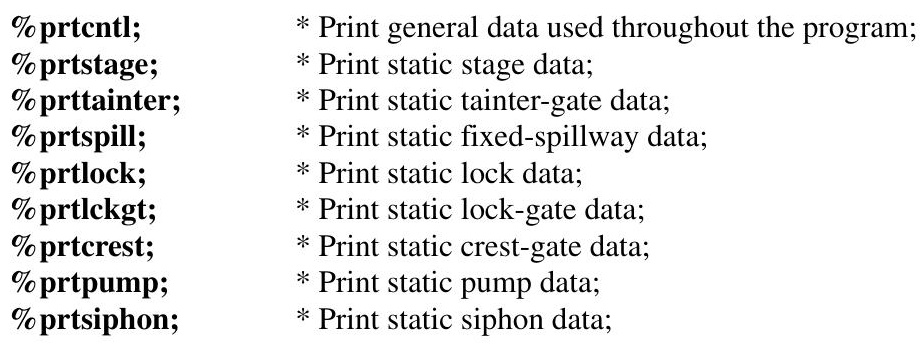

* dam ('name of input unit-value file', number of groups of unit-value data in file, 'beginning date', 'ending date for computations')

Describes input unit-value file and gives beginning and ending dates for computations. Reads input unit-value file;

\%stage $(1,1)$

\%stage $(2,2)$

* stage(stage-gage identification number, group number of unit-value data)

Loads unit-value stage data;

* The following 7 commands cause computation of flows through Tainter gates, spillways, locks, lockgates, crest gates, pumps, and siphons;

\% tainter $(1,1,2,3,0,1)$;

* Tainter(set number, group numbers of unit-value headwater stage data, tailwater stage data, and gate-opening data, distance from gate sill to downstream streambed, and gate number);

\%tainter $(1,1,2,4,0,2)$;

\%tainter $(1,1,2,5,0,3)$;

$\%$ tainter $(1,1,2,6,0,4)$;

\% spillway $(1,1,2)$;

* spillway(set number, group numbers of unit-value headwater and tailwater stage data;

\%lock $(1,1,2,4)$;

* lock(set number, group numbers of unit-value headwater stage data, tailwater stage data, and lock-count data);

\% lockgate $(1,1,2,5)$;

* lockgate(set number, group numbers of unit-value headwater stage data, tailwater stage data, and gate-opening data); $\%$ crest $(1,1,6)$;

* crest(set number, group numbers of unit-value headwater stage data and crest-gate count data);

$\%$ pump $(1,1,2,7,1)$

* pump(set number, group numbers of unit-value headwater stage data, tailwater stage data, and pump revolutions per minute, and pump number);

$\% \operatorname{siphon}(1,1,2,8)$;

* siphon(set number, group numbers of unit-value headwater stage data, tailwater stage data, and number of functioning siphons); $\%$ adduvq $(1,9,10)$;

* adduvq(set number, group number of unit-value flow data to be added to flows computed by DAMFLO.2, number of days per plot)

Adds flows computed external to DAMFLO.2 to flows computed by DAMFLO.2;

\%uvq (10, 'uvcards');

* uvq(group number of unit-value tailwater flow data to be used when flow cannnot be computed by DAMFLO.2, "name of file to hold unit-value total flow from dam')

Cumulates total flows from all outlets of dam, defaults to flows that may be entered from a downstream flow station, and creates a file of total unit-value flow data in B-card format for entry into ADAPS;

\% uvprimry ('uv.primary');

* uvprimry( 'name of file to hold unit-value primary data')

Creates file holding unit-value primary data table;

\%dvq ('dv.primary', 'mean.cds', 'min.cds', 'max.cds');

* dvq( 'name of file to hold daily value primary table', 'name of file to hold daily mean flow data', 'name of file to hold daily minimum flow data', 'name of file to hold daily maximum flow data'). Summarizes total unit-value flows, creates files holding daily value primary table and daily mean, minimum, and maximum flows in 2- and 3-card format for entry into ADAPS;

\% plotwrat (2);

* plotwrat(group number of tailwater stage data)

Plots total unit-value flow against tailwater stage data to demonstrate presence or lack of backwater effect on downstream stage-flow rating;

run;

Figure 20. Annotated run.primary file. 
As previously discussed, the user has the option of sending the plots and tables generated from the following programs or calls to the screen or to a printer. This discussion of the purpose and use of the summary tables is not repeated for each program. The mean, minimum, maximum, and sum of the appropriate input value, rate of change in input value, output value, submergence ratio and fall (as appropriate), and warning flags are tabulated (fig. 21). The information is useful for determining which program caused warning messages tabulated by the daily-values primary, submergence ratios outside the calibration range, very large rates of change indicating erroneous data, and the sum of warning messages for each program run.

\section{$\%$ dam}

Example: \%dam ('andrews.long.dat', 8, '881022', '881121');

The \%dam program converts the input unit-values data set into a SAS data set accessed by most of the programs. The arguments are:

A. Name of the flat file holding the unit-value time-series data sets retrieved from the ADAPS database, enclosed in single quotes.

B. The number of data groups within the flat file. In other words, this is the number of concatenated timeseries data of headwater, tailwater, and gate-opening observations contained in the flat file identified in item A above.

C. Date (YYMMDD) to begin computations, enclosed in single quotes. The first total computed unit-values flow will be missing, because a preceding midnight flow is not available for trapezoidal averaging. Therefore, it may be desirable to begin computations a day earlier than the intended first day.

D. Date (YYMMDD) to end computations, enclosed in single quotes.

U. S. GEOLOGICAL SURVEY STREAMFLOW PRIMARY -- PROVISIONAL DATA
TAINTER GATE COMPUTATIONS

12:35 Tuesday, April 29, 1997

STATION NUMBER=021343801 FILENUMB $=4$

\begin{tabular}{lrrrr} 
Variable & Mean & Minimum & Maximum & Sum \\
\hline HG & 1.42 & 0.21 & 4.81 & 1055.45 \\
DIFF & 0.00 & -2.83 & 2.23 & 1.76 \\
SRATIO & 1.58 & 0.00 & 14.67 & 1174.76 \\
OUTVAL & 2202.85 & 355.97 & 6755.69 & 1638917.26 \\
NMNMAX & 0.00 & 0.00 & 0.00 & 0.00 \\
NRATECH & 0.04 & 0.00 & 1.00 & 28.00 \\
NRATERR & 0.00 & 0.00 & 0.00 & 0.00
\end{tabular}

Figure 21. Summary of computations for one Tainter gate. 


\section{\%stage}

Example: \%stage $(1,1)$;

The \%stage program makes datum corrections and gives warning messages for stage data. The arguments are:

A. Stage-gage identification number. Assign stage-gage identification numbers sequentially with each use of the \% stage program.

B. Data-group number for the stage data based on the sequential order of data groups in the time-varying input data file.

The program outputs plots (fig. 22) and an interactive table of stage data (fig. 23) with warning flags. Rates of change of stages also are tabulated. The search command can be used to list periods where an excessive rate of change of stage may indicate erroneous data or to list data with warning flags.

\section{U. S. GEOLOGICAL SURVEY STREAMFLOW PRIMARY - - PROVISIONAL DATA STATION NUMBER=07263450 FILENUMB $=1$ PLOT $=5$}

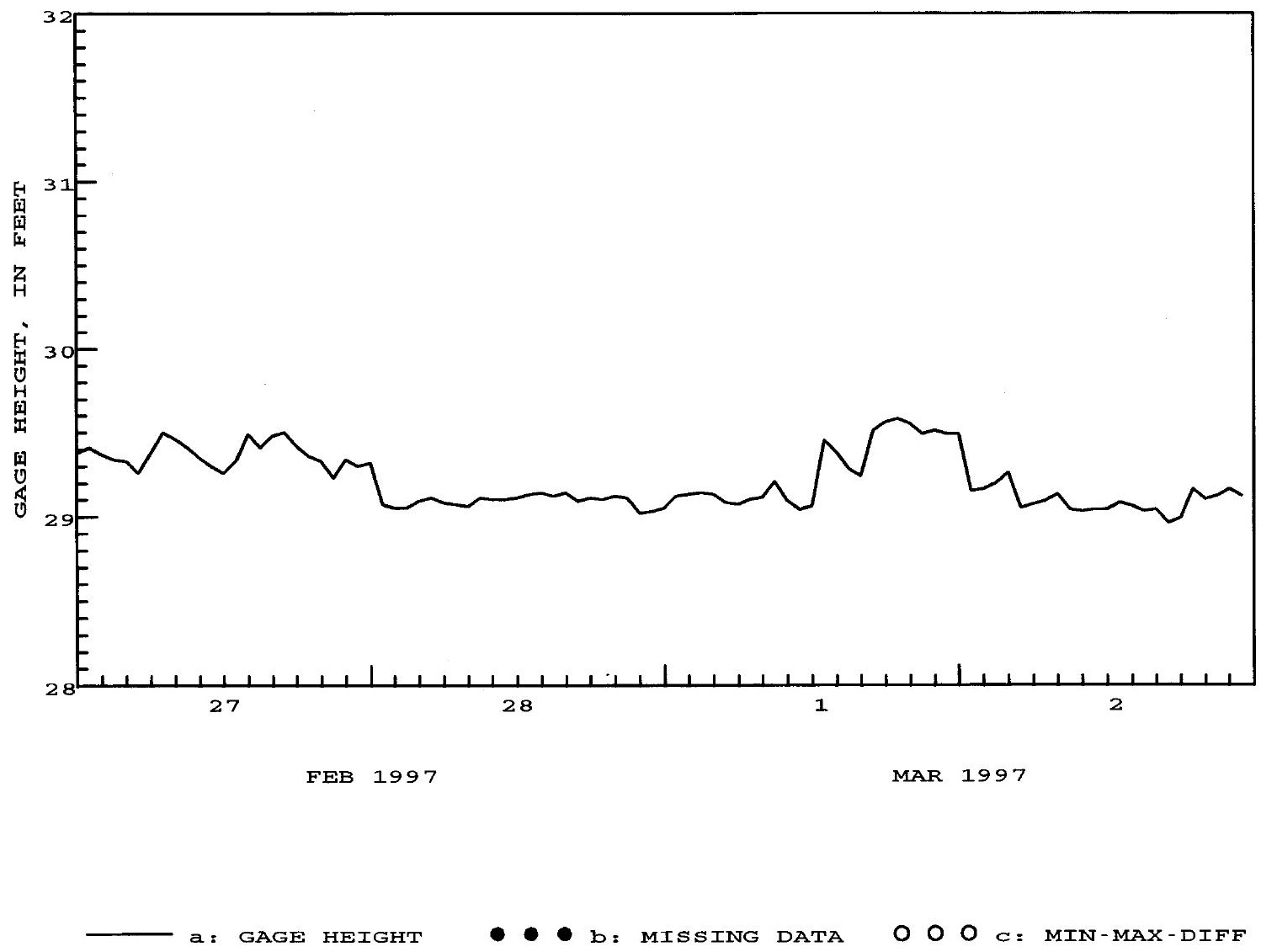

Figure 22. Plot of stage data. 


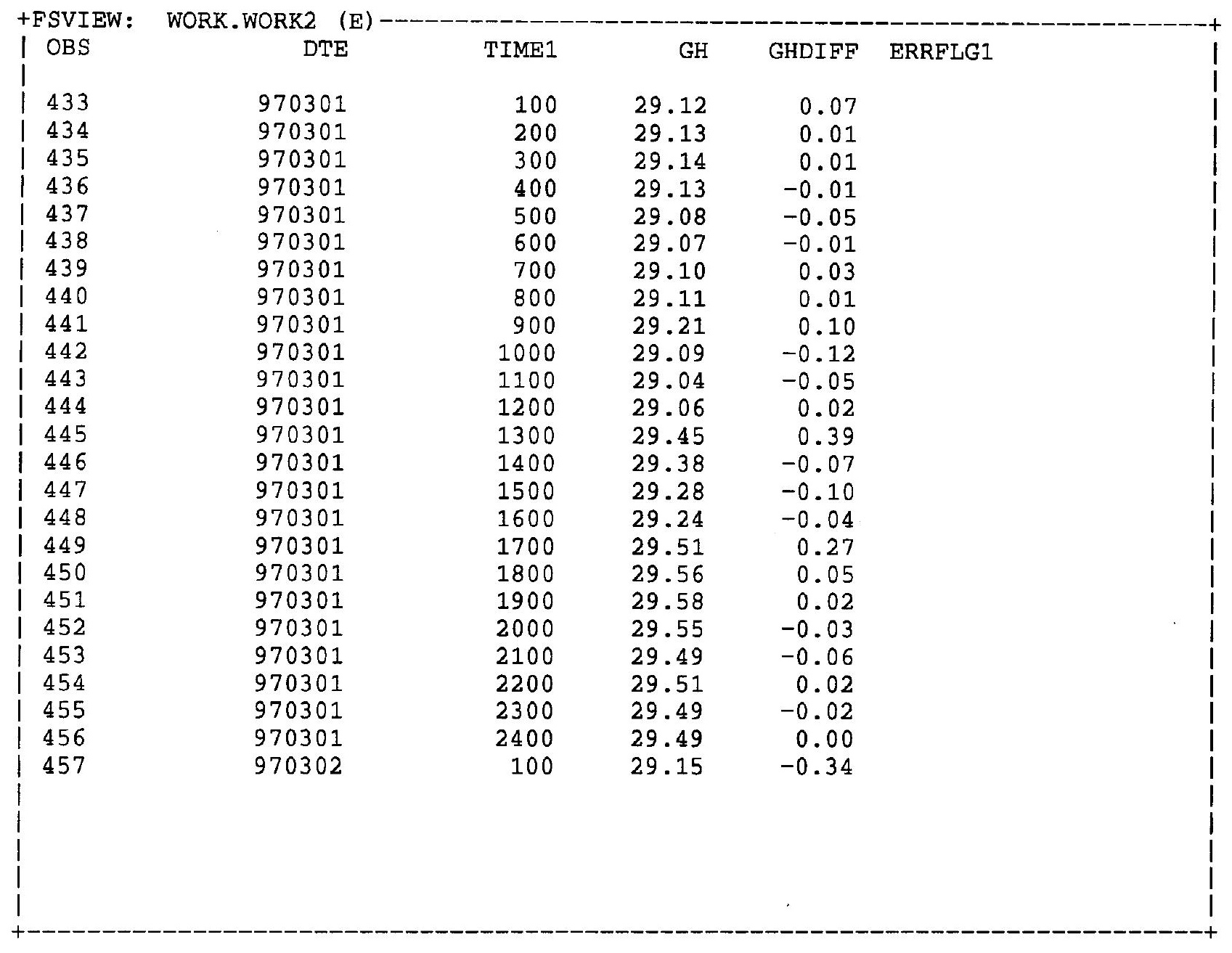

Figure 23. Interactive table of stage data.

\section{\%tainter}

Example: \%tainter $(\mathbf{1}, \mathbf{1 , 2}, \mathbf{3 , 0} \mathbf{0})$;

The \%tainter program computes flow through Tainter and sluice gates and the arguments are:
A. Set number.
B. Data-group number for the headwater stage data.
C. Data-group number for the tailwater stage data.
D. Data-group number for the gate opening data.

E. Vertical distance from gate sill to downstream streambed, for use of flow classification method number 3 (table 1) for differentiating between free and submerged orifice flow, as documented in the "Differentiation Between Free- and Submerged-Weir Flow Conditions" section of this report. Enter zero if method 3 is not used.

F. For this particular set of gates, this is an arbitrary number identifying the gate where flow is being computed, such as gate number 1 . It is suggested that the gates be numbered sequentially beginning with 1 . For example, if there were two Tainter gates in set number 1, there would be a second command as follows for gate 2 : \%tainter $(\mathbf{1}, \mathbf{1}, \mathbf{2}, \mathbf{3}, \mathbf{0}, \mathbf{2})$; 
The program outputs gate opening, rate-of-change of gate opening, flow, flow types, tailwater elevation, and warning messages in both plots (fig. 24) and an interactive table (fig. 25). Headwater elevations also are included in the table output. Suggested analytical procedures are as follows:

A. Check validity of warning messages and look for unusual changes or non-changes of data plots.

B. Evaluate flow types for validity by comparing flow type symbol with the relation of the tailwater elevation to the gate opening in the plots. In other words, if the tailwater elevation is greater than the gate opening, and free flow exists, is a hydraulic jump of this height reasonable? At what times of day and under what conditions do unusual flow types occur? Are there discontinuities of flow when flow types

\section{U. S. GEOLOGICAL SURVEY STREAMFLOW PRIMARY - - PROVISIONAL DATA} STATION NUMBER $=07263450$ GATSET=1 GATENUMB $=1$ FILENUMB $=3$ PLOT=5
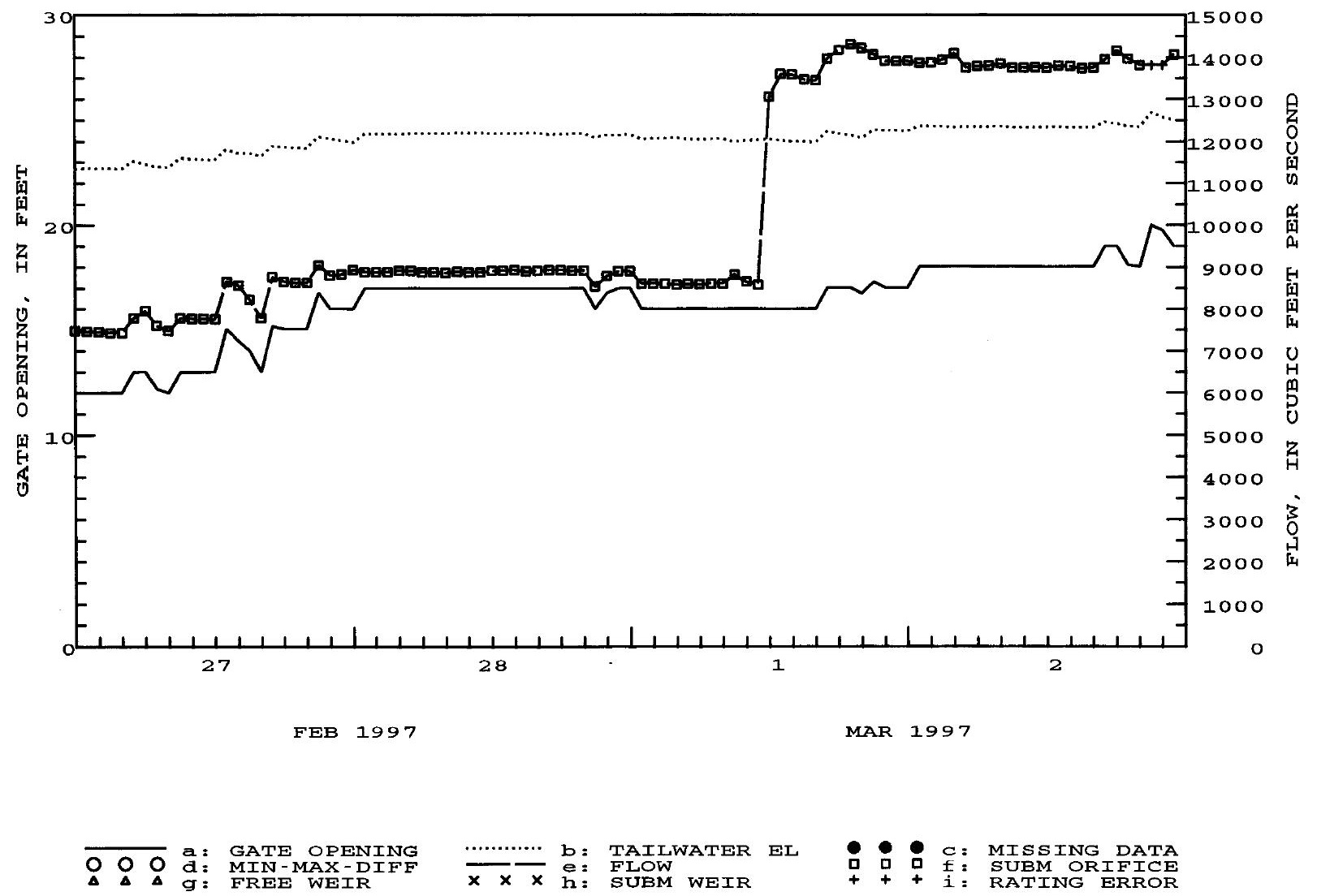

Figure 24. Plot of Tainter gate data. 


\begin{tabular}{|l} 
+FSVIEW: \\
OBS
\end{tabular}

Figure 25. Interactive table of Tainter gate data.

change from submerged-orifice flow to submerged-weir flow and back? Are there discontinuities when orifice or weir flows change from free to submerged flow? Can variations in flow be explained by variations in gate opening and downstream head?

C. If submerged-orifice flow is defined by an equation, then it is possible that flows might be computed by extrapolating past the range of the data used to derive the equation. Use the interactive table to search for unusually large submergence ratios. The table also can be searched for selected flow types, warning flags, rates of change of gate opening, flow magnitude, and so forth.

D. If submerged-weir flow exists, search the interactive table for extremely large submergence ratios where a submerged-weir flow rating might be invalid. 


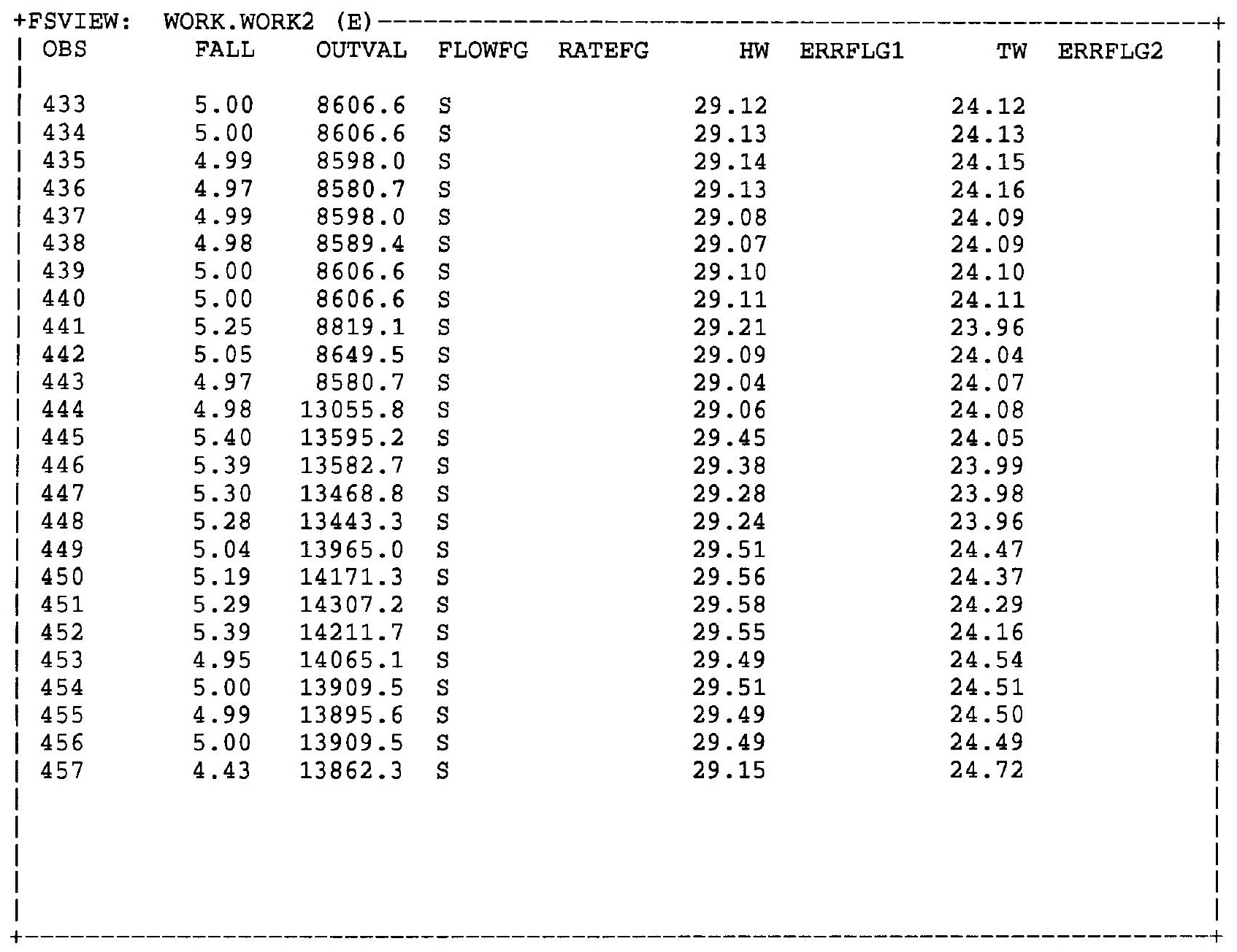

Figure 25. Interactive table of Tainter gate data. (Continued)

\section{\%spillway}

Example: \%spillway $(1,1,2)$;

The \% spillway program computes free and submerged-weir flow over fixed spillways, and the arguments are:
A. Set number.
B. Data-group number for the headwater stage data.
C. Data-group number for the tailwater stage data.

The program outputs headwater elevations, tailwater elevations, flows, warning flags, and flow types in plots (fig. 26) and an interactive table (fig. 27). The program also plots the elevation of the fixed spillway. Suggested analytical methods include: 


\section{U. S. GEOLOGICAL SURVEY STREAMFLOW PRIMARY -- PROVISIONAL DATA}

SPILLWAY COMPUTATIONS
STATION NUMBER=021343801 SPILISTN=1 PLOT=1

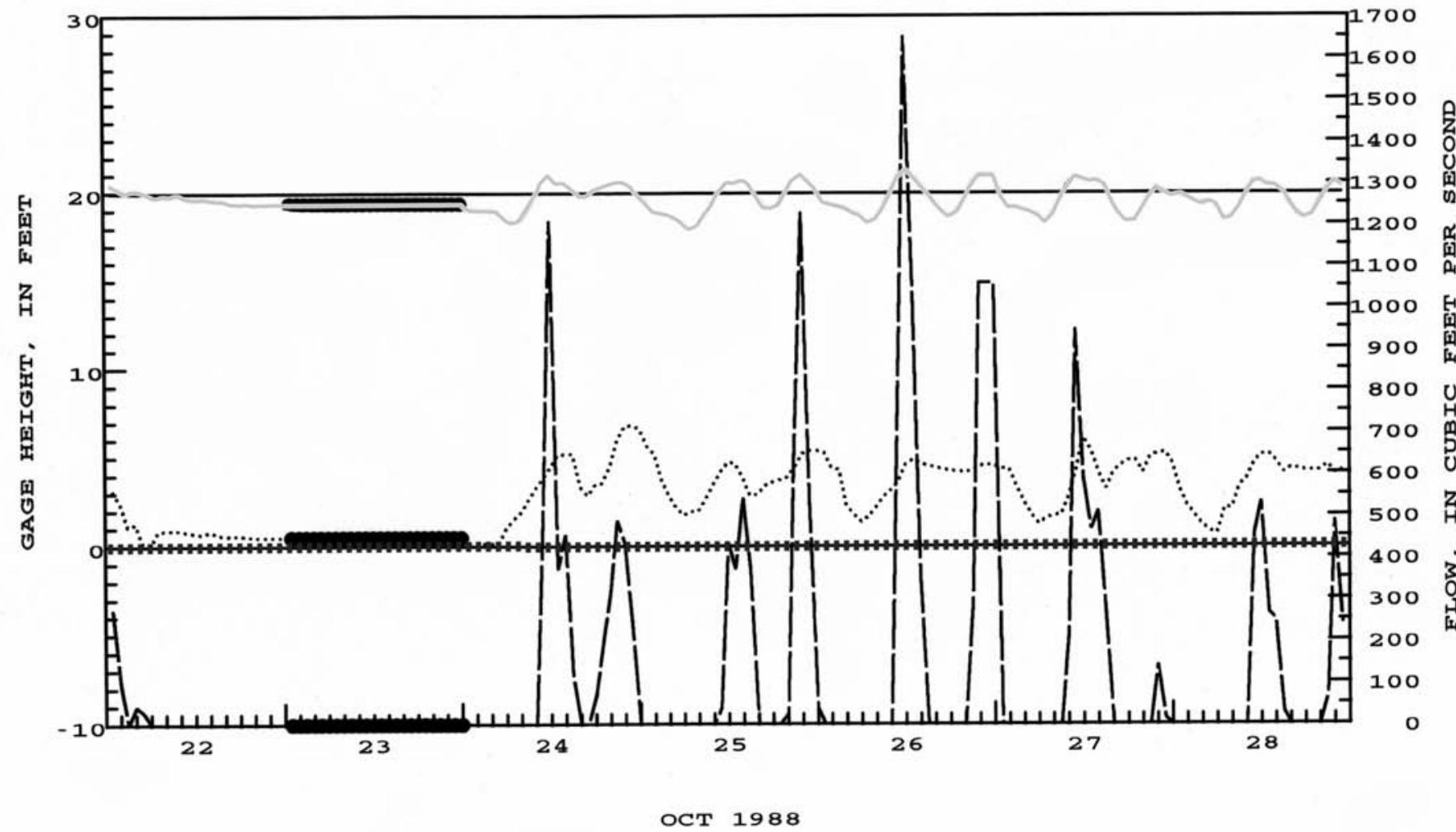

: HEADWATER EL

e: FLOW $b:$ TAILWATER EL $\times \times \mathbb{E}:$ SUBM WEIR
C: SPILLWAY EL

++ + g: RATING ERROR
- - d: MISSING DATA W: GAGE HEIGHT EQUALS O FEET

Figure 26. Plot of spillway data. 


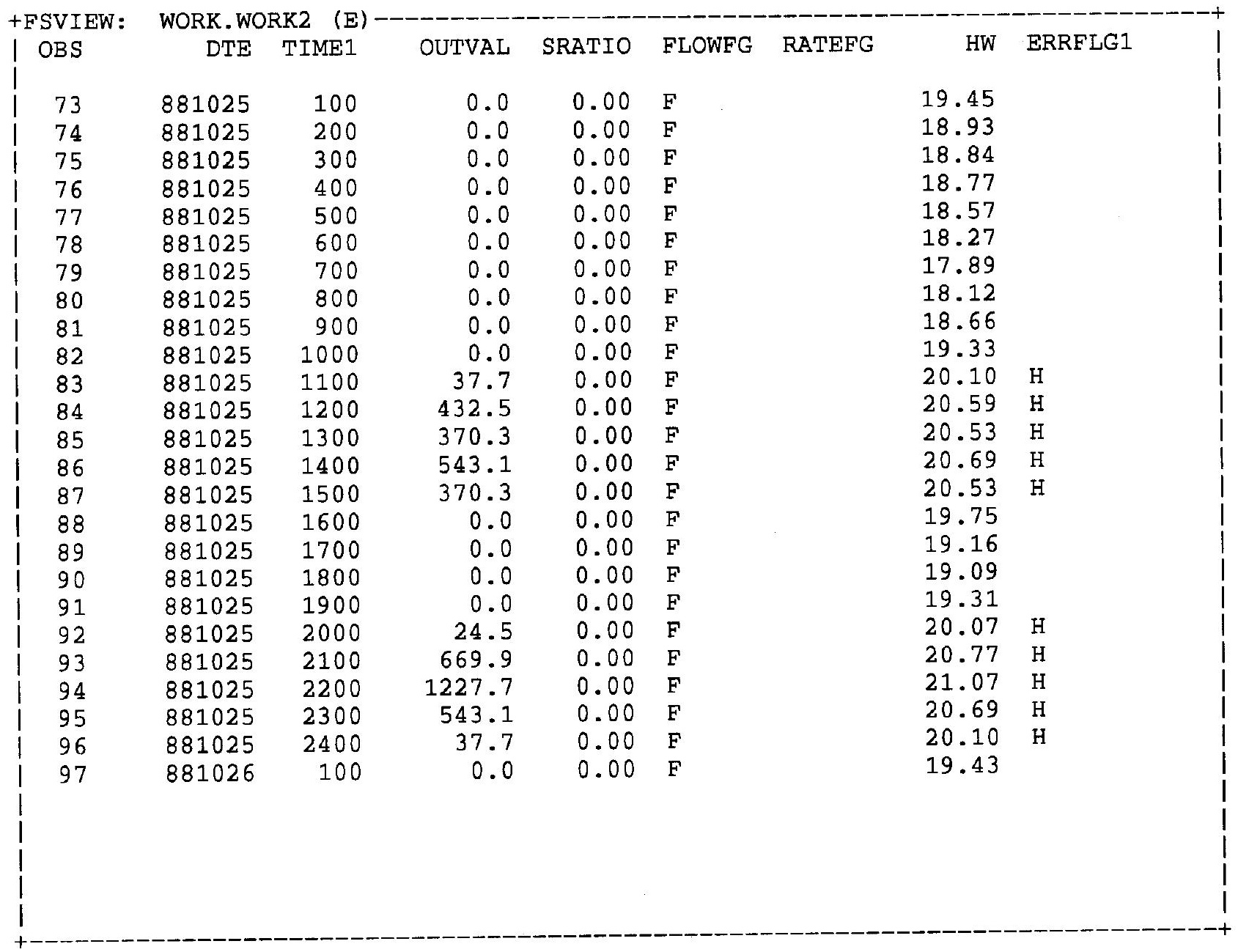

Figure 27. Interactive table of spillway data.

A. On the plot, compare the headwater and tailwater elevations with the elevation of the spillway to determine when flow will overtop the fixed spillway, and when submerged-weir flow might occur. Additionally, look for flags indicating submerged-weir flow both on the plot and in the table.

B. If submerged-weir flow exists, search the interactive table for extremely large submergence ratios where a submerged-weir flow rating might be invalid.

\section{\%lock}

Example: \%lock $(1,1,2,4)$;

The \%lock program computes flow through locks and the arguments are:
A. Set number.
B. Data-group number for the headwater stage data.
C. Data-group number for the tailwater stage data.
D. Data-group number for the lock-count data. 


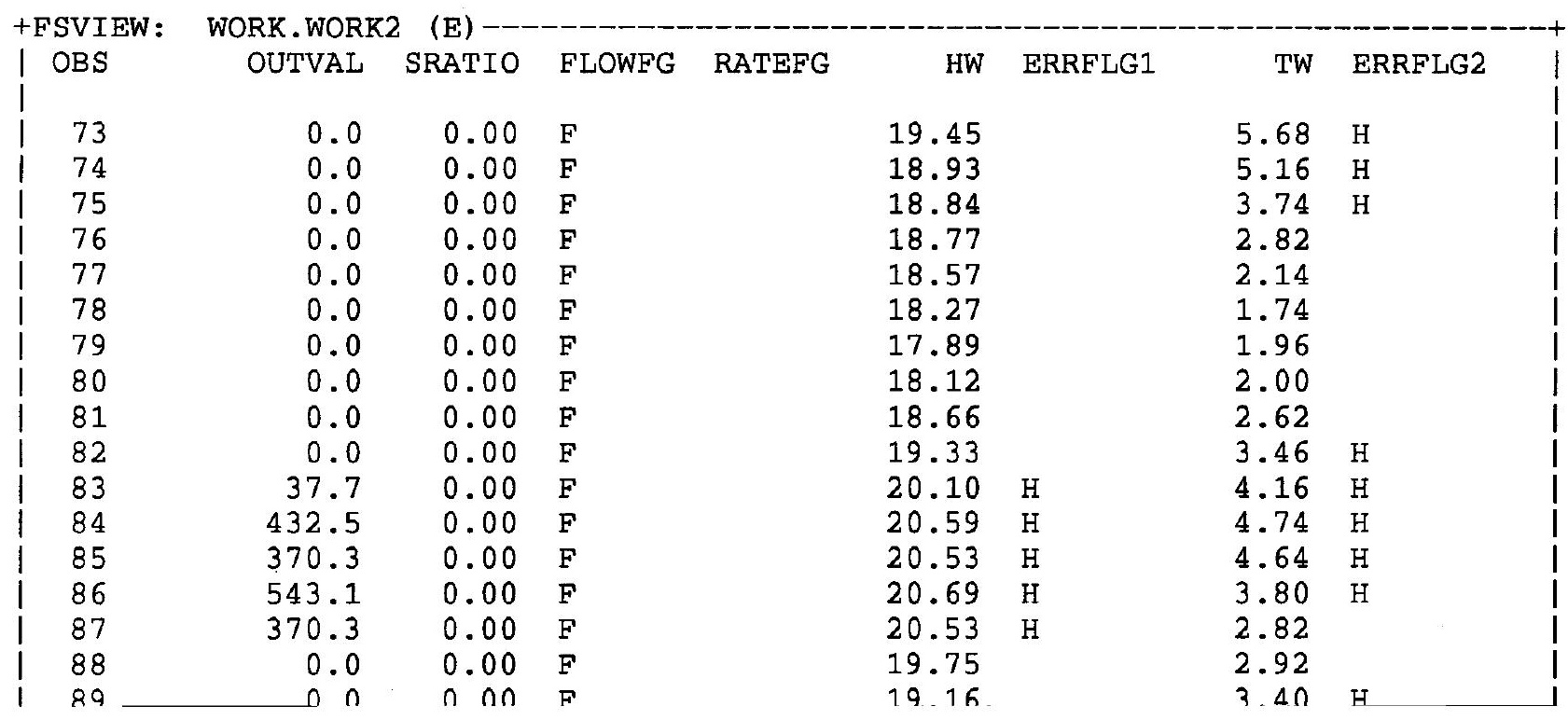

Figure 27. Interactive table of spillway data. (Continued)

The program outputs lockage counts, flows, leakages, and warning messages in plots (fig. 28) and an interactive table (fig. 29). The table also lists rate of change of lockage count. The plots and table can be searched for an unusually large number of lockages in a time increment or unusually long periods without lockages.

\section{\%lockgate}

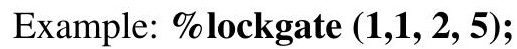

The \%lockgate program computes flow through partially opened lock gates and the arguments are:
A. Set number.
B. Data-group number for the headwater stage data.
C. Data-group number for the tailwater stage data.
D. Data-group number for the gate-opening data. 


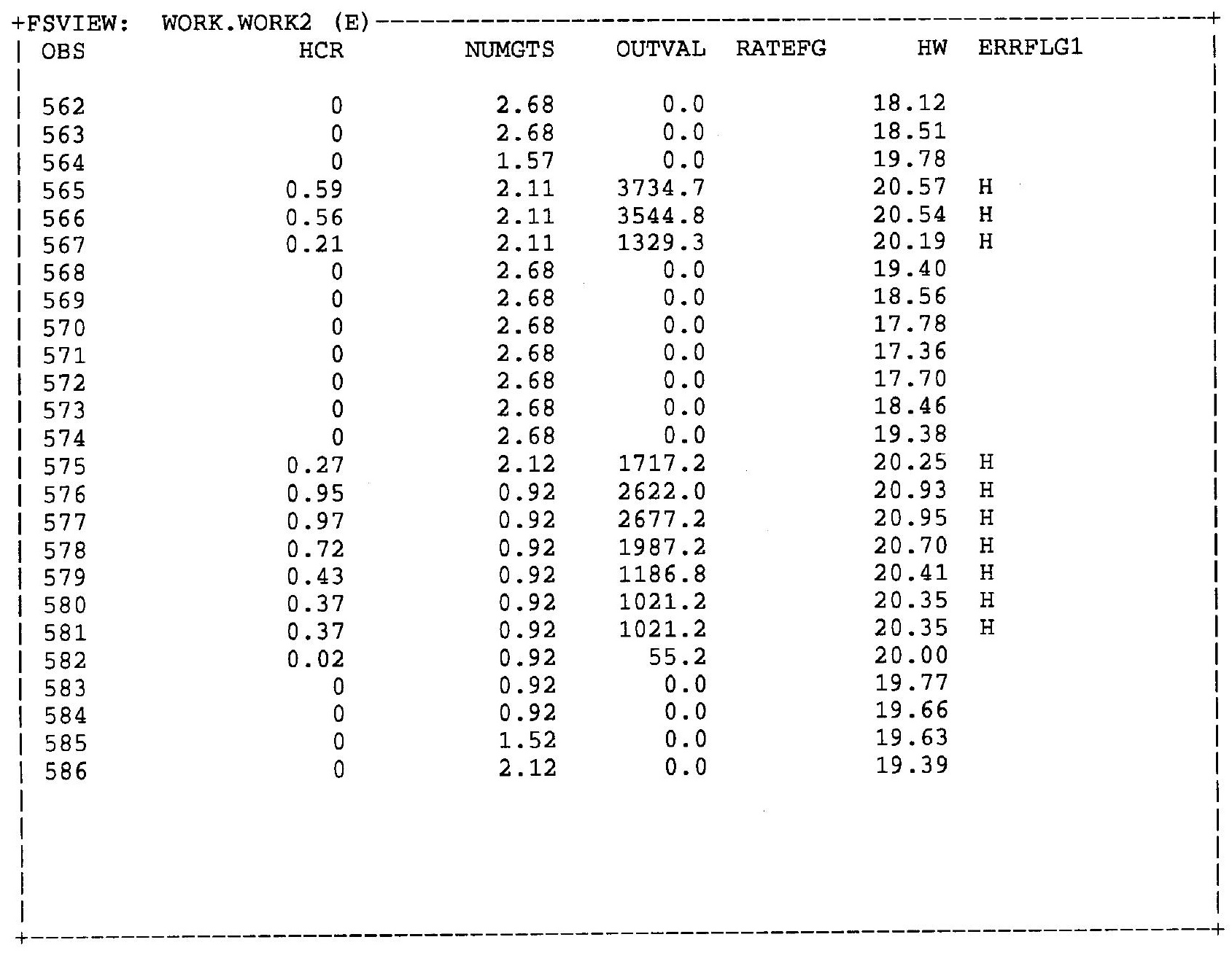

Figure 33. Interactive table of flow-through-crest-gate data. (Continued)

A. Data-group number for the flow data at the downstream gaging station to be used if flow cannot be computed by DAMFLO.2. Enter zero if not needed.

B. Name of file to hold unit-value total flow data in B-card format for entry into the ADAPS database, enclosed in single quotes.

\section{\%uvprimry}

Example: \%uvprimry ('uv.primary');

The \% uvprimry program creates a file containing the unit-values primary listing (fig. 44) for review and storage in the station files. The primary has a width of 132 columns, and can be printed on 8.5- by 11-inch paper on the SUN computer, using the command:

\section{asa uv.primary | lp -y landscape}


U. S. GEOLOGICAL SURVEY STREAMFLOW PRIMARY - - PROVISIONAL DATA CREST GATE COMPUTATIONS - FLOW OVER TOP OF GATE

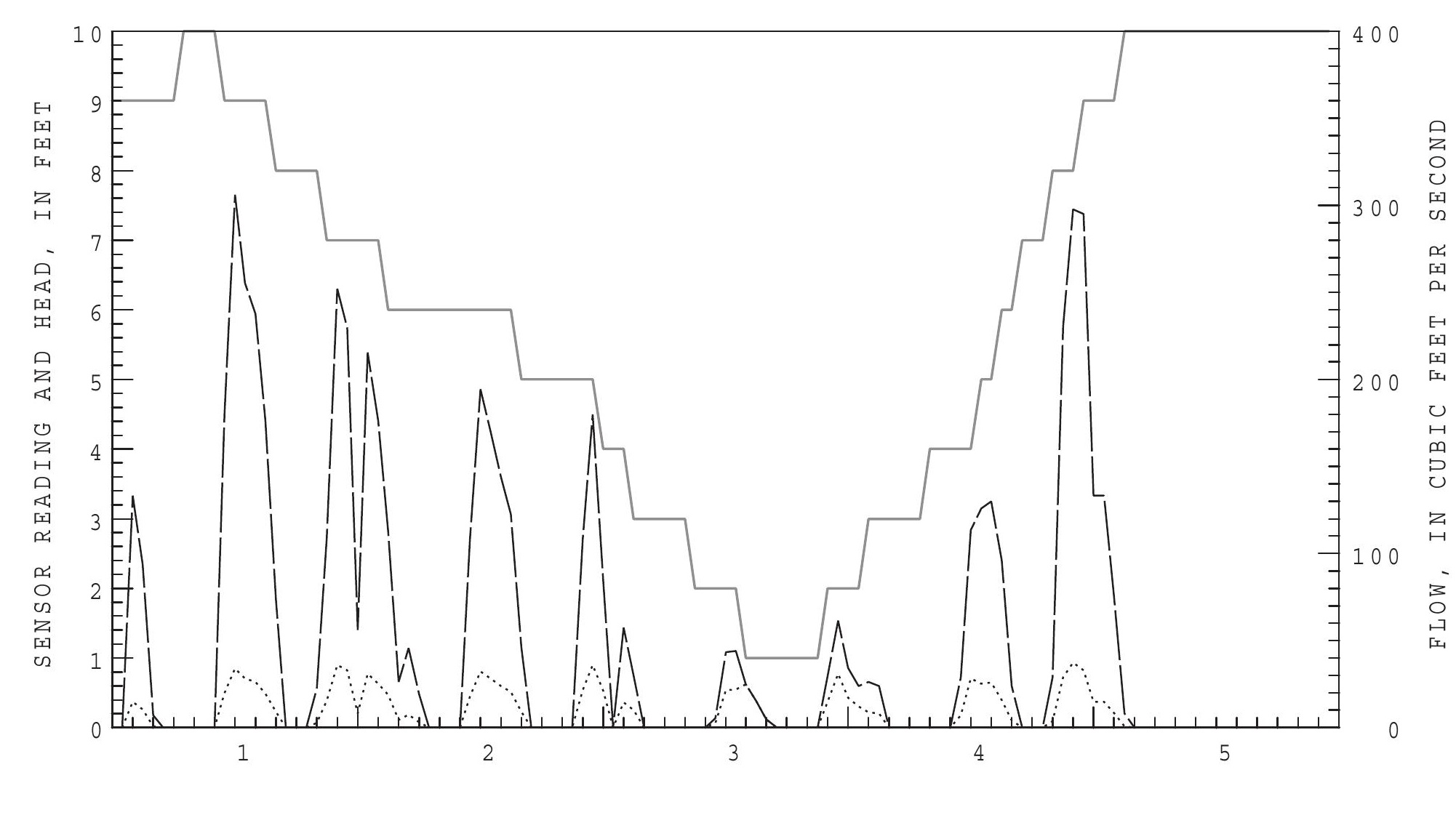

NOV 1988

a: SENSOR READNG $\cdots \cdots \cdots \cdots$

$+\quad$ C: MISSING DATA

Figure 34. Plot of flow-over-crest-gate data. 


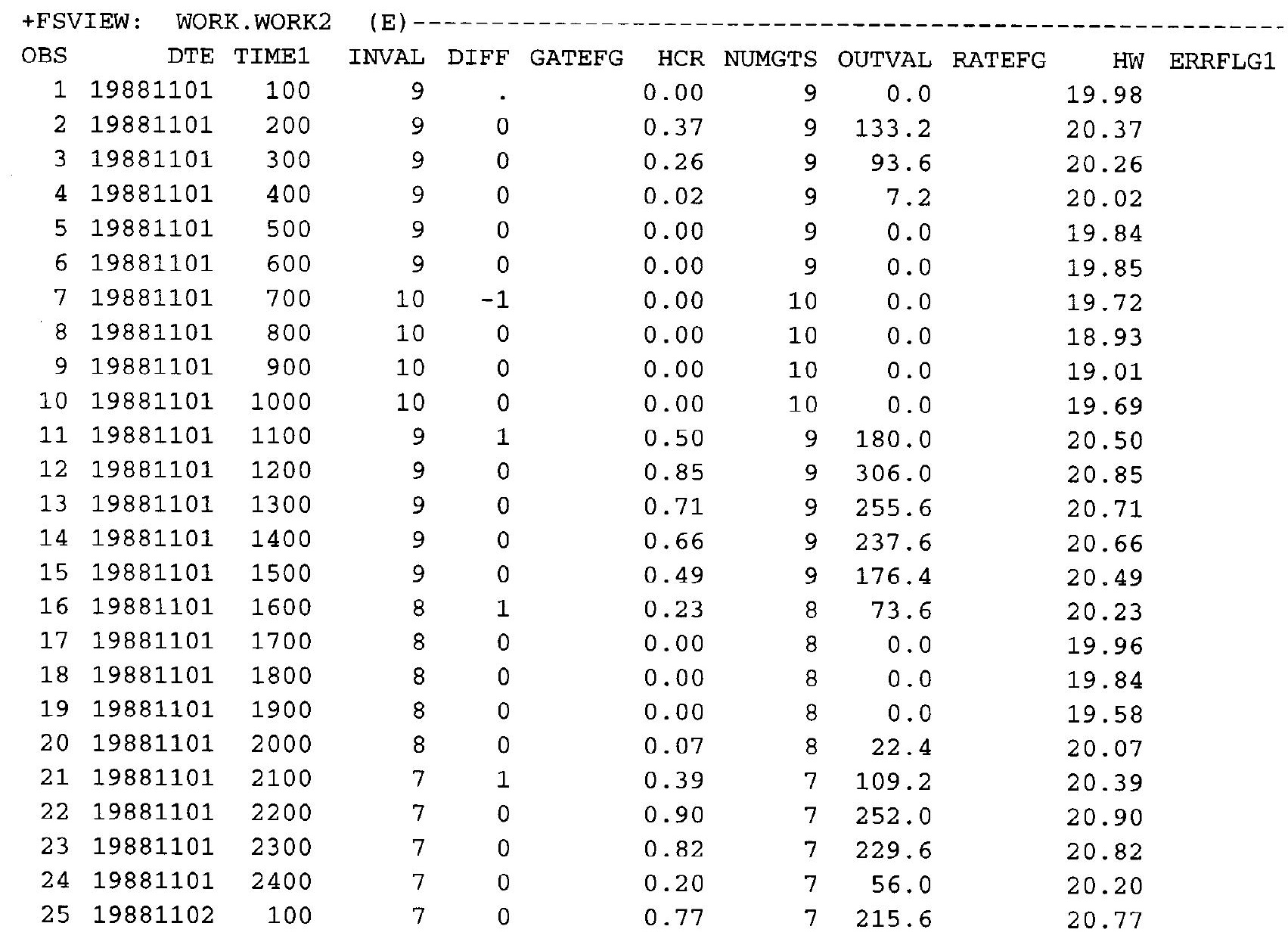

Figure 35. Interactive table of flow-over-crest-gate data.

The primary displays all input data, appropriate submergence ratios, leakages, flow types, warning messages, and computed flows. The number of printed readings per day can be varied in even multiples of 12 by use of the control program (damflo menu, option 4). All data shown in the primary are represented in the unit-value plots and an interactive table. The argument for the program is the name of the file to contain the unit-values primary, enclosed in single quotes. 
PUMPAGE COMPUTATIONS
STATION NUMBER $=02286400$ PUMPSTN $=1$ PUMPNUMB $=1$ PLOT $=1$

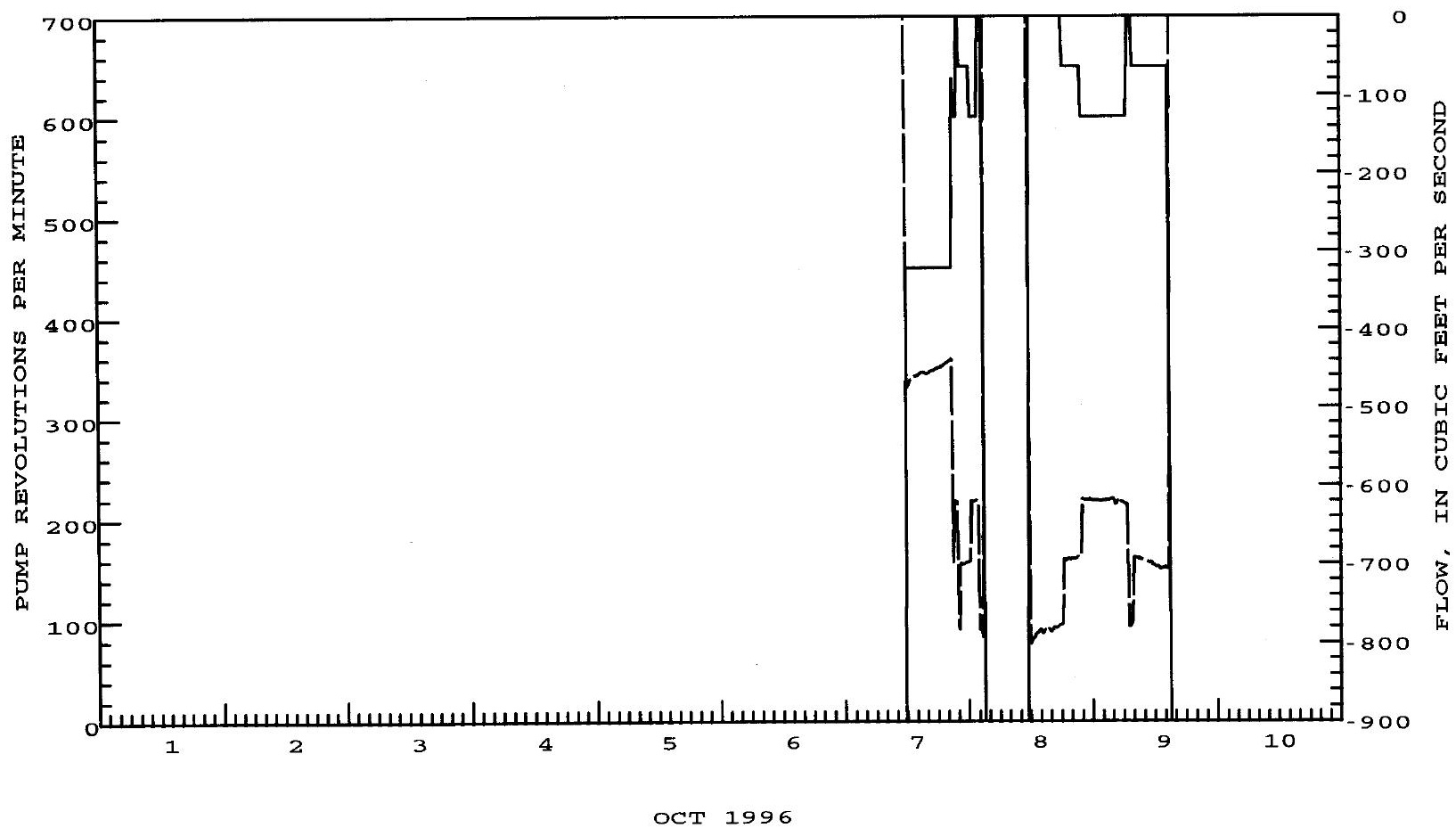

二- a: $\underset{\text { a: }}{\text { FLOW RPMS }}$

$+\div ; b:$ MISSING DATA

OO $O:$ MIN-MAX-DIFF

Figure 36. Plot of pump data. 


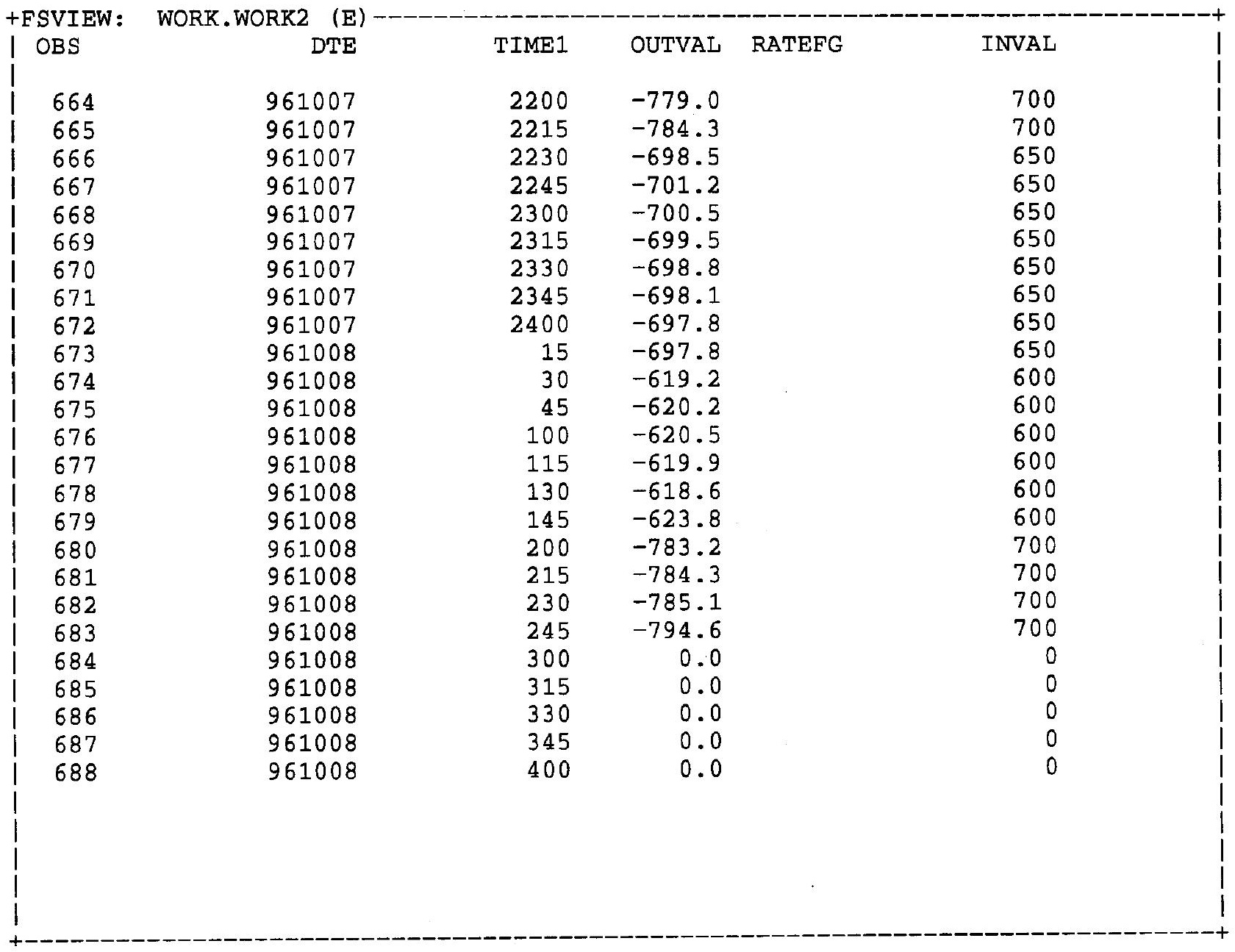

Figure 37. Interactive table of pump data.

\section{$\% d v q$}

Example: \%dvq ('dv.primary', 'mean.cds', 'min.cds', max.cds');

The \%dvq program computes, tabulates, and plots daily-value flow data from the total unit-values flows. The program also creates files of daily minimum, daily maximum, and daily mean flows in 2- and 3-card-format for entry into the ADAPS database. Arguments for the program are the following:

A. Name of file to hold daily-values primary listing, enclosed in single quotes.

B. Name of file to hold daily mean values flows, enclosed in single quotes.

C. Name of file to hold daily minimum flows, enclosed in single quotes.

D. Name of file to hold daily maximum flows, enclosed in single quotes.

The program outputs daily mean flows, daily minimum flows and time of minimum flow, daily maximum flow and time of maximum flow, and warning messages to a daily-values primary file (fig. 45), plots (fig. 46), and an interactive table (fig. 47). For each day, the program tabulates the total number of minimum-maximum, rate-of- 


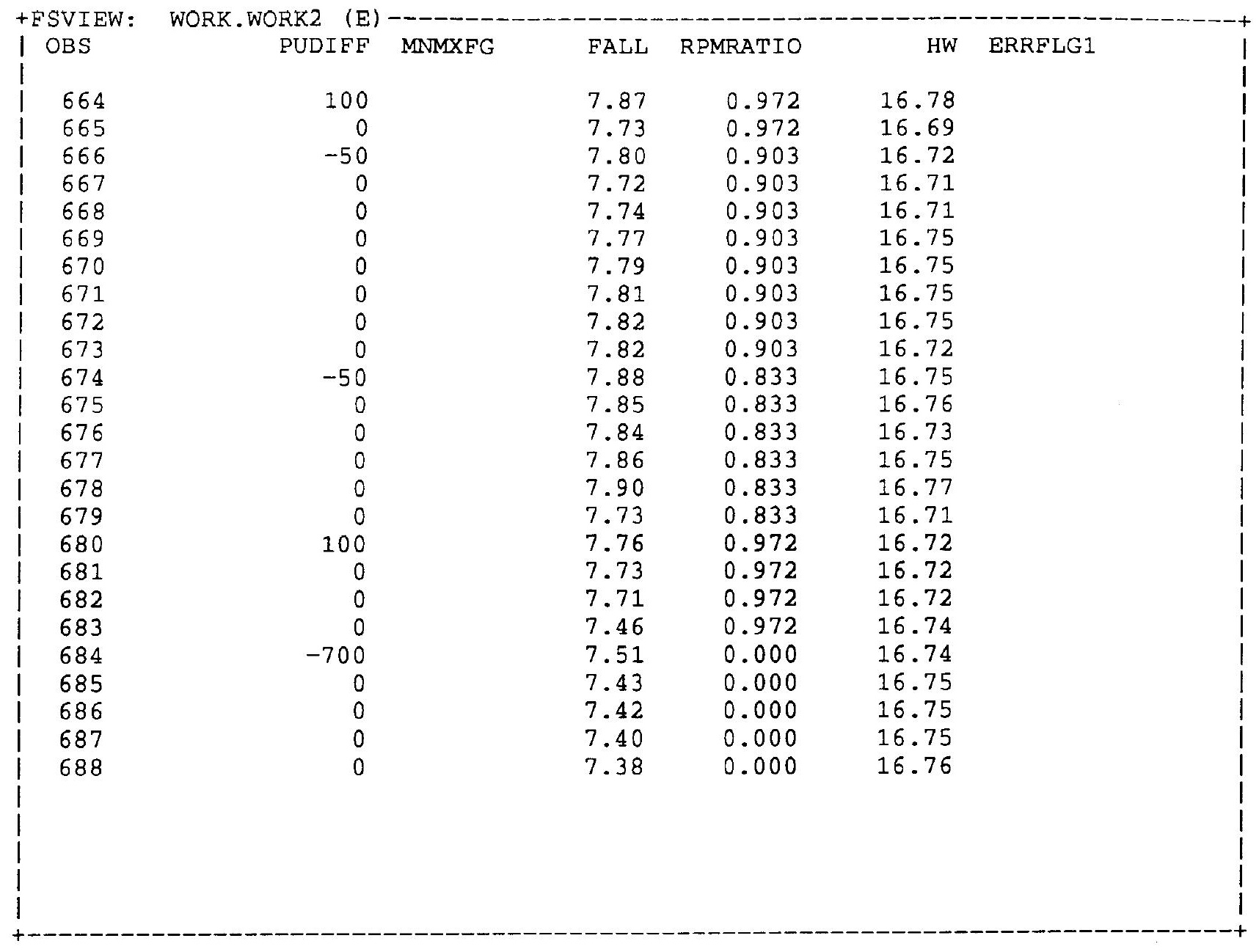

Figure 37. Interactive table of pump data. (Continued)

change-of-stage, and rating errors detected throughout the computations, and gives the total number of tailwater gaging station flows that were substituted for missing data. The program also tabulates the number of total unitvalues flows used to compute the daily mean. The overall performance of the program can be evaluated by scanning the warning flag summaries. If an unacceptable number of warnings are detected, then a detailed investigation of the tables, plots, and summaries for the various data types is in order. For example, the summaries can be reviewed to determine the number of errors that were detected for each outlet of the dam. Then, the unitvalues plots of that outlet can be searched for the possibly erroneous data or all plots can be reviewed.

Daily mean, minimum, and maximum flows, and warning messages shown in the daily-values primary appear on the plots and in the interactive table for scanning and search. 


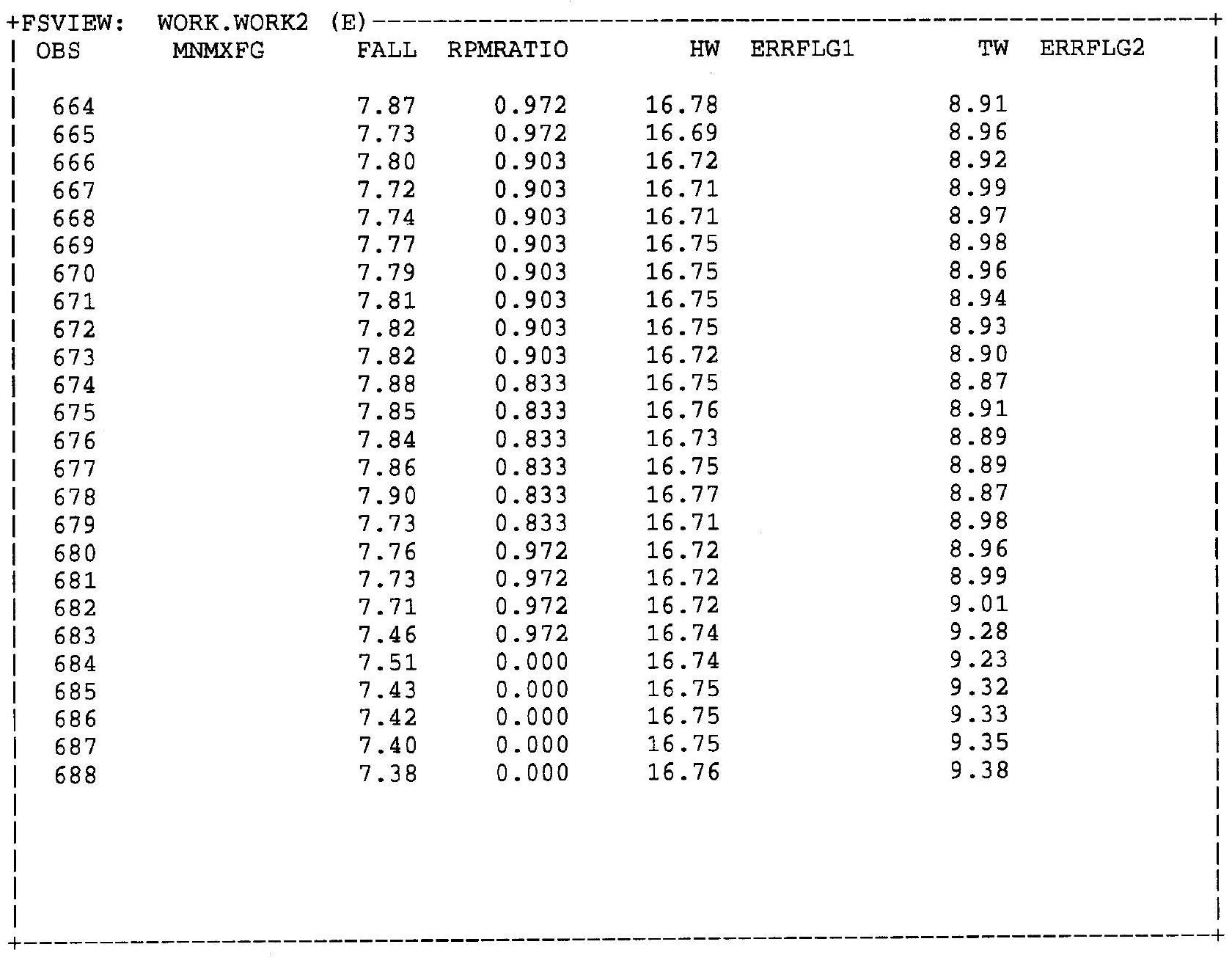

Figure 37. Interactive table of pump data. (Continued)

\section{\%plotwrat}

\section{Example: \%plotwrat (2);}

The \%plotwrat program plots the computed unit-values total flows against a selected tailwater elevation for both the period of computation (fig. 48) and by day (fig. 49). The purpose of the program is to display the effect or non-effect of backwater on a downstream stage-discharge relation. If backwater from a downstream dam is held constant for long periods of time, then flow measurements may define a smooth rating that could change drastically when the downstream backwater does change. This plot can serve as a warning. In addition, at high stages, when there is insufficient fall for accurate weir-flow computations, it is desirable to change to a stagedischarge rating, if one can be accurately determined. This plot will help show if there is a lack of backwater at high flows. All the data for the period of computation are shown on one plot, to demonstrate the whole relation, and then the data are plotted one day at a time, to demonstrate how the relation changes as backwater changes with time. The only argument for the program is the data-group number for the tailwater stage data. 


\section{U. S. GEOLOGICAL SURVEY STREAMFLOW PRIMARY - - PROVISIONAL DATA}

STATION NUMBER $=02286400$ SIPSET $=1$ FILENUMB $=3$ PLOT $=1$

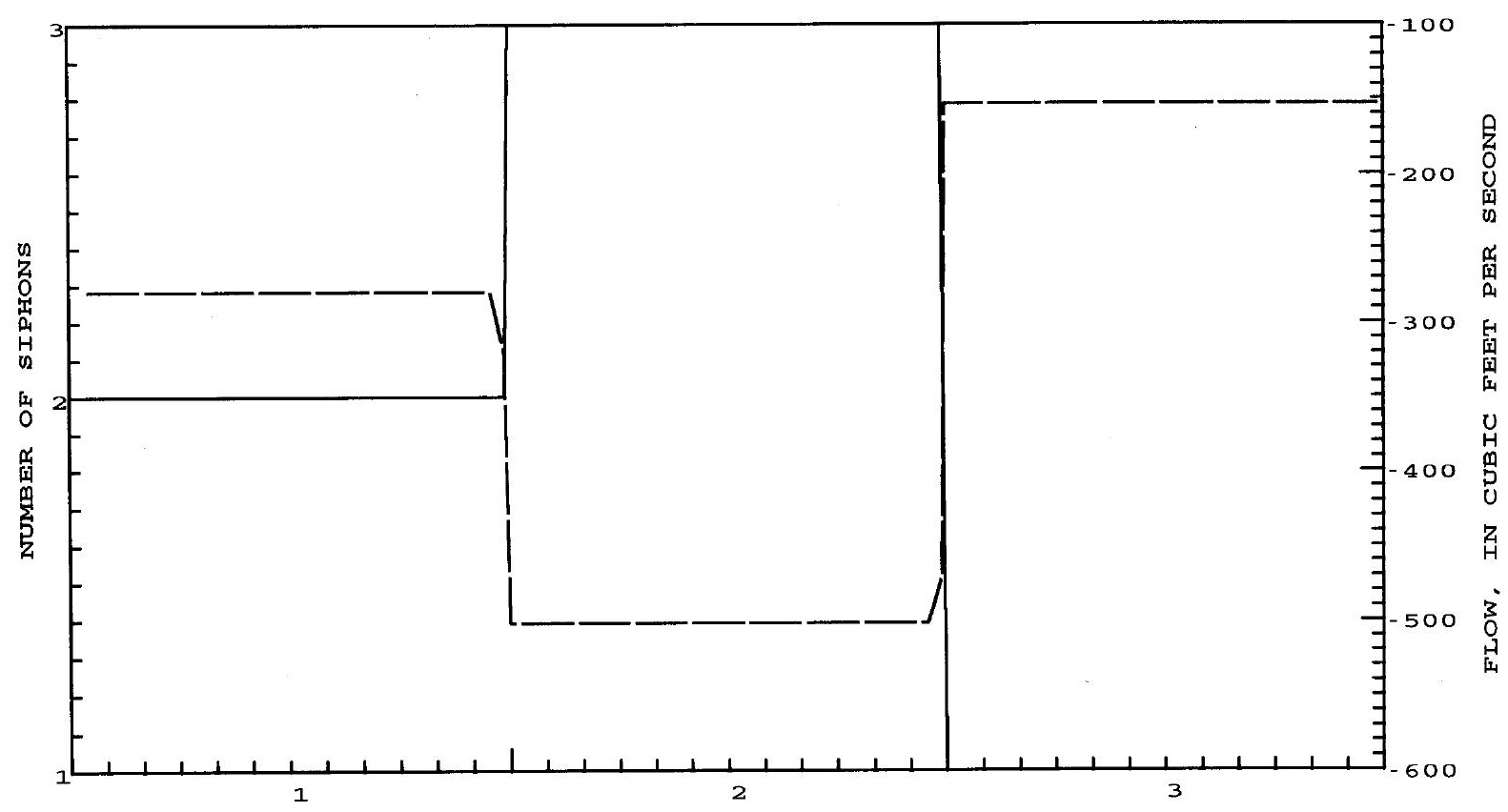

JAN 1997 


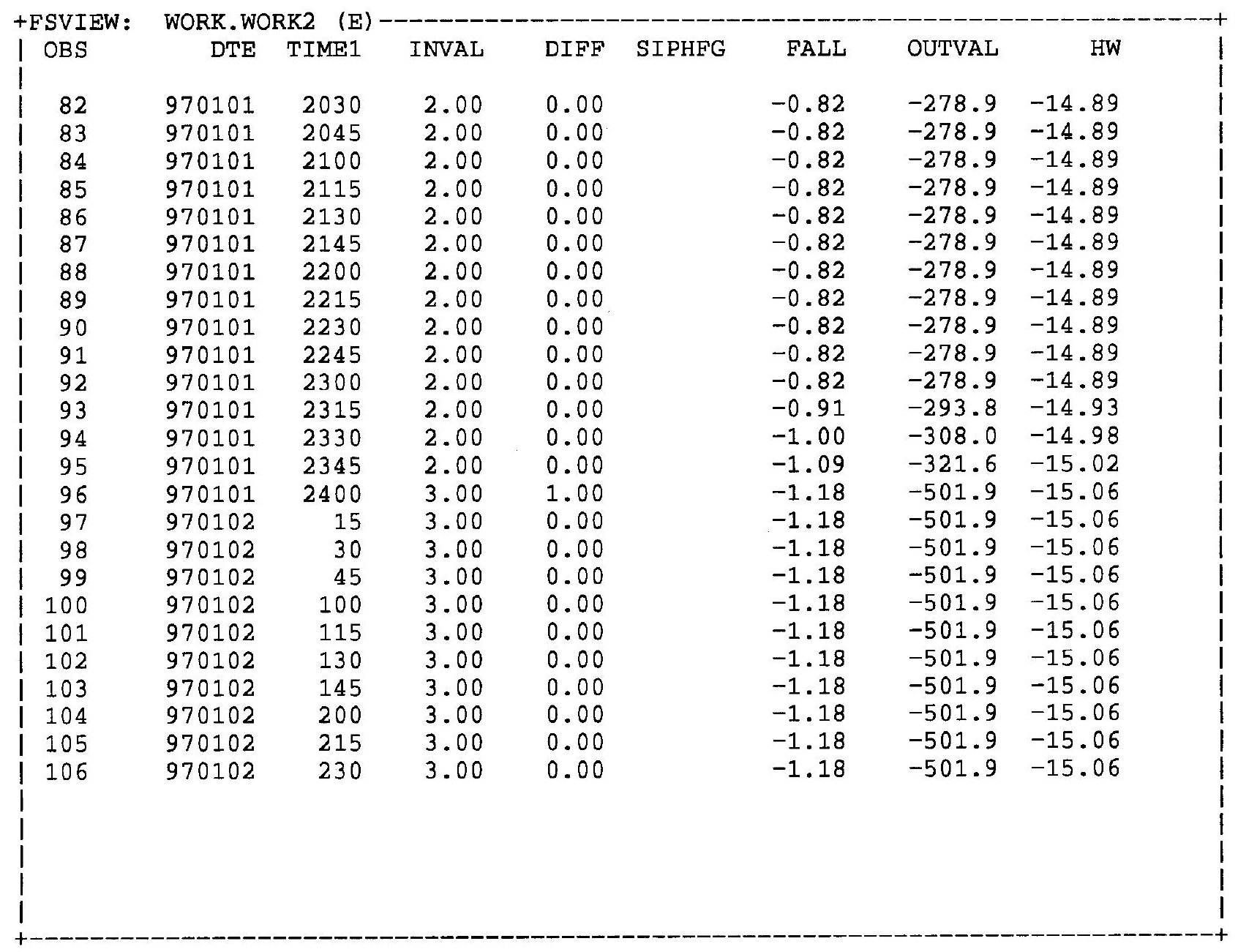

Figure 39. Interactive table of siphon data.

\section{UTILITY PROGRAMS}

The programs described in the previous section are the major programs accessed by the user. The following is a discussion of the utility programs that are not accessed by the user, but are called by the major programs. The user has no need to understand these programs, but a discussion is provided for use by program maintenance personnel.

\section{\%anno}

This program computes positional information for the horizontal axis of the unit-values plots, for the purpose of centering the day of the month within the day. The information is stored by the program in a temporary SAS data set named annodat, which is accessed by the GPLOT procedure. 


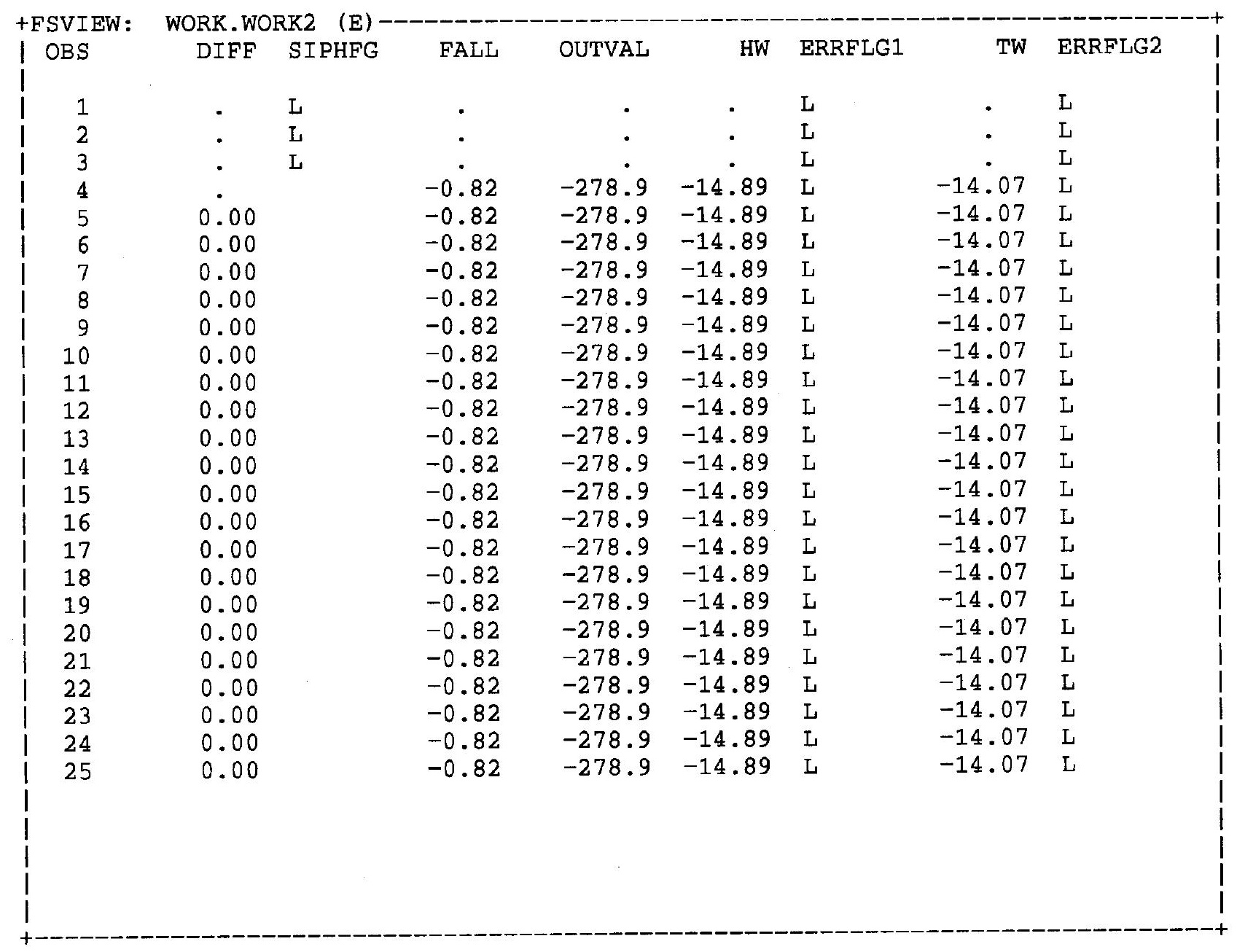

Figure 39. Interactive table of siphon data. (Continued)

\section{\%ratread}

This program reads in rating table data as it is merged into unit-values data, and converts the data to logarithms, if necessary.

\section{\%rtlook}

This program does rating table lookups and sets error flags. 


\section{U. S. GEOLOGICAL SURVEY STREAMFLOW PRIMARY -- PROVISIONAL DATA}

STATION NUMBER=07263450 - ON FLOW

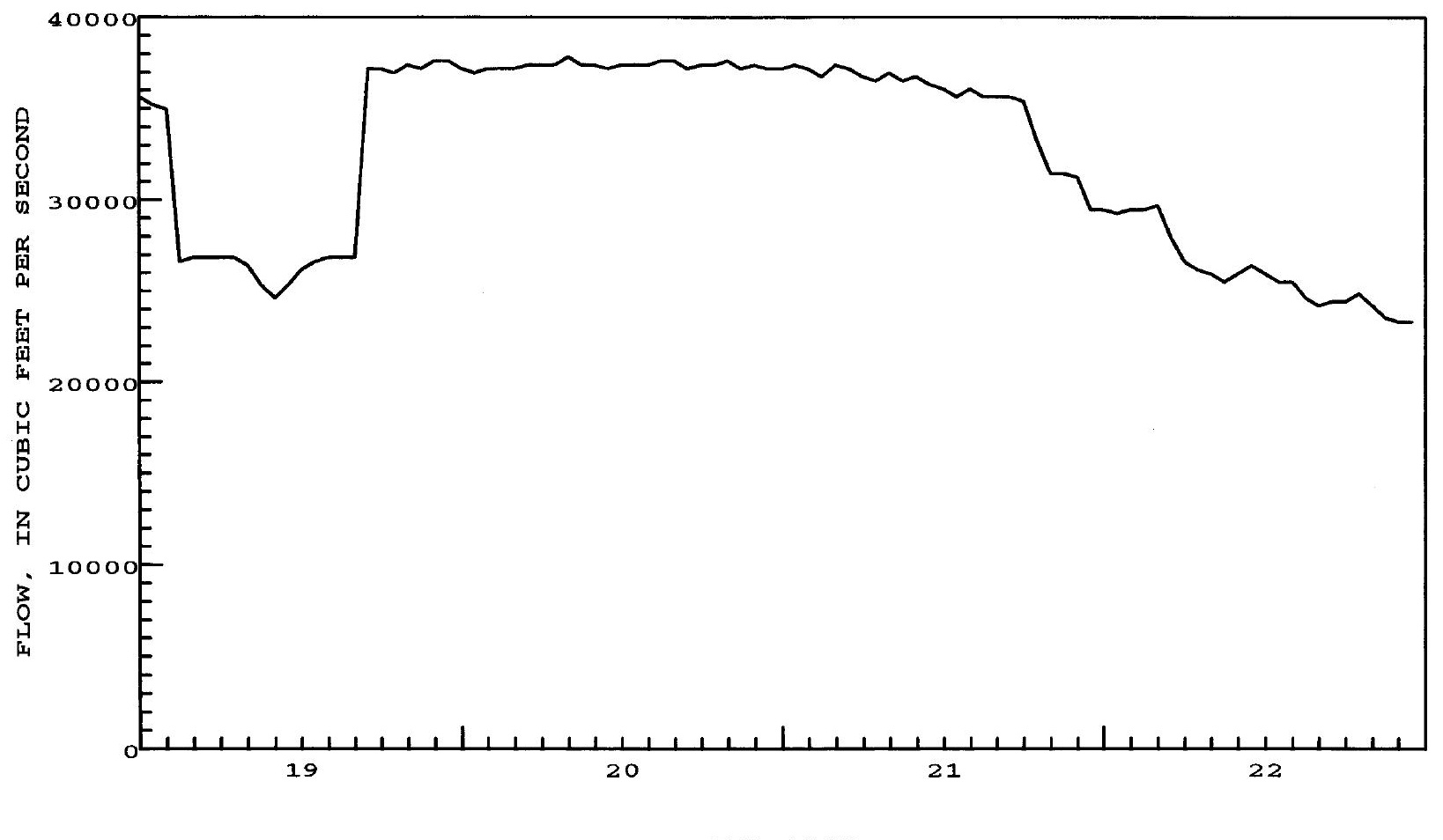

FEB 1997 


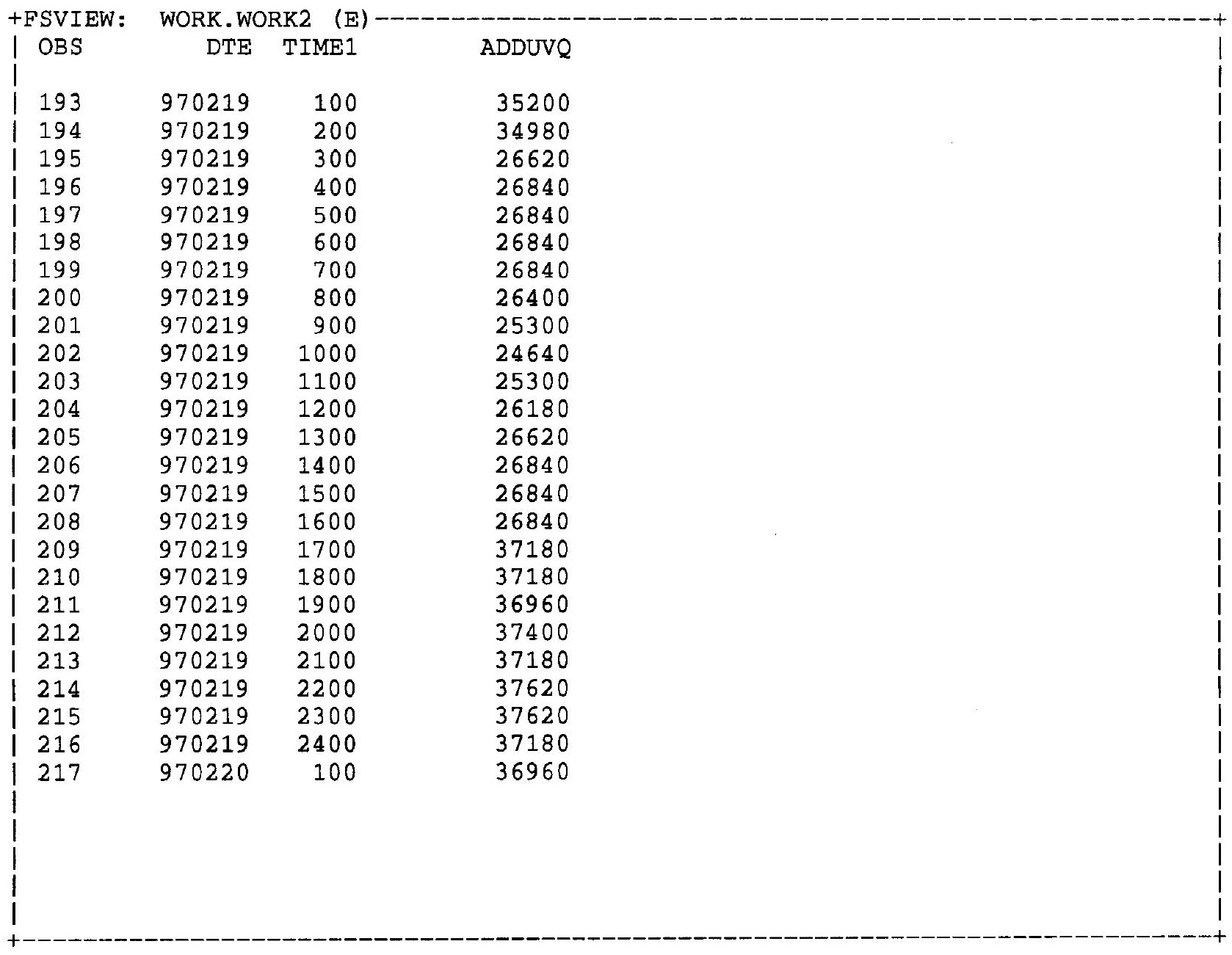

Figure 41. Interactive table of unit-value flow data to add with flows computed by program DAMFLO.2.

\section{\%sethwtw}

The program reverses headwater and tailwater elevations when falls $\left(h_{1}-h_{3}\right)$ are negative, and then restores them as they were. The only argument is "dir." When "dir" equals " $S$ " for "set," it sets $h_{1}$ to $h_{3}, h_{3}$ to $h_{1}$, takes the absolute value of the fall for computations, and sets flows negative. When "dir" is " $R$ " for reset, it restores $h_{1}$ to $h_{1}$, $h_{3}$ to $h_{3}$, and sets the fall negative. This subroutine facilitates the computation of negative flows when fall is negative for selected outlets, such as weirs or gates.

\section{\%uvcd}

This program writes unit-values data in B-card format for input into the ADAPS database. 


\section{U. S. GEOLOGICAL SURVEY STREAMFLOW PRIMARY -- PROVISIONAL DATA}

STATION NUMBER $=07263450$ PLOT $=5$

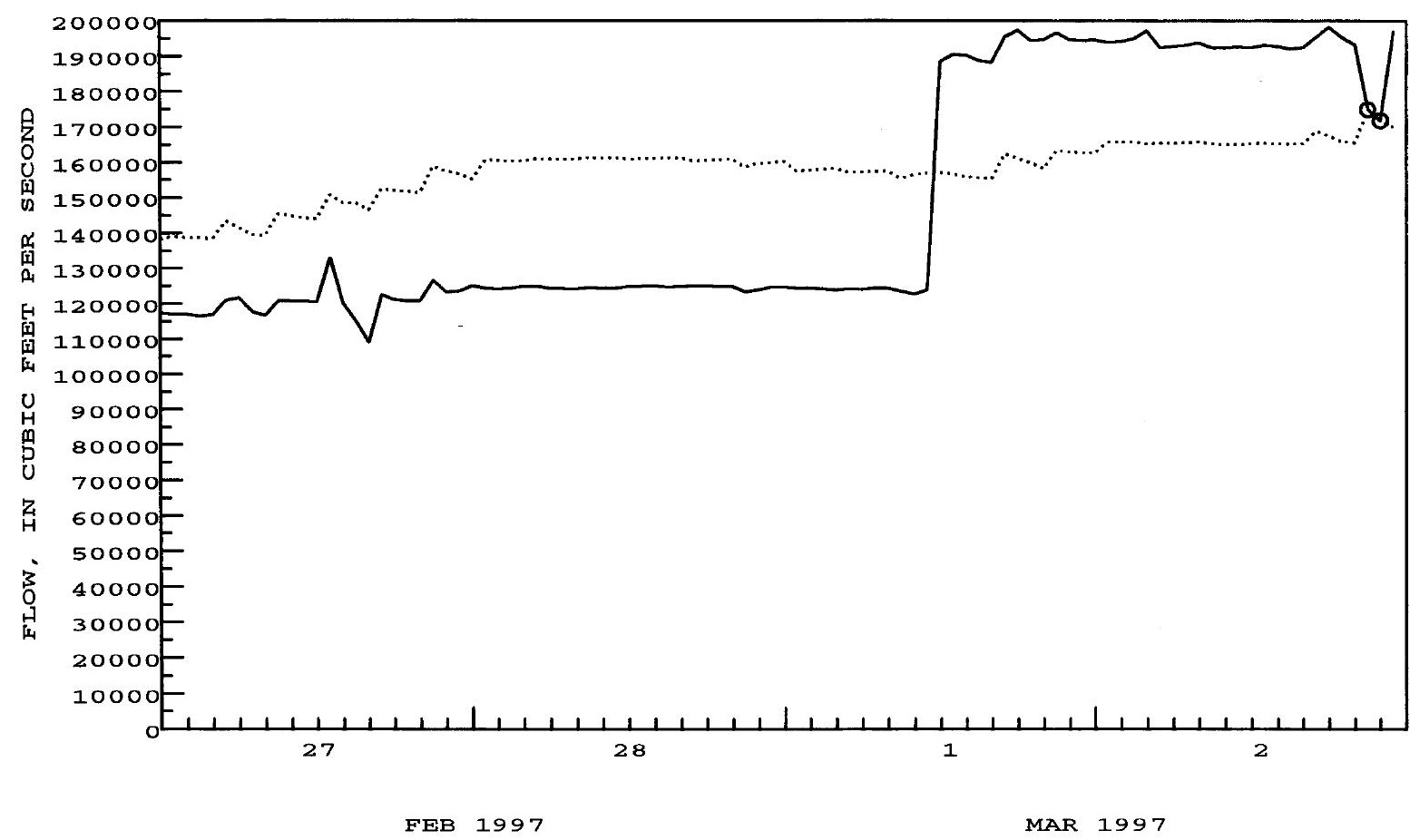




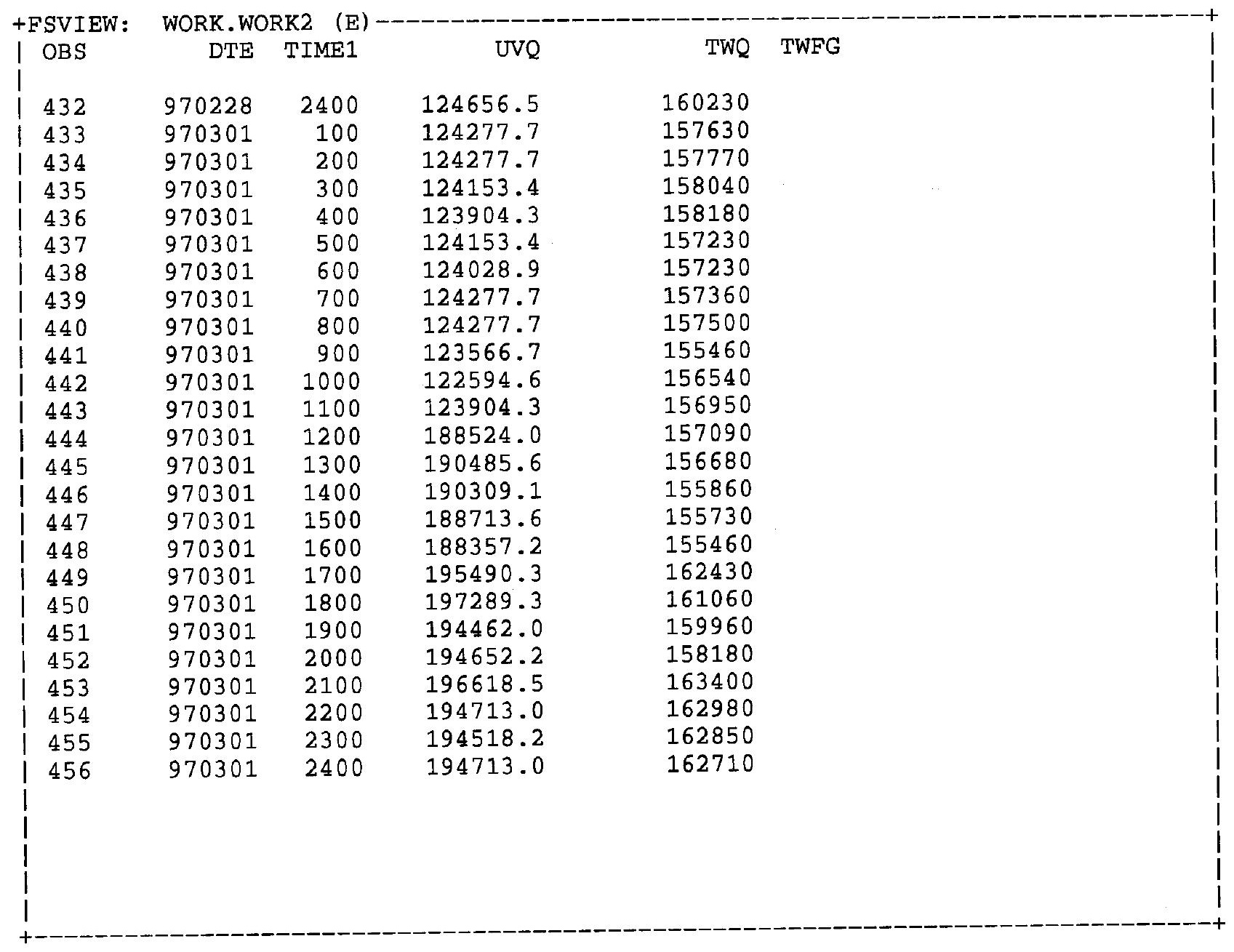

Figure 43. Interactive table of total unit-value flow. 
UNITED STATES DEPARTMENT OF THE INTERIOR - GEOLOGICAL SURVEY

DAMFLOW COMPUTATION USING PROGRAM DAMFLO, DOCUMENTED IN OPEN-FILE REPORT XXXX

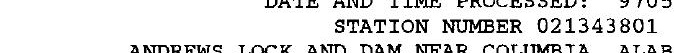

ANDREWS LOCK AND DAM NEAR COLUMBIA, ALABAMA

$\begin{array}{lll} & \\ \text { PROVISIONAL DATA } & \text { DAILY DISCHARGE } & \\ & & \end{array}$

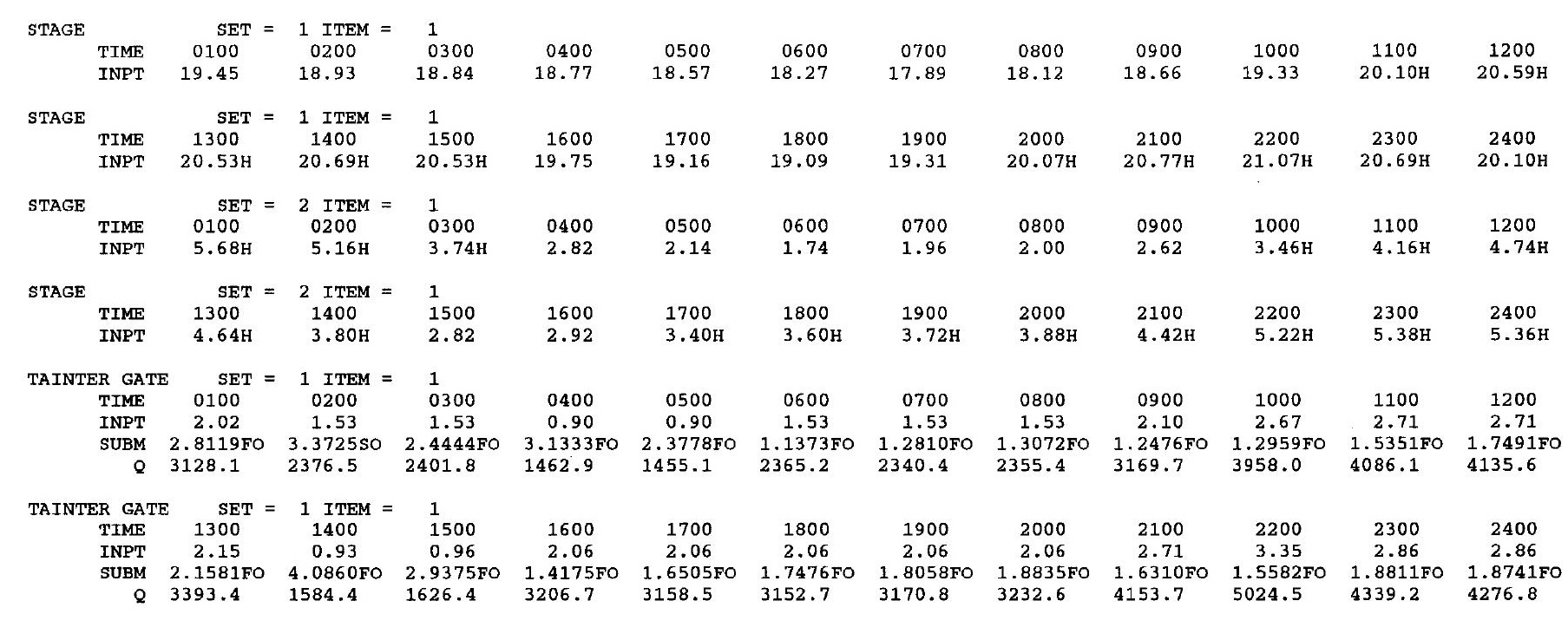

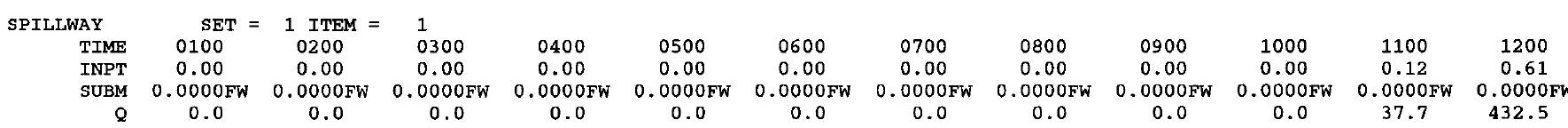

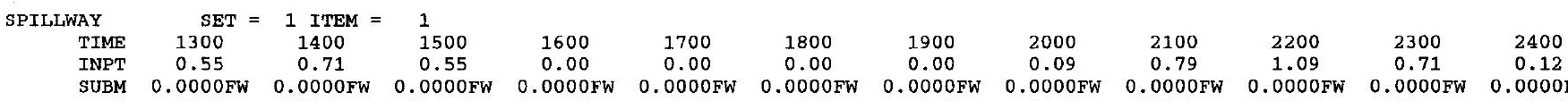

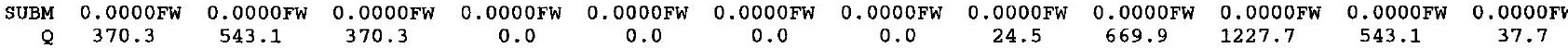

LOCK

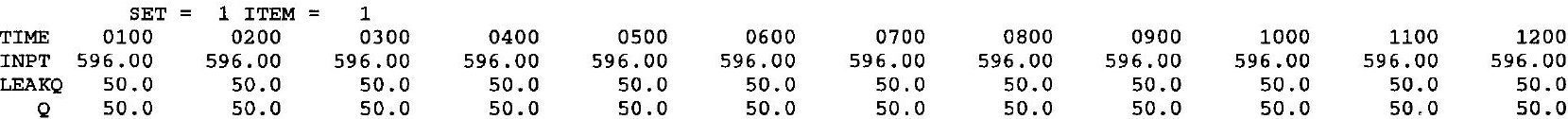

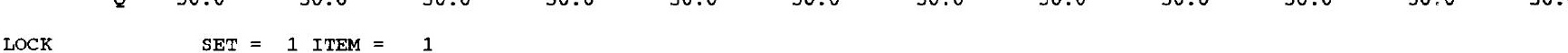

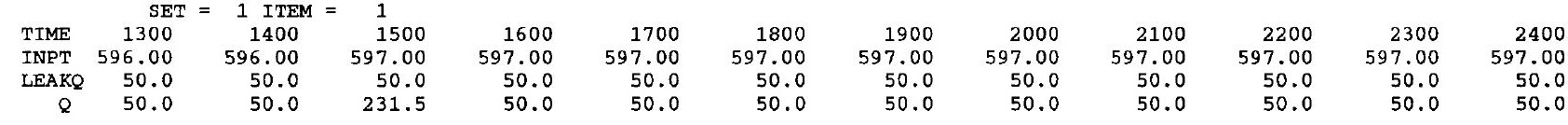

ERROR OR MESSAGE FLAGS:

$L=$ LESS THAN MINIMUM ERROR CHECK

$\begin{aligned} \dot{c}= & \text { MISSING DATA VALUE } \\ \mathrm{C} & =\text { GREATER THAN FIRST DIFFERENCE ERROR CHECK }\end{aligned}$

= TAILWATER-DISCHARGE RATING WAS USED

H = HIGHER THAN MAXIMUM ERROR CHECK

$S=$ SUBMERGED WEIR OR ORIFICE FLOW EXISTS

= RATING TABLE WAS EXCEEDED $\quad W=$ WEIR FLOW EXISTS

Figure 44. Unit-value primary. 
UNTTED STATES DEPARTMENT OF THE INTERIOR - GEOLOGICAL SURVEY

DAMFLOW COMPUTATION USTNG PROGRAM DAMFLO, DOCUMENTED IN OPEN-FILE REPORT XXXX DATE AND TIME PROCESSED: 970515 15:35

STATTON NUMBER 021343801

DAM NEAR COLUMBIA, ALABAMA
SUBJECT TO REVISION

DAILY DISCHARGE
DAME OF OF RECORD:
881025

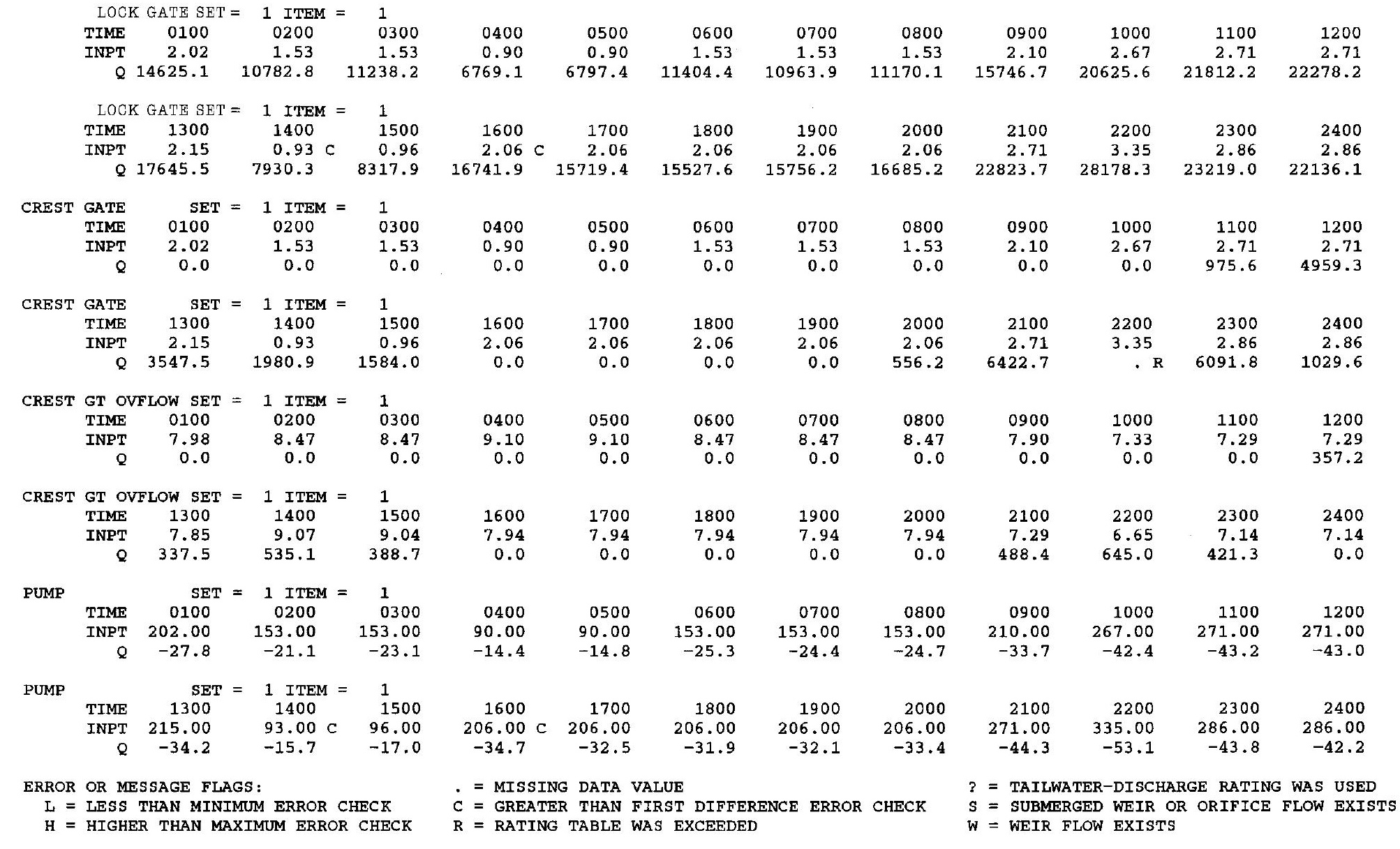

Figure 44. Unit-value primary. (Continued) 
1 UNITED STATES DEPARTMENT OF THE INTERIOR - GEOLOGICAL SURVEY

DAMFLOW COMPUTATION USING PROGRAM DAMFLO, DOCUMENTED IN OPEN-FILE REPORT XXXX DATE AND TIME PROCESSED: 970626 16:55

STATION NUMBER 07263450

ARKANSAS RIVER AT MURRAY DAM NEAR LITTLE ROCK, ARK

PROVISIONAL DATA

$\begin{array}{ccc} & & \\ \text { DATE } & \text { MIN } & \begin{array}{l}\text { TIME } \\ \text { MIN }\end{array} \\ 970211 & 24883 & 2300 \\ 970212 & 20703 & 1200 \\ 970213 & 23783 & 0100 \\ 970214 & 39016 & 1600 \\ 970215 & 35003 & 2300 \\ 970216 & 24883 & 2100 \\ 970217 & 16303 & 1300 \\ 970218 & 16743 & 0100 \\ 970219 & 24663 & 1000 \\ 970220 & 37202 & 2300 \\ 970221 & 37422 & 0400 \\ 970222 & 89738 & 0300 \\ 970223 & 118659 & 2200 \\ 970224 & 113358 & 1700 \\ 970225 & 104485 & 1300 \\ 970226 & 114040 & 1500 \\ 970227 & 108968 & 1600 \\ 970228 & 123279 & 2100 \\ 970301 & 122595 & 1000 \\ 970302 & 171870 & 2200 \\ 970303 & 177070 & 0400 \\ 970304 & 175230 & 0900\end{array}$

SUBJECT TO REVISION

DAILY DISCHARGE SUMMARY
MIN- RAT- TWQ

MAX DIFF ING FLG
MEAN COUNT ERRS ERRS ERRS CNT

MAX MAX MEAN COUNT

$\begin{array}{rlr}39929 & 1300 & 35457 \\ 25103 & 0200 & 22550 \\ 57495 & 0700 & 32992 \\ 39682 & 2100 & 39360 \\ 39684 & 0200 & 38029 \\ 35443 & 0200 & 29150 \\ 24883 & 0100 & 18471 \\ 35663 & 1800 & 27866 \\ 39191 & 2100 & 30800 \\ 39880 & 0800 & 38550 \\ 93655 & 2200 & 60341 \\ 127956 & 0000 & 110556 \\ 127808 & 0300 & 122760 \\ 121421 & 0200 & 118118 \\ 123196 & 1600 & 113008 \\ 118170 & 1900 & 115256 \\ 133053 & 1300 & 120155 \\ 125050 & 1700 & 124564 \\ 197289 & 1800 & 159885 \\ 198195 & 1800 & 191130 \\ 184300 & 1300 & 182523 \\ 193902 & 1500 & 184106\end{array}$

$\begin{array}{rr}23 & 0 \\ 24 & 0 \\ 24 & 0 \\ 24 & 0 \\ 24 & 0 \\ 24 & 0 \\ 24 & 0 \\ 24 & 0 \\ 24 & 0 \\ 24 & 0 \\ 24 & 8 \\ 24 & 12 \\ 24 & 8 \\ 24 & 0 \\ 24 & 0 \\ 24 & 0 \\ 24 & 0 \\ 24 & 0 \\ 24 & 0 \\ 24 & 0 \\ 24 & 0 \\ 24 & 0\end{array}$

$\begin{array}{rrr}0 & 0 & 0 \\ 0 & 0 & 0 \\ 3 & 0 & 0 \\ 0 & 0 & 0 \\ 0 & 0 & 0 \\ 0 & 0 & 0 \\ 0 & 0 & 0 \\ 0 & 0 & 0 \\ 0 & 0 & 0 \\ 0 & 0 & 0 \\ 0 & 0 & 0 \\ 0 & 0 & 0 \\ 0 & 0 & 0 \\ 0 & 0 & 0 \\ 0 & 0 & 0 \\ 0 & 0 & 0 \\ 0 & 0 & 0 \\ 0 & 0 & 0 \\ 0 & 0 & 0 \\ 0 & 44 & 2 \\ 0 & 56 & 24 \\ 0 & 336 & 12\end{array}$

Figure 45. Daily-value primary. 
U. S. GEOLOGICAL SURVEY STREAMFLOW PRIMARY -- PROVISIONAL DATA

STATION NUMBER=07263450 YEAR=1997 MONTH=2

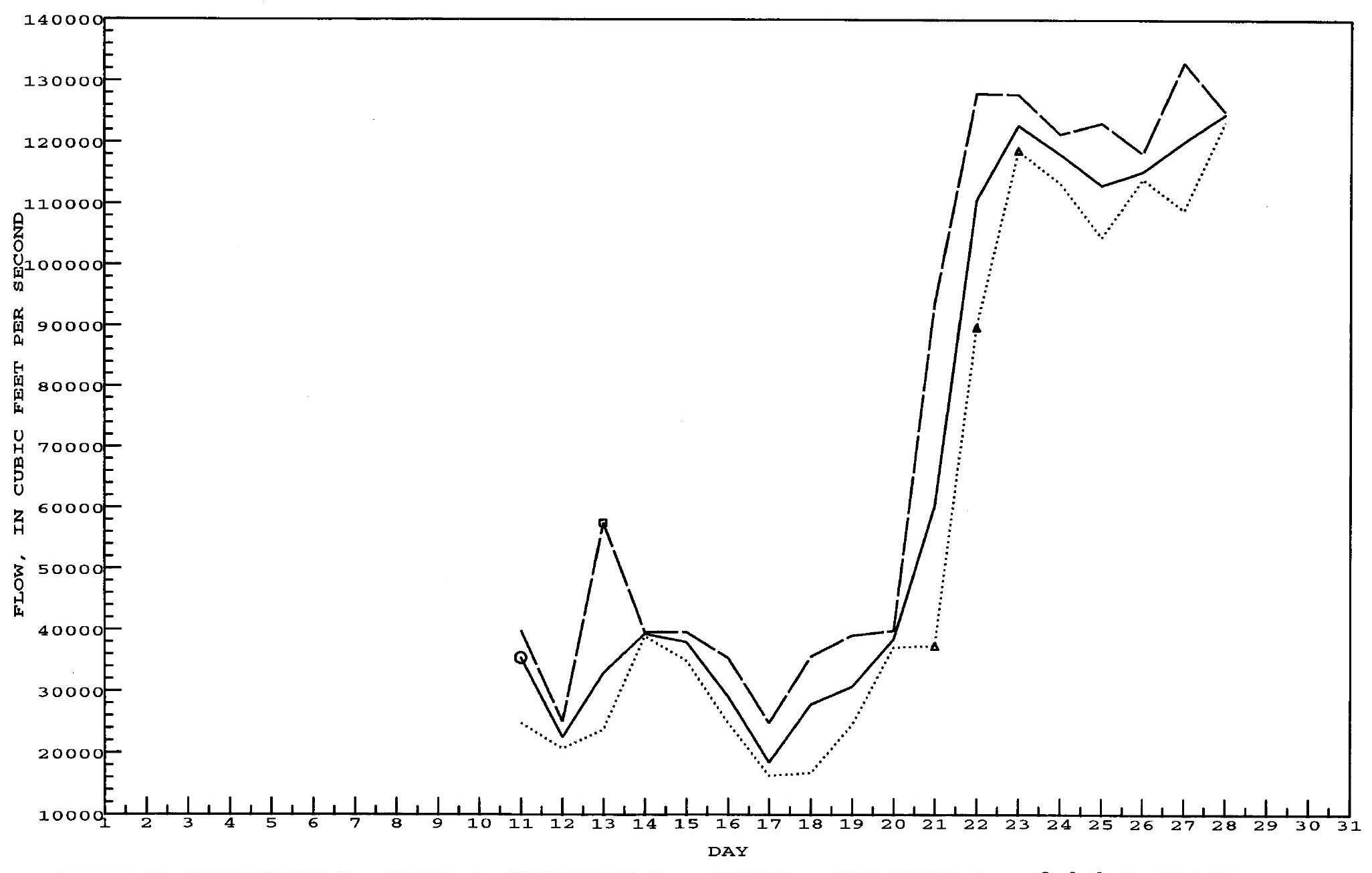

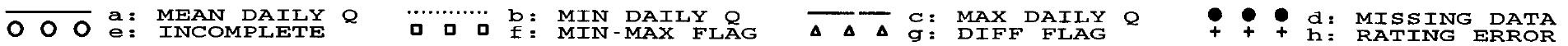

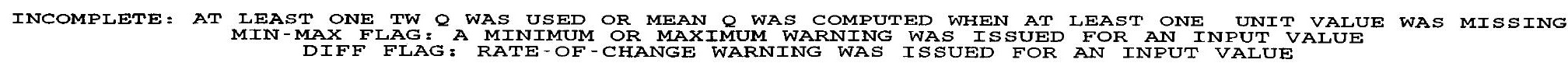

Figure 46. Plot of daily-value flows. 


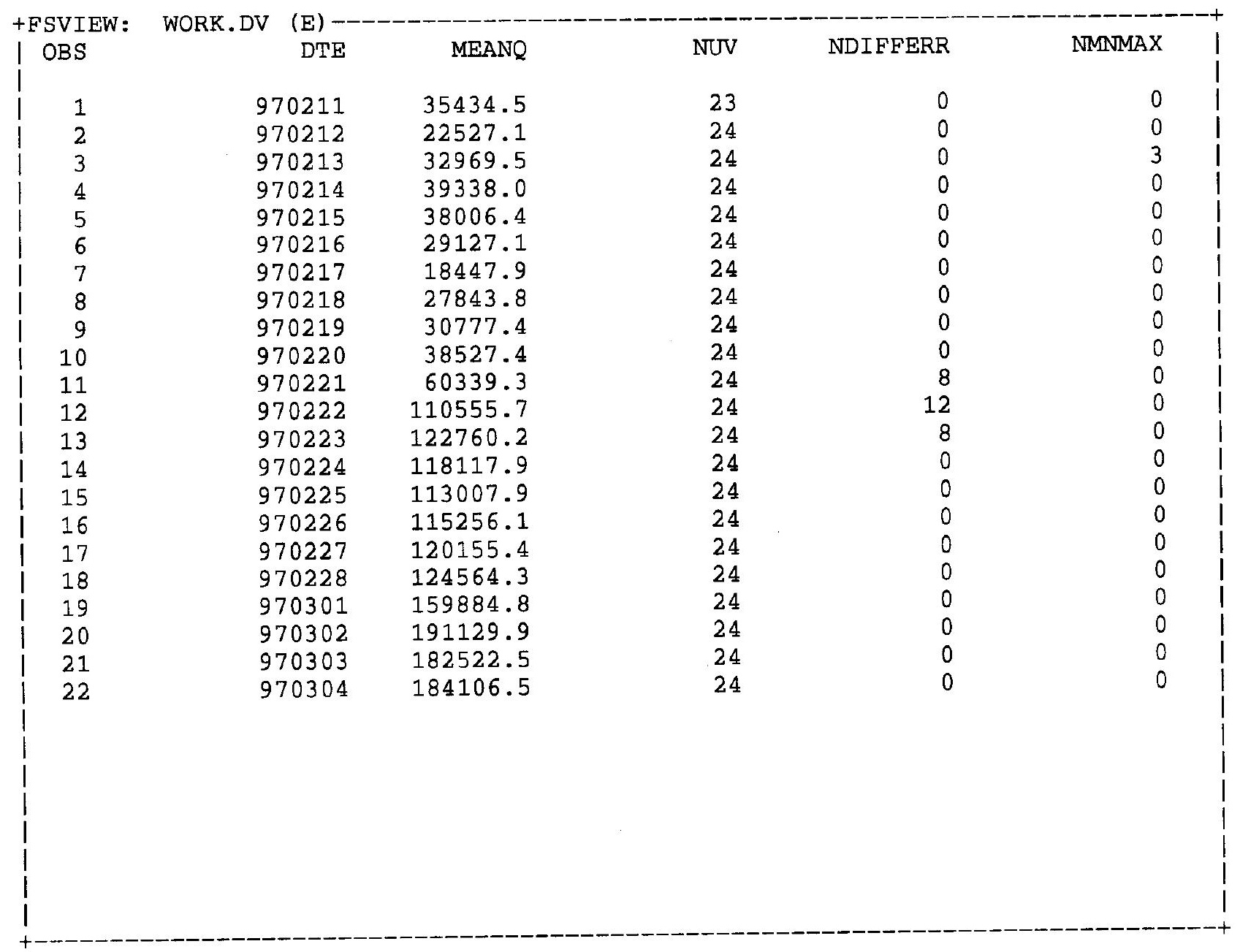

Figure 47. Interactive table of daily-value flows. 


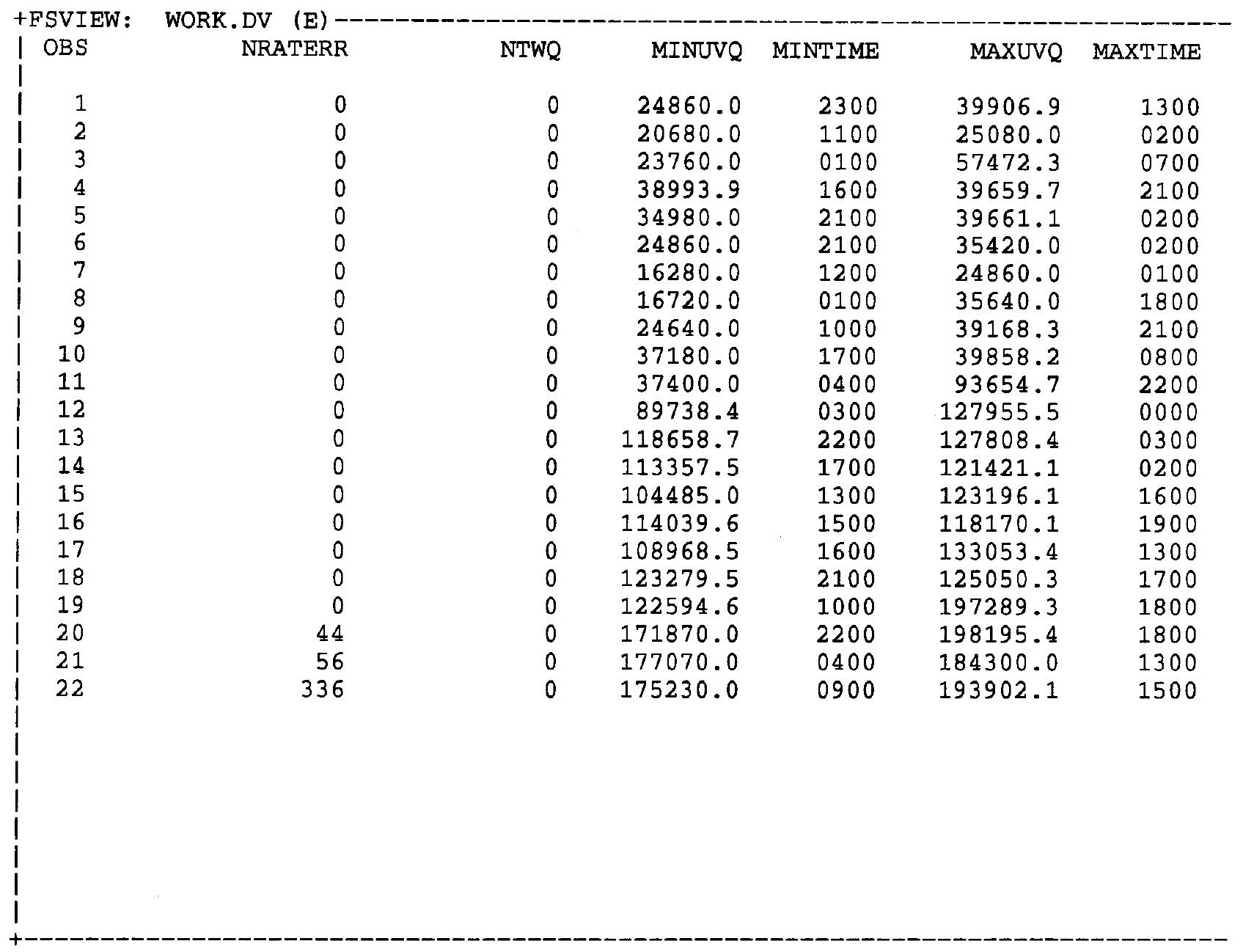

Figure 47. Interactive table of daily-value flows. (Continued) 
U. S. GEOLOGICAL SURVEY STREAMFLOW PRIMARY -- PROVISIONAL DATA

TAILWATER GAGE HEIGHT VERSUS TOTAL UNIT-VALUES FLOW FROM DAM

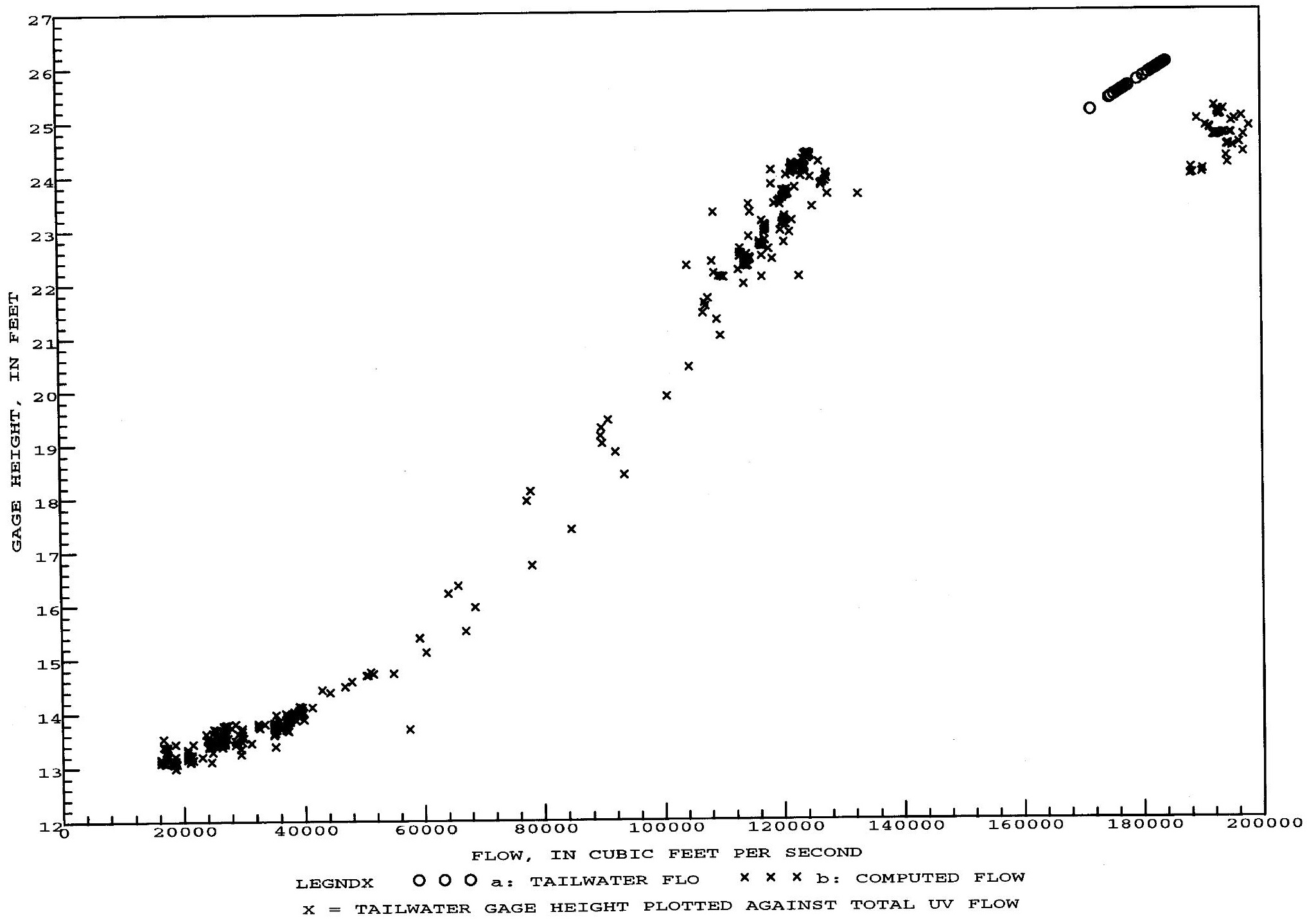


U. S. GEOLOGICAL SURVEY STREAMFLOW PRIMARY - - PROVISIONAL DATA

TAILWATER GAGE HEIGHT VERSUS TOTAL UNITT - VALUES FLOW FROM DAM
STATION NUMBER $=07263450$ YEAR $=1997$ MONTH $=2$ DAY $=21$

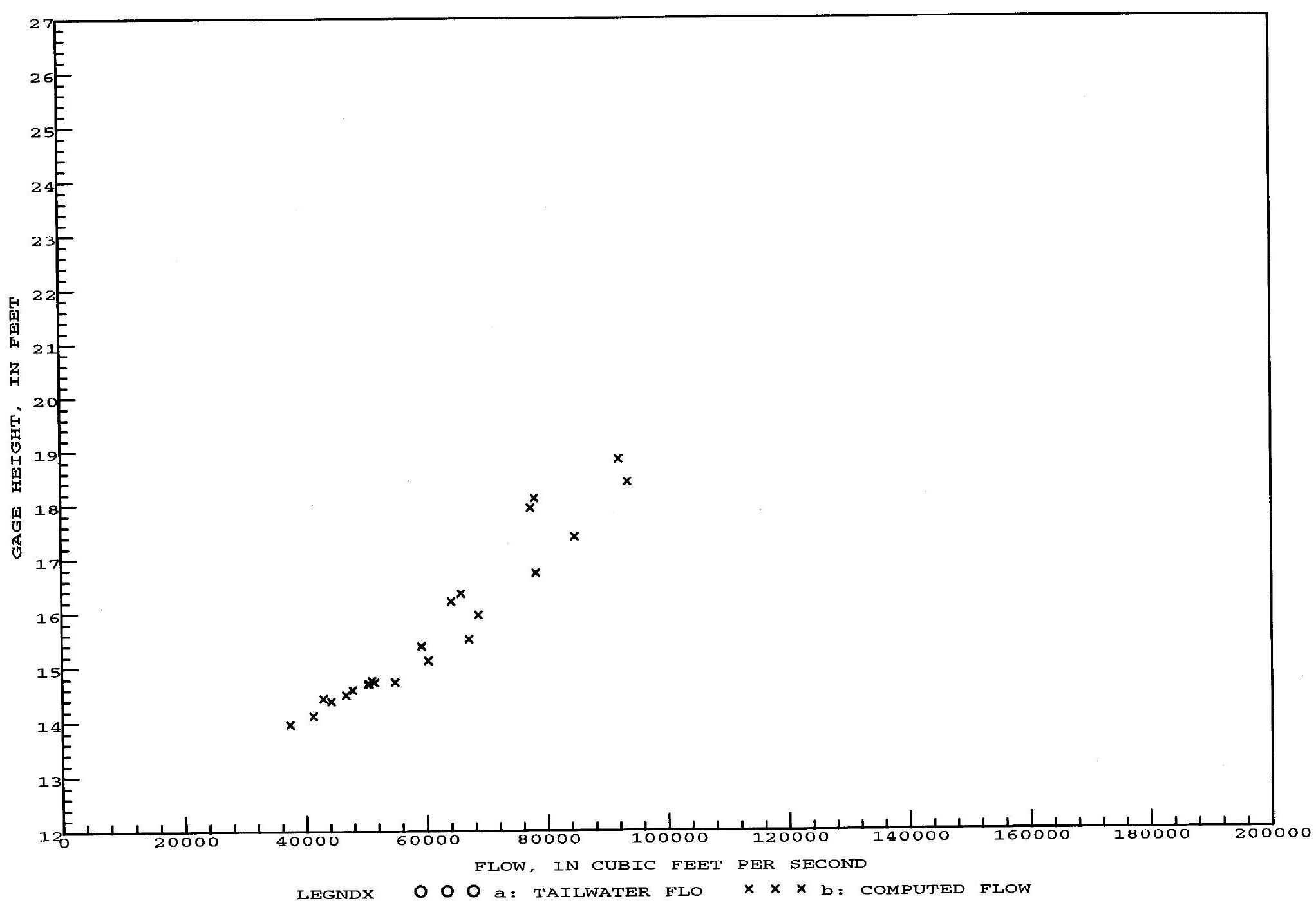

$x=$ TAILWATER GAGE HEIGHT PLOTTED AGAINST TOTAL UV FLOW 


\section{SUMMARY}

The program DAMFLO.2 computes, tabulates, and plots flow through dam structures using data describing the physical properties of the dams and various hydraulic parameters and ratings. The program also uses ASCII (flat) files of time-varying data, such as lake elevation or gate openings, retrieved from the U.S. Geological Survey Automated Data Processing System database. Time-varying flow data computed by the DAMFLO.2 program is output in flat files in a format suitable for entry into the Automatic Data Processing System database. The DAMFLO.2 program was created using procedures and language developed by the SAS Institute Inc. The SAS software is used to utilize its integrated plotting, interactive tabling, data entry by forms, and various statistical, date-time, and data-handling programs.

\section{REFERENCES}

Chow, V.T., 1959, Open-channel hydraulics: New York, McGraw-Hill, p. 412-414.

Collins, D.L., 1977, Computation of records at control structures: U.S. Geological Survey Water-Resources Investigations Report 77-8, $57 \mathrm{p}$.

Hulsing, H., 1967, Measurement of peak discharge at dams by indirect methods: U.S. Geological Survey Techniques of WaterResources Investigations, book 3, chap. A5, 29 p.

Kennedy, E.J., 1984, Discharge ratings at gaging stations: U.S. Geological Survey Techniques of Water-Resources Investigations, book 3, chap. A10, 59 p.

King, H.W., and Prater, E.F., 1963, Handbook for hydraulics for the solution of hydrostatic and fluid-flow problems: New York, McGraw-Hill, sect. 4, p. 3.

Merritt, F.S., 1983, Standard handbook for civil engineers: New York, McGraw-Hill, p. 21-30.

SAS Institute Inc., 1993, SAS language and procedures (1st ed.): SAS Institute Inc., Introduction, Version 6, 124 p.

Stuthman, N.G. and Sanders, C.L., Jr., 1982, Instructions for processing digital stream flow data collected at dams (Program E466): U.S. Geological Survey WATSTORE User's Guide, v. 5, chap. 2, 45 p. 


\section{APPENDIX 1. VELOCITY-FALL METHOD FOR COMPUTING SUBMERGED-WEIR FLOW}

A method (velocity-fall method), also referred to as flow classification method number 2 (see table 1, eq. 9) for computing submerged-weir flow using velocity and fall, was developed by the principal author and Ellie C. Price of the USGS in Miami, Florida, using flow data from dams in south Florida and synthetic data from a stepbackwater model. A rating table is not needed. In the velocity-fall method, velocity $/(2 \mathrm{~g})^{0.5}$ is related to the square root of the fall and the cross-product of the square root of $h_{3}$ and the square root of fall, based on the following derivations. If the difference between the velocity head at the approach and the friction loss between section 1 (headwater) and section 3 (tailwater) can be ignored, and the weir resembles a bridge contraction, the flow can be computed by using the following equation:

$$
Q=A_{3} V_{3 \square}=C A_{3} \sqrt{2 g\left(h_{1 \sqsubset} h_{3}\right)},
$$

where

$Q \quad$ is flow, in cubic feet per second;

$A_{3}$ is the area at $\mathrm{h}_{3}$, in square feet;

$V_{3}$ is the velocity at $\mathrm{h}_{3}$, in feet per second;

$C$ is a contraction coefficient, dimensionless;

$g$ is the acceleration of gravity, in feet per second squared;

$h_{1}$ is the static headwater elevation, referenced to the gate sill, in feet; and

$h_{3}$ is the static tailwater elevation, referenced to the gate sill, in feet.

Rearrangement of equation A1-1 gives the following equation:

$$
\frac{V_{3}}{\sqrt{2 g} \square}=C \sqrt{h_{1 \sqsubset} h_{3}} .
$$

The contraction coefficient for subcritical flow in box culverts and bridges (C) usually ranges from 0.82 to 0.98 . If the coefficient $\mathrm{C}$ is assumed to be the regression constant, then a regression line based on equation A1-2, where the left side of the equation is the response variable and the right side of the equation is the explanatory variable, should be fairly close to a 1:1 line and pass through the origin. Inferences can be made about the energy head and losses, and whether or not measured data are valid by comparing the measured data with the 1:1 line. Whether or not the difference between the velocity head in the approach and the friction loss between $h_{1}$ and $h_{3}$ can be neglected, the relation can be defined by a regression equation:

$$
V_{h 3}=J \sqrt{h_{1} \sqsubset h_{3}}+K \sqrt{h_{3}} \sqrt{h_{1 \sqsubset} h_{3}},
$$

where

$V_{h 3}$ is the velocity at $\mathrm{h}_{3}$ divided by $(2 \mathrm{~g})^{0.5}$, in feet ${ }^{0.5}$;

$J$ is a regression coefficient, dimensionless; and

$K$ is a regression coefficient, dimensionless.

The regression has an intercept of zero. The product of the square roots of $h_{3}$ and $h_{1}-h_{3}$ results in a series of tailwater curves with spacing determined by the square root of $h_{3}$, and where all the curves pass through the origin. Equation A1-4 is obtained by multiplying $\mathrm{V}_{\mathrm{h} 3}$ in equation $\mathrm{A} 1-3$ by $(2 \mathrm{~g})^{0.5}, \mathrm{~h}_{3}$, and $\mathrm{B}$.

$$
Q=\sqrt{2 g} h_{3 \square} B\left(J \sqrt{h_{1 \sqsubset} h_{3}}+K \sqrt{h_{3 \square}} \sqrt{h_{1 \sqsubset} h_{3}}\right) .
$$


The velocity-fall method was verified by a theoretical experiment by the principal author using a stepbackwater model, measured flow data, and approximate cross-sectional data at station 02282700, Middle River Canal at S-36, near Fort Lauderdale, Florida. The step-backwater model was used because a wide variety of flows and stage conditions could be generated for use in testing the theory of this method.

The weir at S-36 is formed when a Tainter gate is pulled clear of the water. The width and length of the weir are both $25 \mathrm{ft}$. The upstream gage is about $130 \mathrm{ft}$ upstream of the weir. Roughness coefficients of 0.04 and 0.017 were used for the canal and the concrete weir, respectively. Canal cross sections were estimated for the test. The model was roughly calibrated using six flow measurements for which the fall in water surface between upstream and downstream gages ranged from 0.06 to $0.11 \mathrm{ft}$. The model was roughly calibrated within $0.03 \mathrm{ft}$ of the observed falls. More accurate calibration was not warranted because measured cross sections were not available for use in the model, and rough calibration was sufficient for theoretical testing.

The step-backwater model was used to simulate headwater elevations for several flows and for tailwater elevations from 4 to $12 \mathrm{ft}$ in 1 -ft increments. These flows were used to compute $\mathrm{V}_{3} /(2 \mathrm{~g})^{0.5}$ and $\left(\mathrm{h}_{1}-\mathrm{h}_{3}\right)^{0.5}$, which were then used in stepwise regression using equation A1-3. Figure A1-1 shows that the use of the product of $\mathrm{Kh}_{3}{ }^{0.5}\left(\mathrm{~h}_{1}-\mathrm{h}_{3}\right)^{0.5}$, of equation A1-3 narrows the distances between the tailwater curves with increasing tailwater elevations. Figure A1-2 compares simulated values with regression curves for tailwater elevations 4-12 ft. The figures graphically demonstrate the validity of equation A1-3, in that the data can be fit by linear regression, that the assumption of a zero intercept is valid, and that the product of $\mathrm{Kh}_{3}{ }^{0.5}\left(\mathrm{~h}_{1}-\mathrm{h}_{3}\right)^{0.5}$ can be used to vary the distance between tailwater curves. The regression had a coefficient of determination of 0.999 and a standard error of $0.12 \mathrm{ft} / \mathrm{s}$.

The submerged-weir flow computation method, documented by Hulsing (1967) was also tested. In Hulsing's method, a submergence coefficient, $\mathrm{C}_{\mathrm{ws}}$ that adjusts the free-weir coefficient, $\mathrm{C}_{\mathrm{w}}$ is related to the submergence ratio $\left(h_{3} / h_{1}\right)$. Data simulated by the step-backwater program verified that this relation was very curvilinear both on arithmetic and logarithmic plots.

If $h_{3}$ does not change much or the difference between the approach-section velocity head and friction loss between $h_{1}$ and $h_{3}$ can be neglected, then the regression coefficient " $K$ " can be assumed to be zero, and the coefficient "J" can be determined by regression or graphically on arithmetic paper. Once again, the velocity-fall method is useful when fall across the weir goes to zero, because the relation goes to zero as the fall goes to zero. 


\section{VELOCITY-FALL METHOD FOR S-36 CANAL}

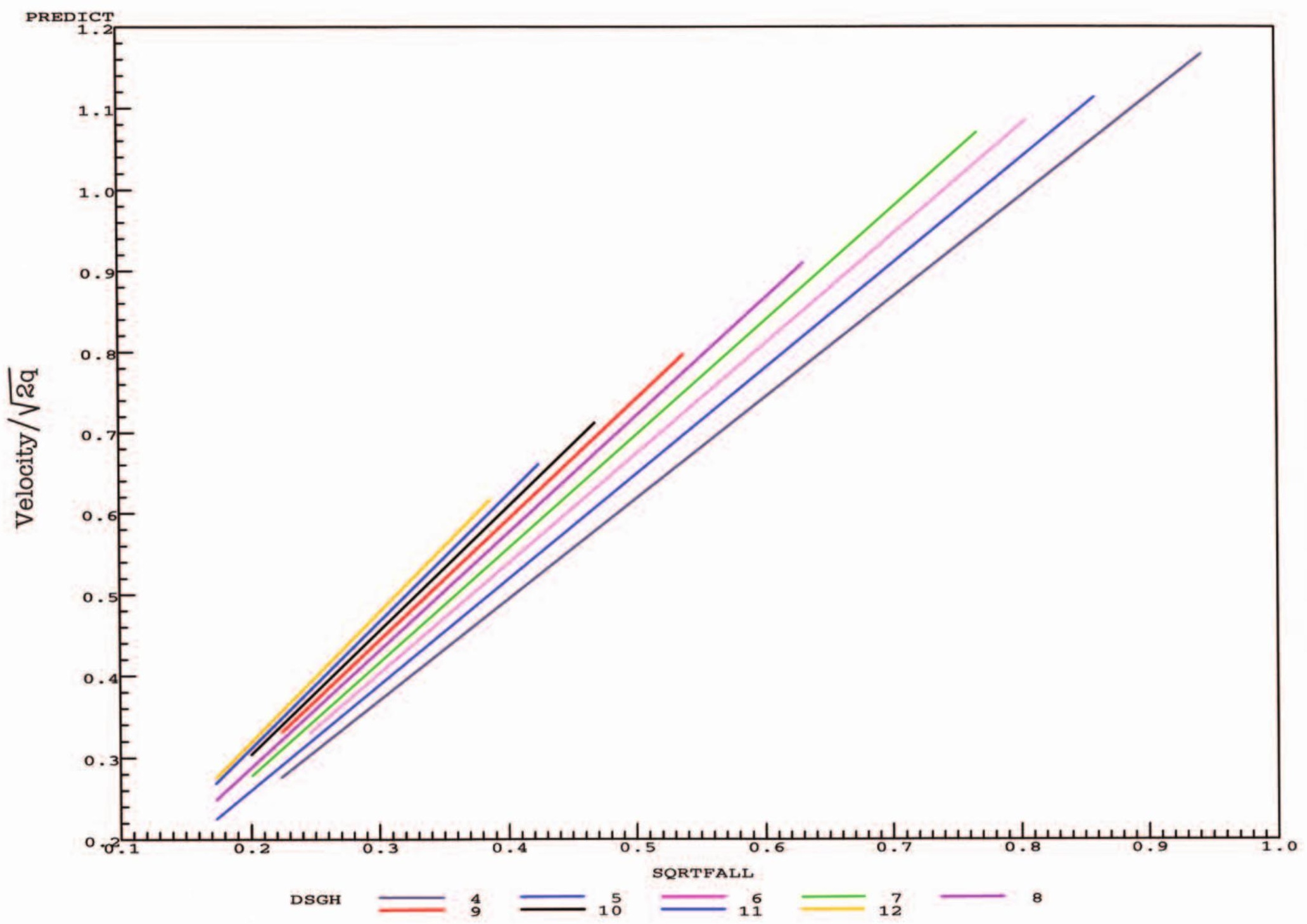

Figure A1-1. Relation of velocity/(2g) $)^{0.5}$ to square root of fall and tailwater elevations, showing convergence of regression lines achieved by cross-product of square roots of tailwater elevation and fall. 

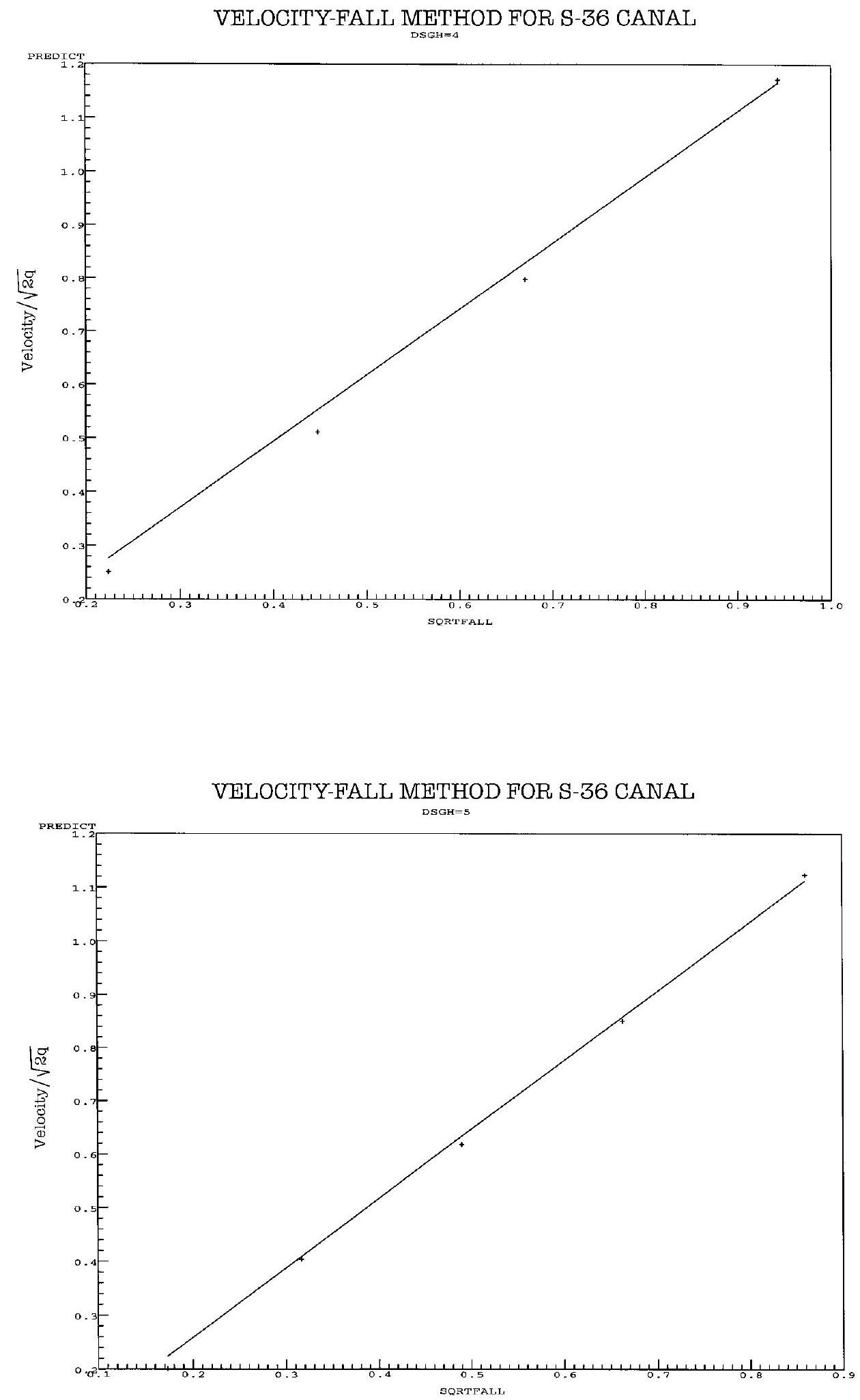

Figure A1-2. Graph of relation of velocity/(2g) ${ }^{0.5}$ to square root of fall and tailwater for elevations of 4 to 12 feet. 

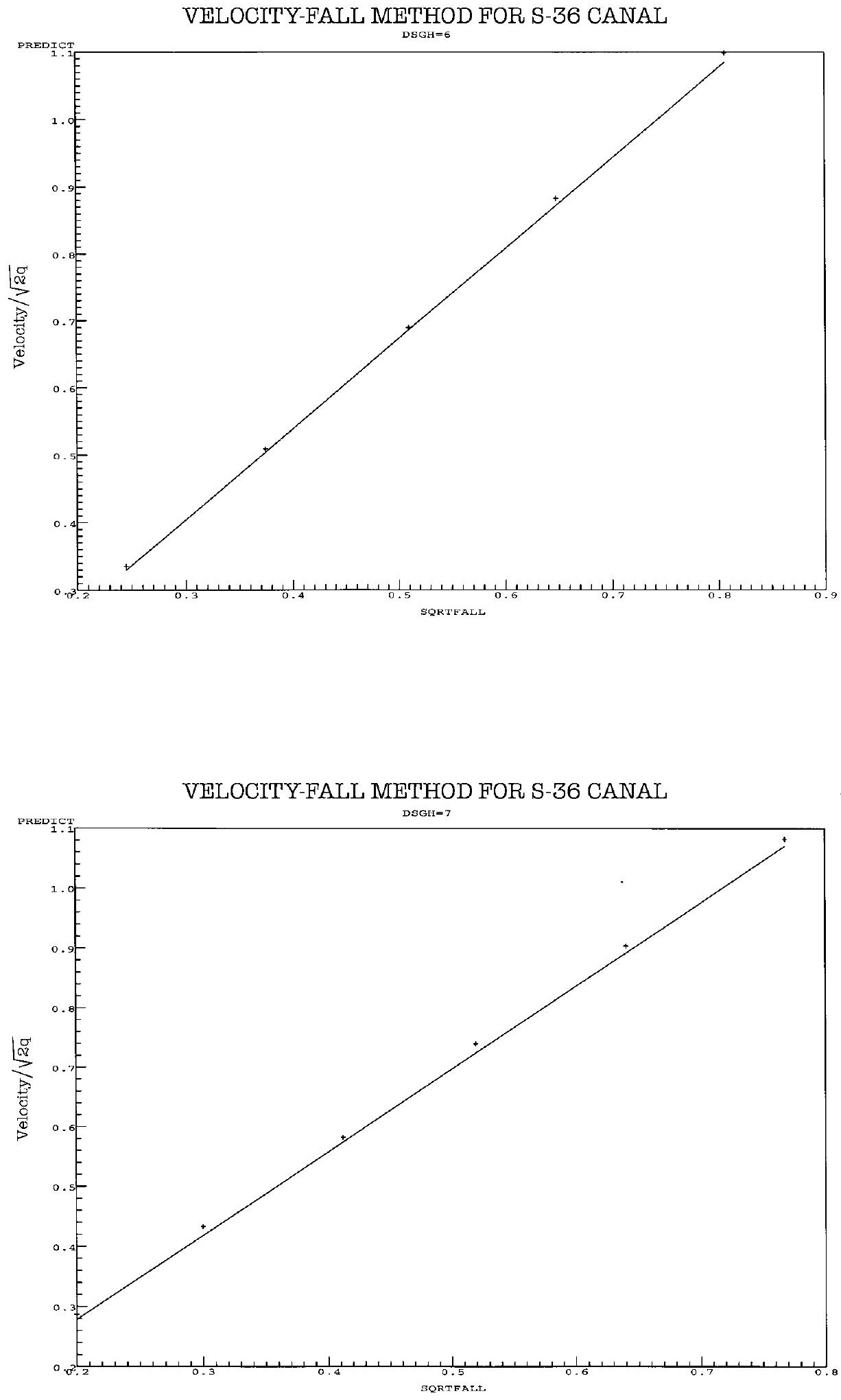

Figure A1-2. Graph of relation of velocity/(2g) ${ }^{0.5}$ to square root of fall and tailwater for elevations of 4 to 12 feet. (Continued) 

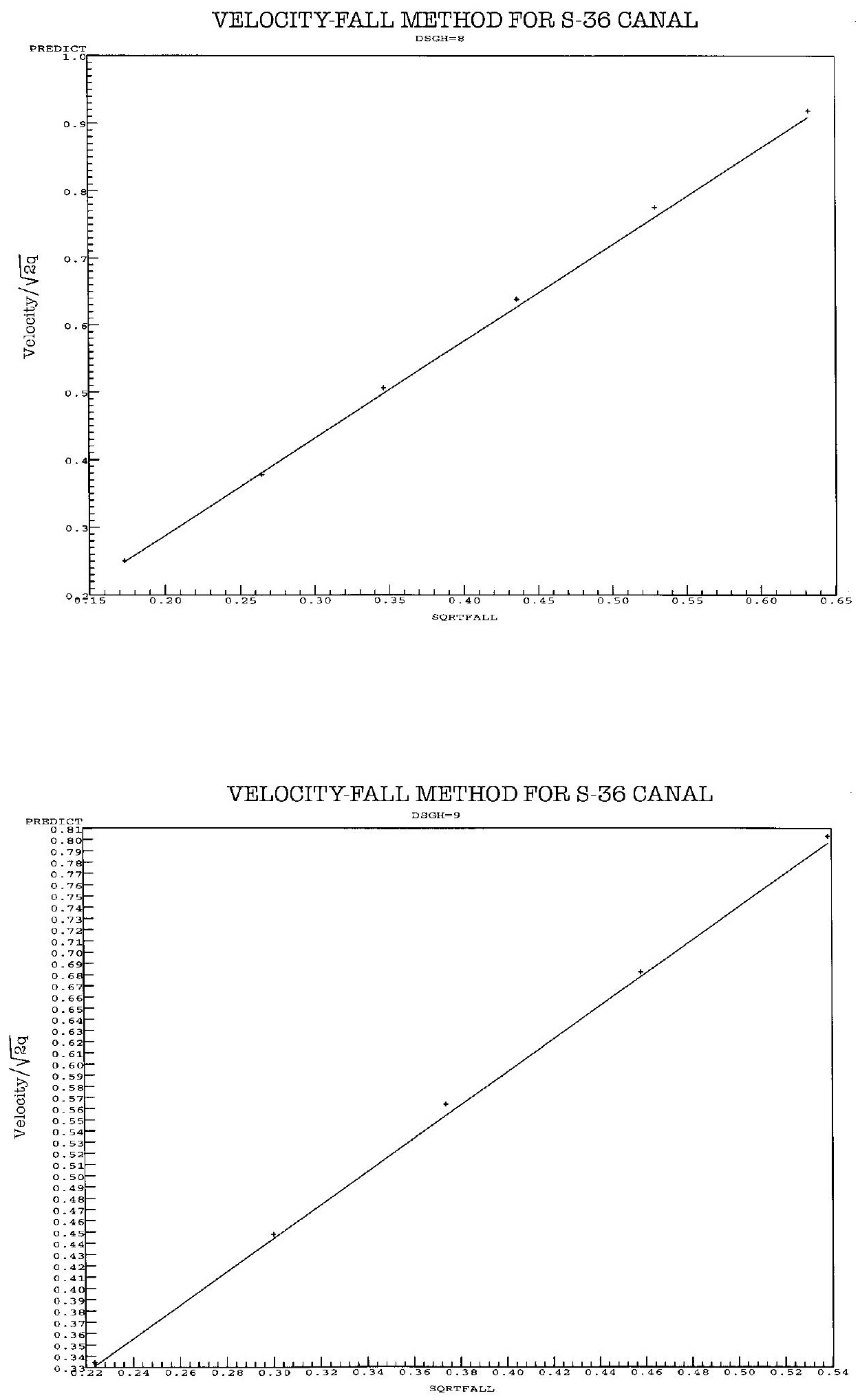

Figure A1-2. Graph of relation of velocity/(2g) ${ }^{0.5}$ to square root of fall and tailwater for elevations of 4 to 12 feet. (Continued) 

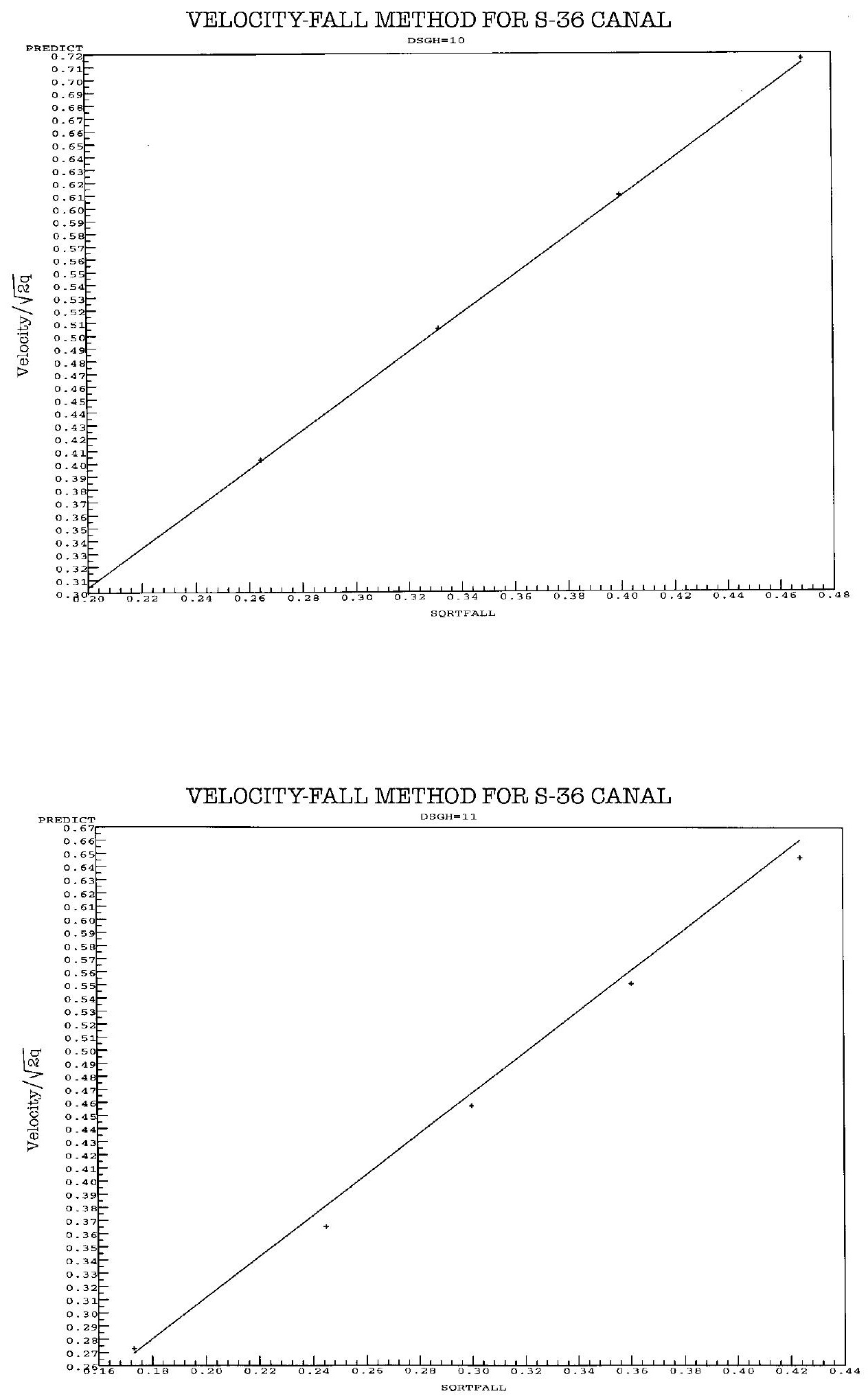

Figure A1-2. Graph of relation of velocity/(2g) ${ }^{0.5}$ to square root of fall and tailwater for elevations of 4 to 12 feet. (Continued) 


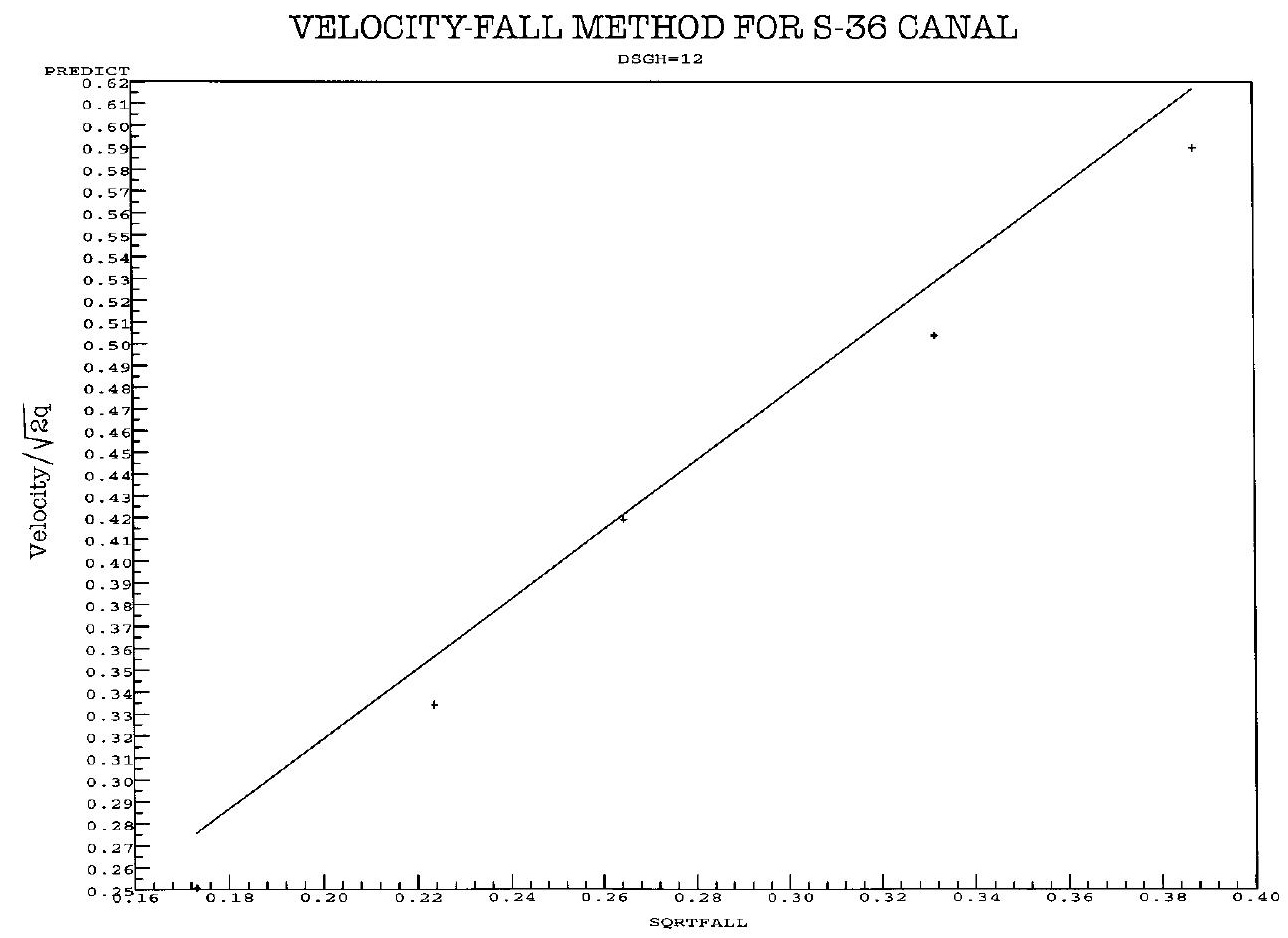

Figure A1-2. Graph of relation of velocity/(2g) ${ }^{0.5}$ to square root of fall and tailwater for elevations of 4 to 12 feet. (Continued) 


\section{APPENDIX 2. COMPUTATION OF VERTICAL OPENINGS AT TAINTER GATES}

As documented by Collins (1977), the following equations can be used to compute vertical gate openings at a Tainter gate using the elevation of a reference point on the gate and the dimensions of the gate (fig. A2-1).

$$
h_{g \sqcup}=R\left(\frac{c-a}{r \square}\right) \cos \square \theta+\square a-R \square \sqrt{1-\left(\frac{c-a}{r \square}\right)^{2}} \square \sin \square \theta,
$$

where

$h_{g}$ is the vertical gate opening, in feet;

$a$ is the elevation difference, trunnion centerline to sill, in feet;

$c$ is the elevation difference, gate reference point to sill, in feet;

$r$ is the radius from trunnion centerline to gate reference point, in feet;

$R \quad$ is the radius from trunnion centerline to upstream face of a Tainter gate, in feet; and

$\theta$ is the included angle between radial lines from the trunnion centerline through the reference point and through the lower lip of the gate, in degrees;

where

$$
\theta=\phi_{L-} \phi_{U,} \text { and }
$$

$\phi_{L} \quad$ is the angle measured from horizontal to the radial line from the trunnion centerline through the lower lip of the gate with the gate in a closed position, $\left(\sin ^{-1} \square\left(\frac{a}{R}\right)\right)$, in degrees; and

$\phi_{U} \quad$ is the angle measured from horizontal to the radial line from the trunnion centerline through the gate reference point with the gate in a closed position, $\left(\sin ^{-1} \square\left(\frac{a-d}{r \square}\right)\right)$, in degrees,

where

$d$ is the elevation difference, gate reference point to sill with the gate in closed position, in feet. 


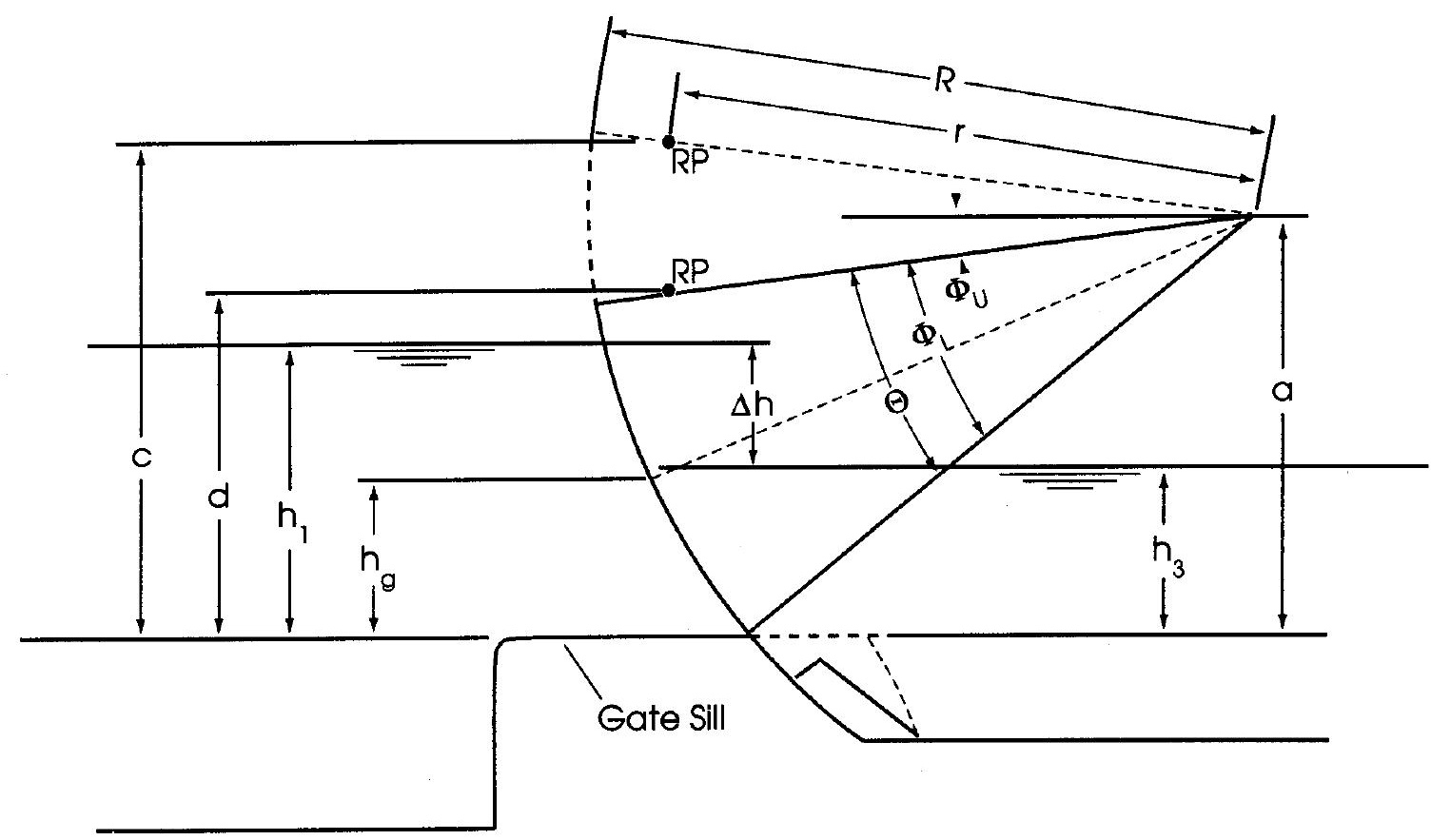
a $=$ Elevation difference, trunnion centerline to sill, in feet
c = Elevation difference, gate reference point (RP) to sill, in feet
d $=$ Elevation difference, gate RP to sill with the gate in a closed position, in feet
$\mathrm{h}_{1}=$ Static headwater referenced to gate sill, in feet
$h_{3}=$ Static tailwater referenced to gate sill, in feet
$\mathrm{h}_{\mathrm{g}} \quad=$ Vertical gate opening, in feet
$r \quad=$ Radius from trunnion centerline to gate RP, in feet
$\mathrm{R}=$ Radius from trunnion centerline to upstream face of a tainter gate, in feet
$\Delta \mathrm{h}=\mathrm{h}_{1}-\mathrm{h}_{3}=$ Static headloss through structure, in feet
$\Theta \quad=$ Included angle between radial lines from the trunnion centerline through the $\mathrm{RP}$ and through the lower lip of the gate, in degrees
$\Phi_{L} \quad=\quad$ The angle measured from horizontal to the radial line from the trunnion centerline through the lower lip of the gate with the gate in closed position, in degrees
$\Phi_{U} \quad=\quad$ The angle measured from horizontal to the radial line from the trunnion centerline through the gate RP with the gate in closed position, in degrees

Figure A2-1. Tainter gate geometry. 


\section{APPENDIX 3. CLASSIFICATION OF FREE- AND SUBMERGED-ORIFICE FLOW BY PROPOSED HYDRAULIC JUMP METHOD}

A method (hydraulic-jump method) is described herewith for distinguishing between free- and submergedorifice flow. Also referred to as flow classification method number 3 in table 1, this method should not be applied without individual site verification using observed flow measurements.

The hydraulic-jump method is based on the idea that a free jet of water flowing through a Tainter gate will be in supercritical flow, which will result in a hydraulic jump downstream (fig. A3-1). If the sequent depth of the hydraulic jump is substantial enough and the jump is too close to the Tainter gate, it may drown out the jet resulting in submerged-orifice flow. The location of the hydraulic jump is a function of the downstream geometry and the jet velocity. Typically, structures are designed so that the hydraulic jump will form near the sill but may actually form closer to the orifice if the jet velocity is too low. The criterion for the flow downstream of the Tainter gate can be expressed in terms of the Froude number $\left(\mathrm{F}_{\mathrm{m}}\right)$ at the vena contracta. A critical value, $\mathrm{F}_{\mathrm{e}}$, as presented by Chow (1959, p. 412-414) can be computed at the vena contracta for the condition where a downstream hydraulic jump will start moving upstream. It is assumed that if the hydraulic jump moves upstream of the vena contracta, then some form of submerged-orifice flow may exist. $\mathrm{F}_{\mathrm{e}}$ is computed using the depth of the water at the vena contracta, the depth of water downstream of the hydraulic jump, and the amount of drop-off in the bottom of the stream in the vicinity of the hydraulic jump. If $F_{m}$ is less than $F_{e}$, then the hydraulic jump will move upstream and some form of submerged-orifice flow should exist otherwise, free-orifice flow should exist.

There can be three types of orifice flow at a gate: (1) free flow where flow at the vena contracta is supercritical, (2) submerged-orifice flow where the water surface downstream of the gate is ponded all the way to the gate, and (3) an indeterminate zone of submerged-orifice flow where the vena contracta downstream of the gate is partially submerged by a hydraulic jump. The hydraulic-jump method would consider flow types 2 and 3 to be submerged-orifice flow.

The Froude number $\mathrm{F}_{\mathrm{m}}$ for free-orifice flow is computed using equation A3-1.

$$
F_{m}=\frac{V_{1}}{\sqrt{g y_{1}}},
$$

where

$V_{1}$ is the velocity at the vena contracta, in feet per second;

$g$ is the acceleration of gravity, in feet per second squared; and

$y_{1}$ is the depth of flow at the vena contracta, in feet.

Velocity, $\mathrm{V}_{1}$, at $\mathrm{y}_{1}$ can be be computed by equation $\mathrm{A} 3-2$.

$$
V_{1}=\frac{Q}{y_{1 \square} B}
$$

where

$Q$ is free-orifice flow, in cubic feet per second;

$y_{1}$ is the depth of water at the vena contracta computed, in feet; and

$B$ is the width of the gate, in feet.

Free-orifice flow, $\mathrm{Q}$, is computed for the gate for use in computing $\mathrm{F}_{\mathrm{m}}$, using equation A3-3. 


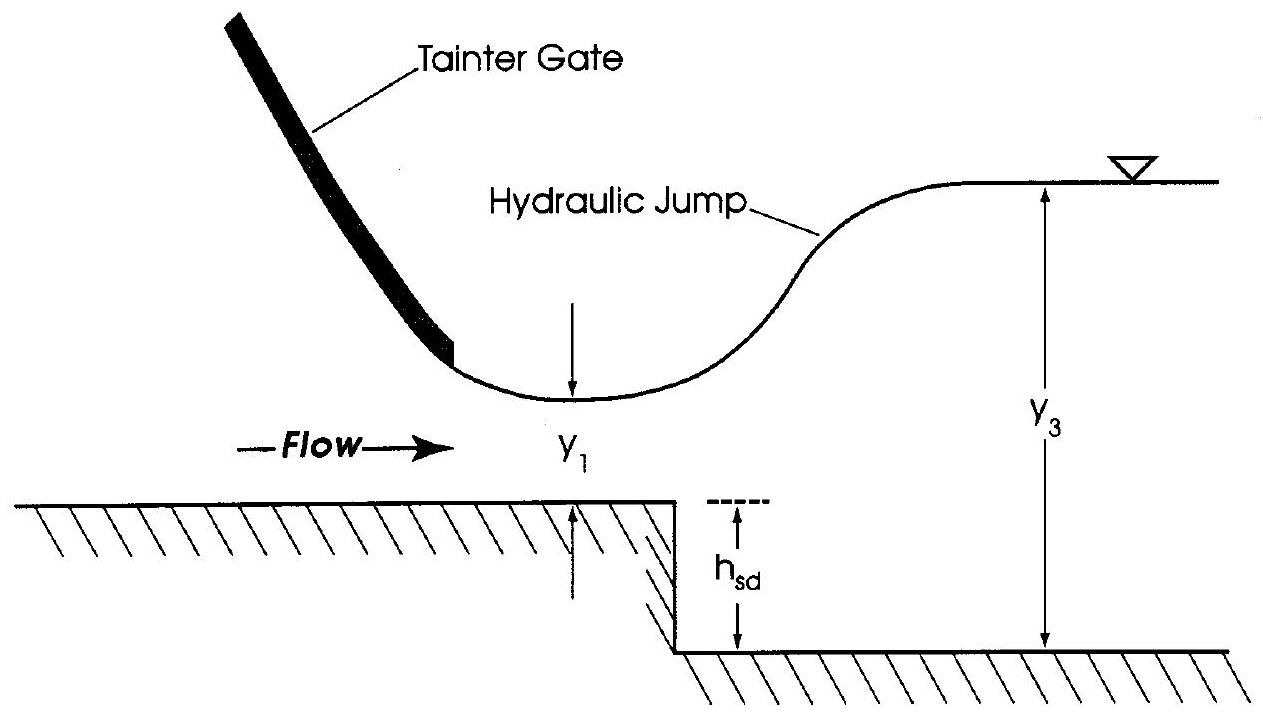

$$
\begin{array}{ll}
y_{1} & =\begin{array}{l}
\text { Depth of water at vena contracta of free-orifice flow downstream } \\
\text { of gate, in feet }
\end{array} \\
y_{3} & =\begin{array}{l}
\text { Depth of water downstream of hydraulic jump downstream of } \\
\text { gate, in feet }
\end{array} \\
h_{s d} & =\begin{array}{l}
\text { Difference between gate sill elevation and streambed elevation } \\
\text { downstream of the sill, in feet }
\end{array}
\end{array}
$$

Figure A3-1. Hydraulic jump downstream of gate.

$$
Q=C h_{g} B \sqrt{2 g h_{1}}
$$

where

\footnotetext{
$C$ is the coefficient of flow, dimensionless;

$h_{g}$ is the vertical gate opening, in feet;

$B$ is the width of the gate, in feet;

$g$ is the acceleration of gravity, in feet per second squared; and

$h_{1}$ is the depth of the water upstream of the gate, in feet.
} 
$\mathrm{y}_{1}$ can be computed by equation A3-4.

$$
y_{1}=C_{c} h_{g \square},
$$

where

$C_{c}$ is the coefficient of contraction from equation A3-5 below, dimensionless.

$\mathrm{C}_{\mathrm{c}}$ can be derived by rearranging equation A3-5 (below) documented by King and Prater (1963), using measured data and assuming that $\mathrm{C}_{\mathrm{v}}$ is 0.95 because of normally ponded conditions in the area upstream of the gates. $\mathrm{C}_{\mathrm{v}}$ is the coefficient of velocity, which should be large because of low energy losses in the zone.

$$
Q=C_{c} C_{v} h_{g} B \sqrt{2 g\left(h_{1 \square}-\frac{h_{g}}{2}\right)},
$$

where

$C_{c}$ is the coefficient of contraction, dimensionless; and

$C_{v}$ is the coefficient of velocity used rather than subtracting energy losses, dimensionless.

A critical value, $\mathrm{F}_{\mathrm{e}}$, can be computed for the section at the vena contracta, with equation A3-6 (below) (Chow, 1959, p. 412-414), at which the hydraulic jump will move upstream from the downstream edge of the sill, and some form of submerged-orifice flow should exist.

where

$$
F_{e}=\sqrt{\frac{\frac{y_{3}}{y_{1}}}{2\left(1-\frac{y_{3}}{y_{1}}\right)}\left[1-\left(\frac{y_{3}}{y_{1}}-\frac{h_{s d}}{y_{1}}\right)^{2}\right]},
$$

$y_{1}$ is the depth of water at the vena contracta of free-orifice flow downstream of the gage, in feet;

$y_{3}$ is the depth of water downstream of the hydraulic jump downstream of the gate, in feet; and

$h_{s d}$ is the difference between gate sill elevation and streambed elevation downstream of the sill, in feet.

According to Chow, equation A3-5 (fig. A3-1) was developed and verified for open channel flow without Tainter gates. The hydraulic-jump method is an attempt to combine use of this equation with equation A3-1 to determine the point at which a hydraulic jump would move upstream of the vena contracta downstream of freeorifice flow and cause some form of submerged-orifice flow.

To test the hydraulic-jump method, $\mathrm{F}_{\mathrm{m}}$ and $\mathrm{F}_{\mathrm{e}}$ should be computed using measured data. If $\mathrm{F}_{\mathrm{m}}$ is less than $\mathrm{F}_{\mathrm{e}}$, then the hydraulic jump should be upstream of the vena contracta, and some form of submerged orifice flow should exist. Measurements classified by this method should be plotted on both the free- and submerged-orifice coefficient rating curves. If flows are classified correctly, then the plotted data points should agree with the curve near which they are plotted. In addition, DAMFLO.2 can be run using the hydraulic-jump method, so that flow classifications can be inspected for periods other than those when flow measaurements are made. 


\section{APPENDIX 4. UNIT-VALUE AND DAILY-VALUE CARD FORMATS}

The unit-value B-card format and daily-value 2- and 3-card formats for data entry to the U.S. Geological Survey Automatic Data Processing System database are described in this appendix.

The B-card format for unit-value data requires a header card identified by a " 2 " in column 1 and then a series of data cards identified by a "B" in column 1 as shown below.

\begin{tabular}{r|l}
\hline \multicolumn{2}{c}{ Unit-value 2-card format } \\
\hline Column number & \multicolumn{1}{c}{ Description } \\
\hline 1 & The number "2" is entered \\
$2-16$ & Station number \\
$29-33$ & Parameter code \\
$34-38$ & Statistic code \\
\hline & Unit-value B-card format \\
\hline 1 & The letter "B" is entered \\
$2-16$ & Station number \\
$17-20$ & Calendar year \\
$21-22$ & Month \\
$23-24$ & Day \\
$25-26$ & Hour of first coded observation \\
$26-28$ & Minute of first coded observation \\
$29-30$ & Second of first coded observation \\
$31-35$ & Readings per day \\
$39-80$ & Unit-value data for 6 consecutive intervals \\
& of time in 7-column fields \\
\hline
\end{tabular}


The 2- and 3-card format for daily-value data requires two card types as shown below.

\begin{tabular}{|c|c|c|}
\hline \multicolumn{3}{|c|}{ Daily-value 2-card format } \\
\hline Column number & \multicolumn{2}{|c|}{ Description } \\
\hline 1 & \multicolumn{2}{|c|}{ The number " 2 " is entered } \\
\hline $2-16$ & \multicolumn{2}{|c|}{ Station number } \\
\hline $29-33$ & \multicolumn{2}{|l|}{ Parameter code } \\
\hline $34-38$ & \multicolumn{2}{|l|}{ Statistic code } \\
\hline $55-57$ & \multicolumn{2}{|c|}{ The character string 'ENT' is entered } \\
\hline \multicolumn{3}{|c|}{ Daily-value 3-card format } \\
\hline 1 & \multicolumn{2}{|c|}{ The number " 3 " is entered } \\
\hline $2-16$ & \multicolumn{2}{|l|}{ Station number } \\
\hline $17-20$ & \multicolumn{2}{|l|}{ Calendar year } \\
\hline $21-22$ & \multicolumn{2}{|l|}{ Month } \\
\hline \multirow[t]{6}{*}{$23-24$} & \multicolumn{2}{|c|}{$\begin{array}{l}\text { A 2-digit number representing the fraction } \\
\text { of the month in which the data values were } \\
\text { collected. The number is coded as follows: }\end{array}$} \\
\hline & Card number & Day \\
\hline & 01 & $1-8$ \\
\hline & 02 & $9-16$ \\
\hline & 03 & $17-24$ \\
\hline & 04 & $25-31$ \\
\hline $25-80$ & \multicolumn{2}{|c|}{$\begin{array}{l}\text { Eight } 7 \text {-column fields in which the daily } \\
\text { values are coded for the designated days }\end{array}$} \\
\hline
\end{tabular}










